\title{
(ब)
}

AUTARQUIA ASSOCIADA À UNIVERSIDADE DE SÃO PAULO

ESTUDO DA REMOÇÃO DE Sr ${ }^{2+}$ DE SOLUÇÕES AQUOSAS UTILIZANDO FIBRAS DE COCO BRUTA E ATIVADA COM PERÓXIDO DE HIDROGÊNIO EM MEIO BÁSICO

\author{
Heverton Cardan Oda Fonseca
}

Dissertação apresentada como parte dos requisitos para obtenção do Grau de Mestre em Ciências na Área de Tecnologia Nuclear - Aplicações

Orientadora:

Profa. Dra. Solange Kazumi Sakata 
INSTITUTO DE PESQUISAS ENERGÉTICAS E NUCLEARES

Autarquia associada à Universidade de São Paulo

\section{ESTUDO DA REMOÇÃO DE Sr2+ DE SOLUÇÕES AQUOSAS UTILIZANDO FIBRAS DE COCO BRUTA E ATIVADA COM PERÓXIDO DE HIDROGÊNIO EM MEIO BÁSICO}

Heverton Cardan Oda Fonseca

Dissertação apresentada como parte dos
requisitos para obtenção do Grau de
Mestre em Ciências na Área
de Tecnologia Nuclear-Aplicações

Orientadora:

Profa. Dra. Solange Kazume Sakata

Versão Original

Versão Original disponível no IPEN

São Paulo

2015 
Aos meus pais: Dorival e Magda.

Aos meus irmãos: Wellington, Victor, Vinicius e Bianca. 


\section{AGRADECIMENTOS}

À Deus por proporcionar força durante toda a realização deste trabalho.

À CAPES pelo apoio financeiro que possibilitou a conclusão deste trabalho.

Aos meus pais pelo apoio e incentivo constantes.

À Dra. Solange pela orientação da pesquisa e conselhos.

Aos pesquisadores Dr. Goro Hiromoto e Dr Ademar José Potiens Jr pelo auxílio no desenvolvimento desta dissertação.

À Dra. Luci D. B. Machado por ceder gentilmente o equipamento de análise térmica.

Aos funcionários da Gerência de Rejeitos Radioativos Robson, Marcos e Vera pela dedicação e ajuda nos trabalhos laboratoriais.

A todos os colegas do IPEN pela ajuda e companheirismo no desenvolvimento da pesquisa.

Ao Ms. Rafael H. L. Garcia pelas análises e auxílio na determinação das estruturas cristalinas por difração de raios- $X$

À Dra. Flávia R. O. Silva pelo auxílio na coleta das micrografias do microscópio de varredura eletrônica.

A todas as pessoas que de alguma forma contribuíram para a realização da pesquisa. 


\title{
ESTUDO DE REMOÇÃO DE Sr ${ }^{2+}$ DE SOLUÇÕES AQUOSAS UTILIZANDO FIBRAS DE COCO BRUTA E ATIVADA COM PERÓXIDO DE HIDROGÊNIO EM MEIO BÁSICO
}

\section{Heverton Cardan Oda Fonseca}

\begin{abstract}
RESUMO
Neste trabalho é apresentado o potencial de remoção de íons estrôncio de soluções aquosas pelas fibras de coco na forma bruta e na forma ativada com peróxido de hidrogênio, $1 \%$ e $4 \%$, em meio básico. Os experimentos de biossorção foram realizados em batelada com $2 \mathrm{mg}^{-\mathrm{L}^{-1}}$ de solução de $\operatorname{Sr}\left(\mathrm{NO}_{3}\right)_{2} \mathrm{e}$ foram estudadas as influências dos seguintes parâmetros: tempo de contato, $\mathrm{pH}$ e a eficiência de biossorção das fibras ativadas em comparação com a fibra de coco bruta (FCB). A caracterização das fibras antes e após o tratamento, e a presença de $\mathrm{Sr}^{2+}$ nas fibras foram realizadas por microscopia de varredura eletrônica com detector de espectroscopia de energia dispersiva, espectroscopia de difração de raios $X$, espectroscopia de infravermelho e por análise térmica. Dentre as fibras estudadas, a fibra de coco ativada com $1 \% \mathrm{H}_{2} \mathrm{O}_{2}$ (FCA 1) apresentou a maior capacidade de biossorção: $3,6 \mathrm{mg} \cdot \mathrm{g}^{-1}$, nas seguintes condições: $5 \mathrm{mg}$ de biomassa em $\mathrm{pH}$ 6, após 90 minutos de tempo de contato à temperatura ambiente. A fibra de coco ativada com $4 \% \mathrm{H}_{2} \mathrm{O}_{2}$ (FCA 2) levou a uma maior degradação dos constituintes da fibra e consequentemente a uma menor remoção de íons de $\mathrm{Sr}^{2+}$.Para os estudos de modelos de isotermas de biossorção de $\mathrm{Sr}^{2+}$, tanto a FCB quanto a FCA 1 ajustaram-se melhor ao modelo de Langmuir e à cinética de pseudo-segunda ordem. Os parâmetros termodinâmicos energia livre de Gibbs $(\Delta G)$ e coeficiente de distribuição $\left(K_{D}\right)$ foram $-0,90 \mathrm{~kJ} \mathrm{~mol}^{-1}$ e $265,3 \mathrm{~L} . \mathrm{Kg}^{-1}$ para a FCB e de $-7,2 \mathrm{~kJ} \mathrm{~mol}^{-1}$ e $824,3 \mathrm{~L} \mathrm{Kg}^{-1}$ para a FCA1. Esses resultados demonstraram que a FCA 1 possui uma boa eficiência para remover íons de $\mathrm{Sr}^{2+}$ de resíduos químicos aquosos e é uma boa alternativa no tratamento de rejeitos radioativos líquidos contendo íons ${ }^{90} \mathrm{Sr}$.
\end{abstract}

Palavras chave: biossorção, estrôncio, rejeitos radioativos, fibra de coco. 


\title{
STUDY OF REMOVAL OF $\mathrm{Sr}^{2+}$ FROM AQUEOUS SOLUTION USING RAW COCONUT FIBERS AND TREATED WITH HYDROGEN PEROXIDE IN BASIC CONDITION
}

\section{Heverton Cardan Oda Fonseca}

\begin{abstract}
This work presents the potential of strontium ions removal from aqueous solutions using coconut fiber in raw and treated form with hydrogen peroxide, $1 \%$ and $4 \%$, in alkaline conditions. The biosorption experiments were performed in batch mode with $2 \mathrm{mg} \cdot \mathrm{L}^{-1}$ solution of $\mathrm{Sr}\left(\mathrm{NO}_{3}\right)_{2}$ and the influence of the following parameters were studied: contact time and $\mathrm{pH}$. It was also evaluate the biosorption efficiency of the treated coconut fibers in comparison with the raw coconut fiber (RCF). The fibers characterizations before and after treatment and the presence of the $\mathrm{Sr}^{2+}$ in the fibers were performed by scanning electron microscopy with a detector energy dispersive spectroscopy, diffraction of $x$-ray spectroscopy, infrared spectroscopy and thermal analysis. Among the studied fibers, the treated coconut fiber with $1 \%$ of $\mathrm{H}_{2} \mathrm{O}_{2}$ (TCF 1) showed the major biosorption capacity of $3.6 \mathrm{mg} \cdot \mathrm{g}^{-1}$ in the following conditions: $5 \mathrm{mg}$ of biomass at $\mathrm{pH} 6,90$ minutes of contact time at room temperature. Treated coconut fiber with $4 \% \mathrm{H}_{2} \mathrm{O}_{2}$ (TCF 2) showed the lowest $\mathrm{Sr}^{2+}$ ions removal due to degradation of the fibers constituents. For studies of biosorption isotherms, both raw and treated coconut fiber (TCF 1) were fitted better to Langmuir model and the kinetics reaction was of pseudo-second order. The thermodynamic parameters Gibbs free energy $(\Delta G)$ and distribution coefficient $\left(K_{D}\right)$ were $-0.90 \mathrm{~kJ} . \mathrm{mol}^{-1}$ and $265.3 \mathrm{~L}_{\mathrm{Kg}} \mathrm{Kg}^{-1}$ for RCF and of $-7,2 \mathrm{~kJ} \mathrm{~mol}^{-1}$ and $824.3 \mathrm{~L} . \mathrm{Kg}^{-1}$ for TCF 1 . These results demonstrated that the TCF 1 has good efficiency for removing $\mathrm{Sr}^{2+}$ ions in the aqueous chemical waste and is a good alternative in treatment of liquid radioactive wastes containing ${ }^{90} \mathrm{Sr}$.
\end{abstract}

Keywords: biosorption, strontium, radioactive wastes. 


\section{SUMÁRIO}

Página

1. INTRODUÇÃO

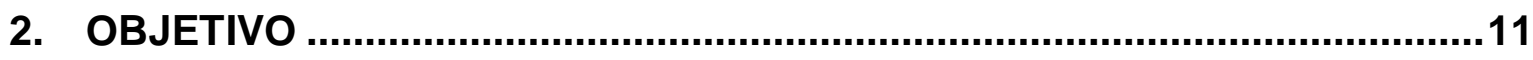

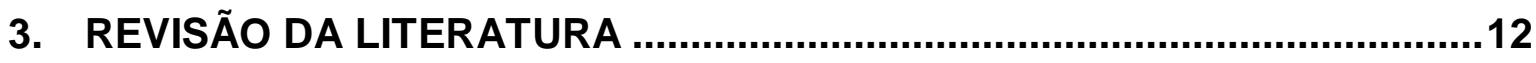

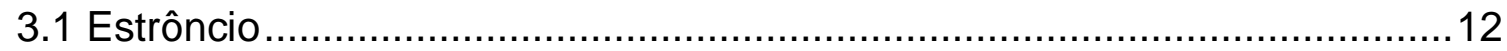

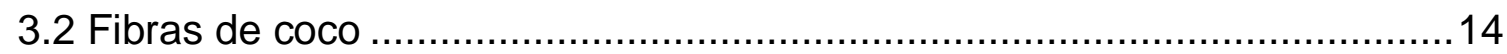

3.3 Processo de Ativação das Fibras com Peróxido de Hidrogênio em meio

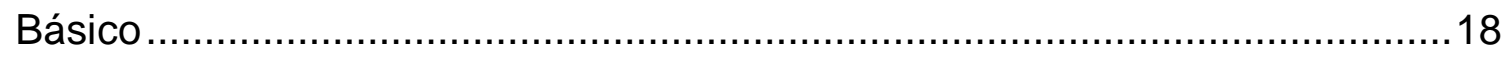

3.4 Tratamentos de rejeitos radioativos contendo íons de ${ }^{90} \mathrm{Sr}$.......................21

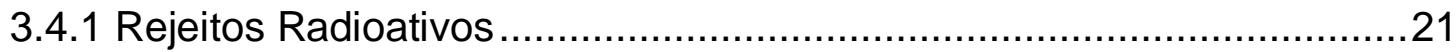

3.4.2 Técnicas de remoção de íons de estrôncio radioativo ............................22

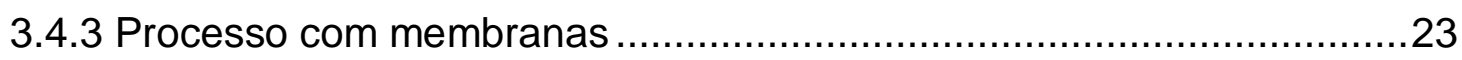

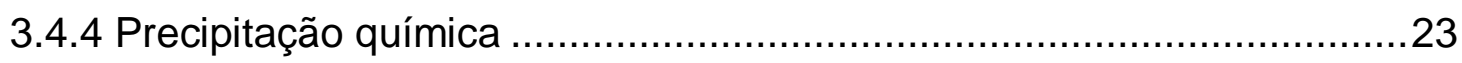

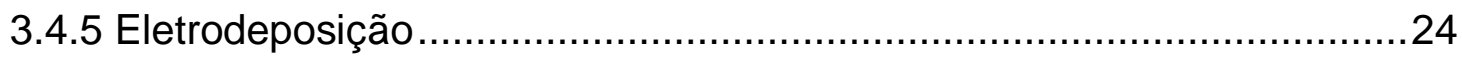

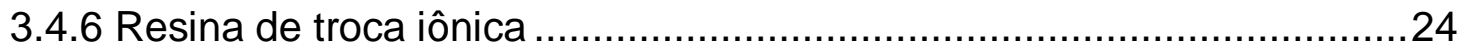

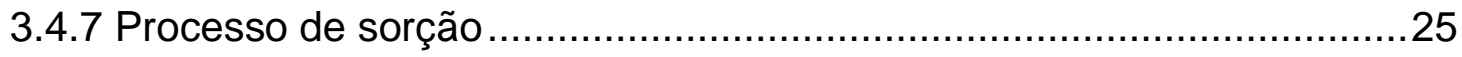

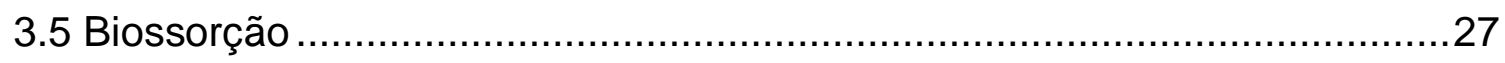

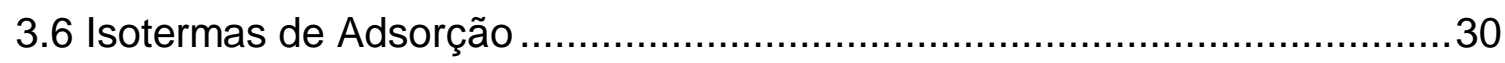

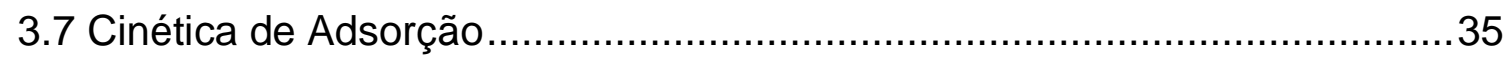

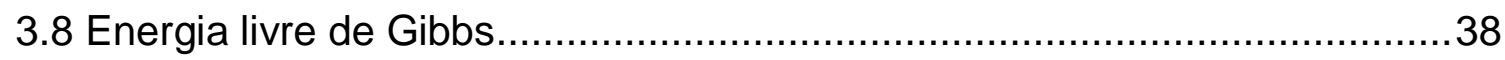

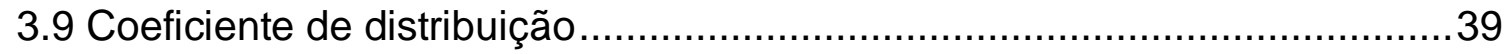

4. METODOLOGIA ….....................................................................................41

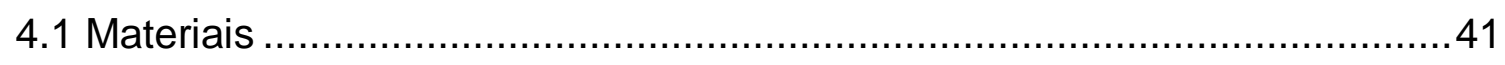

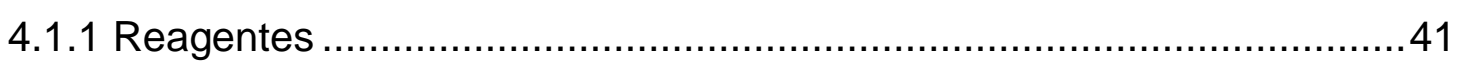

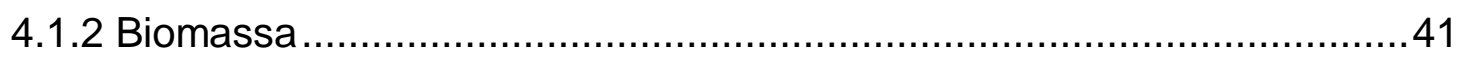

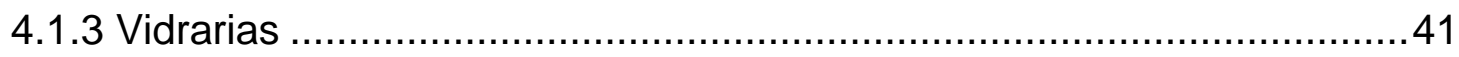

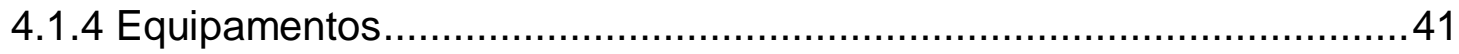

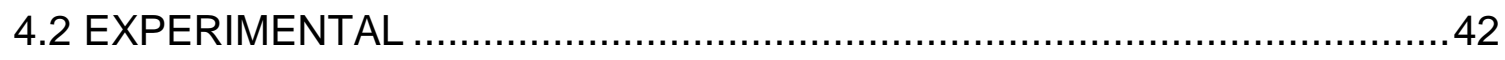

4.2.1 Tratamento da fibra de coco bruta.................................................... 42

4.2.2 Determinação do teor de peróxido de hidrogênio ..................................43

4.2.3 Ativação da fibra de coco com $\mathrm{H}_{2} \mathrm{O}_{2}$ em meio básico........................... 43 
4.2.4 Caracterização do ponto de carga zero das fibras

4.3 Preparação das soluções estoque de $\mathrm{Sr}\left(\mathrm{NO}_{3}\right)_{2}$ para a curva de calibração 44

4.4 Experimentos de biossorção de $\mathrm{Sr}^{2+}$ 45

4.4.1 Análise de estrôncio $\left(\mathrm{Sr}^{2+}\right)$ por Espectrometria de Emissão Óptica........46 4.5 Análise das Fibras por Microscopia Eletrônica de Varredura (MEV) e por Espectroscopia de Energia Dispersiva (EDS) ...................................................46

4.6 Análise de Infravermelho com Transformada de Fourier ............................47

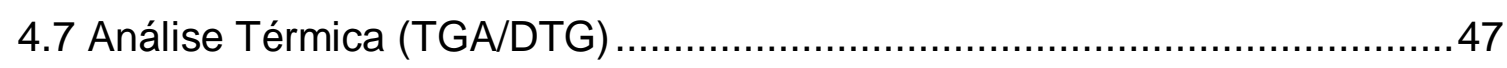

4.8 Caracterização por Difratometria de Raios X........................................... 47

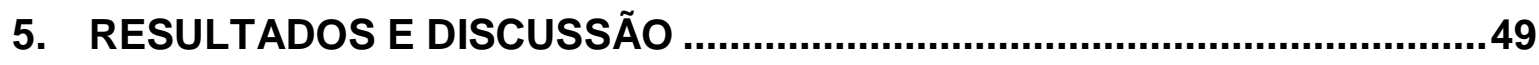

5.1 Biossorção de metais com fibra de coco …………................................ 49

5.2 Ativação da fibra de coco com $\mathrm{H}_{2} \mathrm{O}_{2}$ em meio básico ..................................49

5.2.1 Determinação do teor de peróxido de hidrogênio .................................49

5.3 Análise das fibras de coco por Microscopia de Varredura Eletrônica ...........50

5.4 Análise das fibras de coco por Espectroscopia de Energia Dispersiva.........51

5.5 Análise de Infravermelho por ATR das fibras ..........................................52

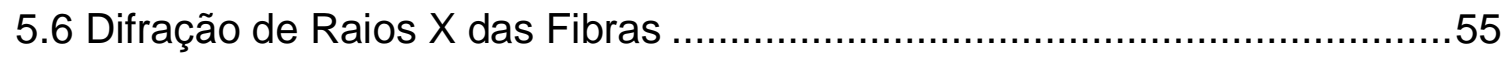

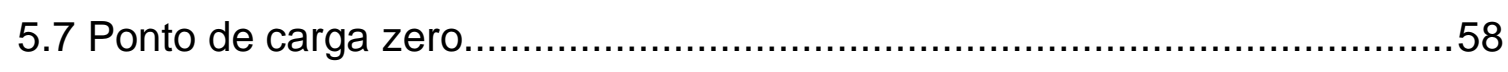

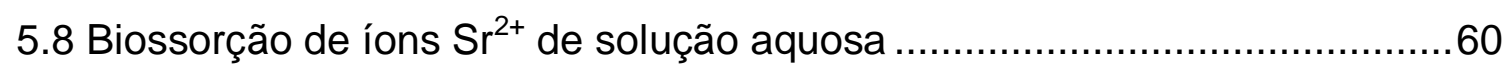

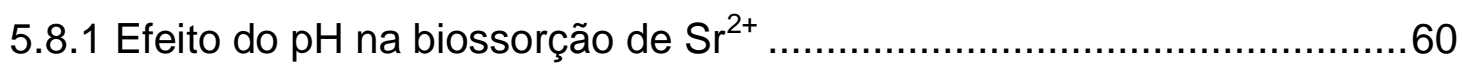

5.8.2 Efeito da ativação da biomassa na remoção dos íons de estrôncio .......62

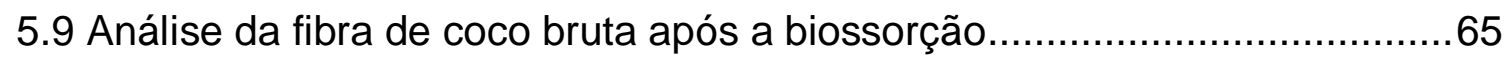

5.9.1 Análise Térmica da FCB antes e após a biossorção de $\mathrm{Sr}^{2+} \ldots \ldots \ldots \ldots \ldots . . .65$

5.9.2 Difração de raios X (DRX) das cinzas ...............................................66

5.9.3 Análise de MEV e EDS das FCB e FCA 1 após o processo de

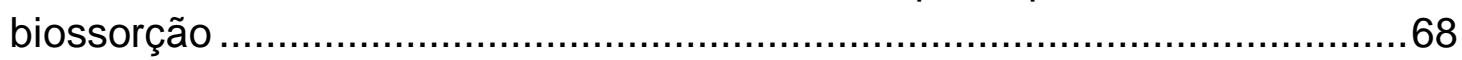

5.9.4 Análise de infravermelho da FCA 2 antes e após a biossorção ............69

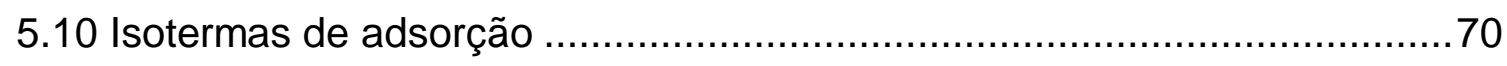

5.11 Cinética de adsorção ..................................................................... 74

5.12 Parâmetros termodinâmicos .............................................................. 77

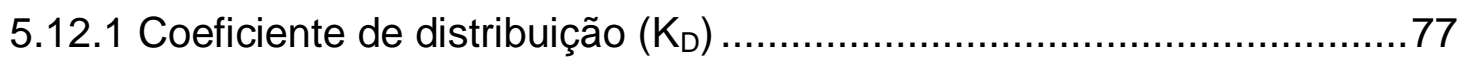

5.12.2 Energia Livre de Gibbs ............................................................. 77

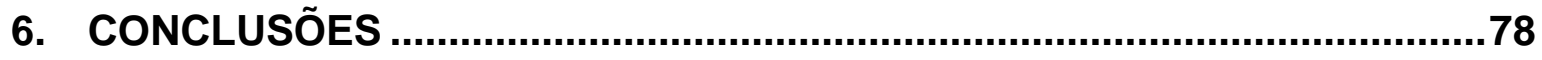


REFERÊNCIAS BIBLIOGRÁFICAS.

. .80 


\section{INTRODUÇÃO}

Os rejeitos radioativos se não tratados de modo adequado podem trazer impactos direta ou indiretamente aos seres humanos e ao meio ambiente (HIROMOTO et al., 1999).

A etapa de tratamento dos rejeitos radioativos é muito importante, porque tem como um dos objetivos reduzir o volume (IAEA, 2001), para diminuir custos em etapas posteriores ao tratamento, como o armazenamento e a disposição final (HIROMOTO et al., 1999).

$\mathrm{O}{ }^{90} \mathrm{Sr}$, um dos isótopos do estrôncio, é um produto de fissão de maior importância radiológica por causa de sua alta toxicidade, meia-vida alta (29 anos), além de estar presente em rejeitos radioativos produzidos em atividades de reatores nucleares (ABDEL, et al., 2011).

Existem várias técnicas comumente utilizadas para remoção de metais tóxicos que pode ser aplicadas aos radionuclídeos que incluem a precipitação química (KADIRVELU E GOEL, 2007), eletrodeposição (KIM, et al., 2002), resinas de troca iônica (AMANO E YANASE, 1990) e o processo com membranas (DING, et al., 2015). Como essas técnicas possuem desvantagens como o alto custo, baixa eficiência em concentrações diluídas de íons metálicos (no intervalo de 1 a $\left.100 \mathrm{mg} \cdot \mathrm{L}^{-1}\right)$ e potencial gerador de resíduos tóxicos secundários (PAPAGEORGION et al., 2006; EROGLU et al., 2009; WANG \& CHEN, 2009), outras tecnologias têm sido desenvolvidas, entre elas a biossorção, que utiliza materiais biológicos no tratamento de resíduos líquidos contaminados com íons metálicos (GOK \& AYTAS, 2009; YANG \& VOLESKY, 1999).

Basicamente, a biossorção é um processo de remoção de compostos orgânicos e inorgânicos por meio de biomassas. A remoção do íon metálico da solução pode ocorrer de forma ativa, com a atuação do seu metabolismo, e de forma passiva, neste caso os mecanismos podem ser resumidos em quelação e adsorção na superfície da célula por forças físicas (WANG \& CHEN, 2009).

A eficiência na biossorção depende de alguns parâmetros que incluem: o pH do meio, a variação da quantidade de adsorvente (ZHENG et al., 2008), a 
concentração do rejeito, a velocidade de agitação, a granulometria da biomassa (EROGLU et al., 2009), o tipo de adsorvente (MOHAN \& CHANDER, 2001), e o ion metálico estudado ( $\mathrm{CHOl}$ et al., 2009).

$\mathrm{Na}$ literatura é descrita a remoção de íons metálicos de soluções aquosas, principalmente na forma de cátions isolados, utilizando resíduos agrícolas como biomassa (MINAMISAWA et al., 2004). Dentre as biomassas estudadas está a fibra de coco, na qual a sorção de íons metálicos se deve aos grupos funcionais encontrados principalmente na lignina e hemicelulose (MONTEIRO, 2009). O reaproveitamento deste resíduo agrícola como adsorvente é uma prática sustentável de baixo custo e fácil manuseio (ZHENG et al., 2008; MONTEIRO, 2009). A alta capacidade desta biomassa em remover radionuclídeos foi comprovada nos experimentos realizados em batelada ao estudar a remoção de $\mathrm{UO}_{2}{ }^{2+}$ e $\mathrm{Th}^{4+}$ (MONTEIRO, 2009). A maioria dos estudos de biossorção é realizada em batelada, pois fornecem informações úteis, como o melhor tipo de biomassa, a concentração e o pH para a remoção de um metal específico de uma solução aquosa. 


\section{OBJETIVO}

O objetivo geral deste trabalho é desenvolver um método de tratamento de resíduos líquidos, contendo íons de $\mathrm{Sr}^{2+}$, utilizando a fibra de coco nas formas bruta e ativada com peróxido de hidrogênio em meio básico, destinado ao tratamento de rejeitos radioativos líquidos.

Os objetivos específicos deste trabalho são:

(a) verificar os efeitos do peróxido de hidrogênio a $1 \%$ e $4 \%$ em meio básico sobre a fibra de coco bruta.

(b) Realizar a modificação da fibra de coco bruta com moléculas de ácido etilenodiamino tetra-acético (EDTA);

(c) estudar os parâmetros que influenciam a biossorção de $\mathrm{Sr}^{2+}$ pelas fibras: $\mathrm{pH}$, tempo de contato e quantidade de biomassa;

(d) comparar a eficiência da fibra de coco bruta com as fibras ativadas na remoção de $\mathrm{Sr}^{2+}$;

(e) verificar os modelos de isotermas de Langmuir e Freundlich e modelos de cinética que melhor descrevem os dados experimentais de biossorção;

(f) determinar parâmetros termodinâmicos de energia livre de Gibbs e coeficiente de distribuição na remoção de $\mathrm{Sr}^{2+}$ pelas fibras de coco nas formas bruta e ativada; 


\section{REVISÃO DA LITERATURA}

\subsection{Estrôncio}

Em 1808, o estrôncio foi isolado na forma de metal branco prateado pelo inglês $\mathrm{H}$. Davy. O seu nome foi dado em homenagem a uma pequena vila da Escócia, Strontiam, onde este minério contendo estrôncio foi encontrado pela primeira vez (VENETSKII, 1971).

Este elemento, de símbolo Sr, número atômico 38 e massa atômica 88, está localizado no grupo $2 \mathrm{~A}$ da tabela periódica, apresenta estado de oxidação $2+$, ponto de fusão de $770^{\circ} \mathrm{C}$, ponto de ebulição de $1.380^{\circ} \mathrm{C}$, massa molar de $87,62 \mathrm{~g} \mathrm{~mol}^{-1}$ e densidade de 2,58 g.cm (ATIKINS, 2006). O estrôncio quando purificado na forma de pó metálico reage violentamente com a presença de água e ocorre a ignição instantânea na presença de ar (SHRIVER E ATKINS, 2008).

O metal estrôncio pode ser obtido através da eletrólise do cloreto de estrôncio na presença de cloreto de potássio, sal utilizado como ponte salina, ou pela redução de óxido de estrôncio sólido na presença de alumínio, conforme mostrado na EQ. 1 (LIDE, 2005; SHRIVER E ATKINS, 2008).

$$
6 \mathrm{SrO}_{(\mathrm{s})}+2 \mathrm{Al}_{(\mathrm{s})} \rightarrow 3 \mathrm{Sr}_{(\mathrm{s})}+\mathrm{Sr}_{3} \mathrm{Al}_{2} \mathrm{O}_{6(\mathrm{~s})}
$$

Segundo Slovak e Paytan (2011) existem quatro isótopos naturais do estrôncio ${ }^{84} \mathrm{Sr},{ }^{86} \mathrm{Sr},{ }^{87} \mathrm{Sr}$ e ${ }^{88} \mathrm{Sr}$, sendo que o último representa $82,53 \%$ da massa total dos isótopos. O estrôncio é encontrado em apenas dois tipos de minérios, a Celestite $\left(\mathrm{SrSO}_{4}\right)$ e a Estroncianite $\left(\mathrm{SrCO}_{3}\right)$.

O estrôncio natural é utilizado na produção de imãs, cristais para tubos catódicos de televisores em cores e na composição da pólvora em fogos de artifício, responsável pela cor vermelha intensa (LIDE, 2005).

As fontes antropogênicas de estrôncio derivam de resíduos industriais, da agricultura, de combustíveis fósseis e em fertilizantes (CRESPI,2013). Traços de estrôncio estão presentes em diversas localidades como em rios, águas 
subterrâneas, no mar, no solo, nas plantas, nos animais, e nas rochas ígneas, sedimentares e metamórficas.

Dentre os isótopos artificiais radioativos do estrôncio destacam-se 0 ${ }^{89} \mathrm{Sr}$ e ${ }^{90} \mathrm{Sr}$ que são formados em reatores por fissão nuclear do ${ }^{235} \mathrm{U},{ }^{238} \mathrm{U}$ ou ${ }^{239} \mathrm{Pu}$, conforme apresentado no decaimento radioativo da EQ. 2.

$$
{ }^{235,238} \mathrm{U},{ }^{239} \mathrm{Pu}+{ }^{1} \mathrm{n} \rightarrow{ }^{90} \mathrm{Sr}+{ }^{89} \mathrm{Sr}+\text { outro produto de fissão }
$$

O isótopo ${ }^{87} \mathrm{Sr}$ é o produto de fissão do decaimento radioativo do ${ }^{87} \mathrm{Rb}\left(\mathrm{T}_{1 / 2}\right.$ = 4,88X1010 anos), conforme a EQ. 3 (FAURE E MENSING, 2005; ICRP, 1978).

$$
{ }^{87} \mathrm{Rb} \rightarrow{ }^{87} \mathrm{Sr}+\beta^{-}
$$

O isótopo de estrôncio de maior risco radiológico é o ${ }^{90} \mathrm{Sr}$, um emissor beta de alta energia de 0,546 MeV e com meia-vida de aproximadamente 29 anos (ATSDR, 2004). O decaimento radioativo do ${ }^{90} \mathrm{Sr}$ é apresentado na FIG. 1.

$$
{ }_{38}^{90} \mathrm{Sr}(29,12 \text { anos }) \stackrel{\beta^{-}}{\longrightarrow}{ }_{39}^{90} \mathbf{Y}_{(64,0 \text { horas })} \stackrel{\beta^{-}}{\longrightarrow}{ }_{40}^{90} \mathbf{Z n}_{\text {(estável) }}
$$

FIGURA 1 - Decaimento do ${ }^{90} \mathrm{Sr}$.

FONTE: ICRP, 1978.

$0{ }^{90} \mathrm{Sr}$ age semelhantemente ao cálcio no organismo humano permanecendo na superfície dos ossos durante anos até dissolver-se completamente. Os efeitos nocivos do ${ }^{90} \mathrm{Sr}$ são por causa dos efeitos da emissão de radiação beta de alta energia, que danifica o material genético presente nas células. No organismo humano $0{ }^{90} \mathrm{Sr}$ possui uma meia vida biológica de aproximadamente 49,3 anos (LEONARDO, 2004).

Fontes seladas de radioisótopos de ${ }^{90} \mathrm{Sr}$ são destinadas a braquiterapia (TAUHATA et al, 2003) e aplicadas na destruição de tecidos indesejáveis presentes na superfície dos olhos ou da pele (ATSDR, 2004). 


\subsection{Fibras de coco}

No Brasil, os coqueiros são bem populares em especial nas regiões litorâneas por questões de gastronomia e paisagismo. Estima-se que a produção de coco seja de aproximadamente 1,5 bilhões de unidades por ano em uma área superior a 280 mil hectares e esse número tende a aumentar, de acordo com dados apresentados em 2003 (SENHORAS, 2003).

Em vista dessa grande produção de coco verde no Brasil, a quantidade de resíduos vem aumentando, ocasionando grandes problemas nos lixões, especialmente nos grandes centros urbanos (SENHORAS, 2003).

O coco verde possui nome científico Cocos Nucifera, é um membro da família das palmeiras, Arecaceae (ALI, 2010). Este fruto é encontrado em todo o globo terrestre e apesar de ainda não haver um consenso acerca de sua origem, sua existência já foi mencionada em relatos na Costa Asiática há cerca de quatro mil anos (EMBRAPA, 2012).

A casca de coco verde é constituída basicamente pelo exocarpo ou epicarpo, mesocarpo e endocarpo (EMBRAPA, 2012). Os componentes do coco estão apresentados na FIG. 2.

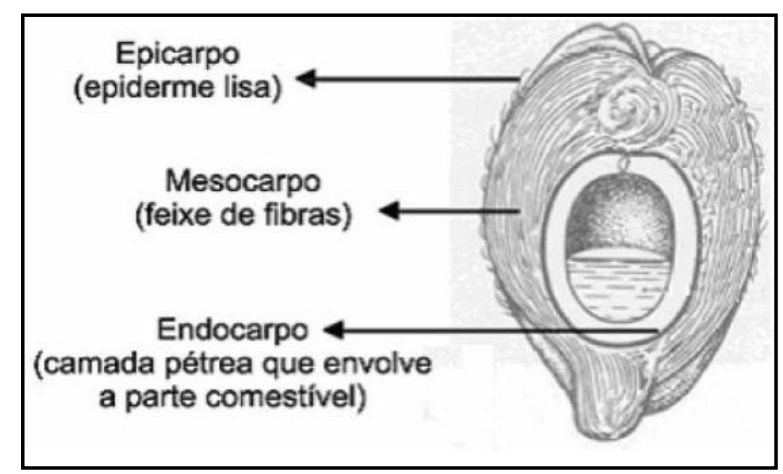

Figura 2 - Corte longitudinal do coco.

FONTE: SÁTIRO et al., 2012.

A fibra de coco obtida a partir do mesocarpo é geralmente classificada como material ligno-celulósico porque contem lignina (35-45\%), celulose (cerca de $30 \%$ ) e outros componentes secundários como a hemicelulose, extrativos 
solúveis em água e cinzas (CORRADINI et al., 2009). A composição química da fibra de coco depende de diversos fatores como a região, o tipo de solo, quantidade de chuvas e época do ano (SOUZA, 2007).

As fibras vegetais são compostas por microfibrilas de celulose ligadas pela parte amorfa da hemicelulose e lignina formando células (HUBBE E LUCIA, 2007), conforme apresentado na FIG. 3.

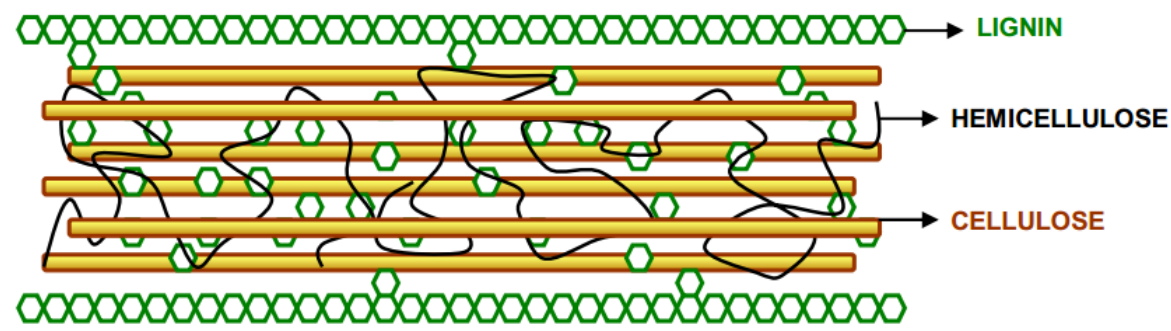

FIGURA 3 - Representação da estrutura de uma fibra vegetal mostrando a celulose, lignina e hemicelulose. FONTE: MUSSATO E TEIXEIRA, 2010.

A celulose é um polissacarídeo de fórmula $\left(\mathrm{C}_{6} \mathrm{H}_{10} \mathrm{O}_{5}\right) \mathrm{n}$, que possui uma cadeia linear formada por diversas unidades repetidas de glicose e celobiose, um dímero de glicose. A celulose apresenta sequencialmente uma estrutura cristalina e outra amorfa, conforme a FIG. 4.

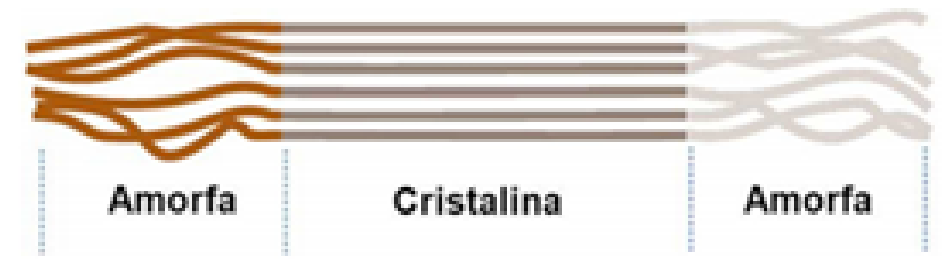

FIGURA 4 - Conformação das microfibrilas de celulose contendo regiões cristalinas intercaladas por regiões amorfas.

FONTE: Adaptado de ALVES, 2011

As regiões cristalinas da celulose fazem aumentar a resistência do material a ataques químicos e biológicos (ALVES, 2011; HE et. al., 2008).

Esse arranjo deve-se às ligações de hidrogênio existentes entre as macromoléculas da celulose. Essas interações intermoleculares ocorrem entre o 
hidrogênio dos grupos hidroxilas com o oxigênio das ligações glicosídicas e do anel cíclico (KLEMM et al., 2005). Na FIG. 5 é apresentada a estrutura parcial da celulose.

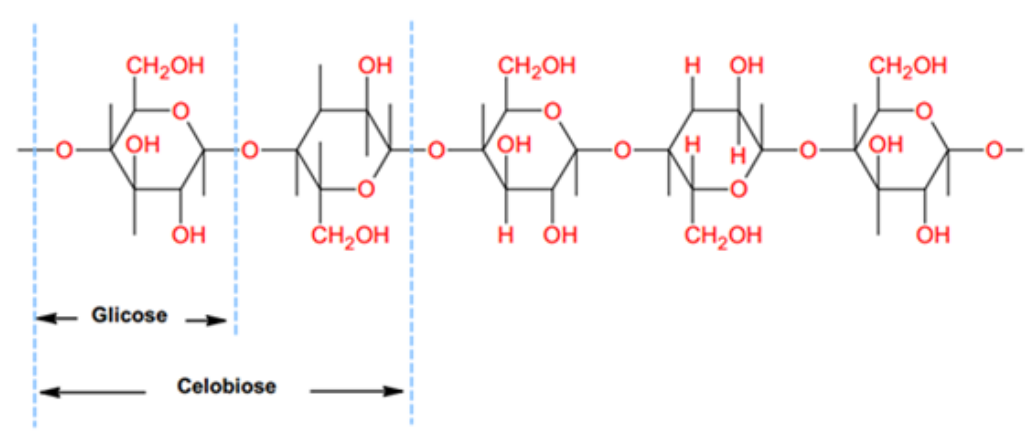

Figura 5 - Estrutura molecular da celulose.

FONTE: ALVES, 2011

As hemiceluloses são macromoléculas formadas por diferentes unidades de açúcares ao longo de toda a cadeia carbônica, que incluem a Dxilose, D-manose, D-glicose, D-galactose e D-galactourônico (CASTRO, 2009). Na FIG. 6 são apresentadas as unidades desses açúcares.
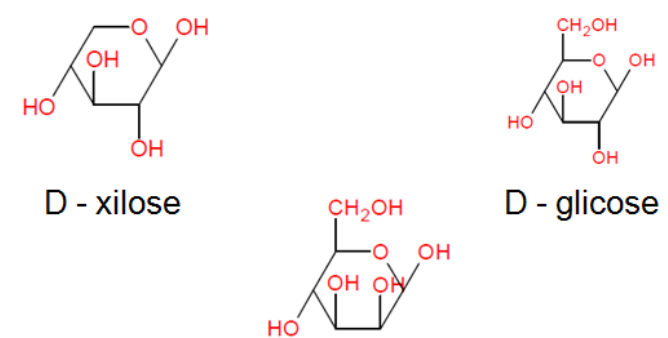

D - glicose

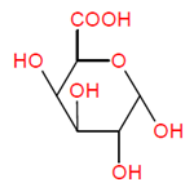

D - manose

D - galactourônico

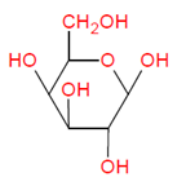

D - galactose

FIGURA 6 - Unidades dos açúcares que compõem a hemicelulose FONTE: Adaptado de ALVES, 2011.

$\mathrm{Na}$ estrutura das hemiceluloses estão presentes ramificações e grupos funcionais laterais, como grupos hidroxilas presentes nos anéis dos monossacarídeos da cadeia carbônica (CASTRO, 2009). A FIG. 7 representa a estrutura molecular da hemicelulose. 


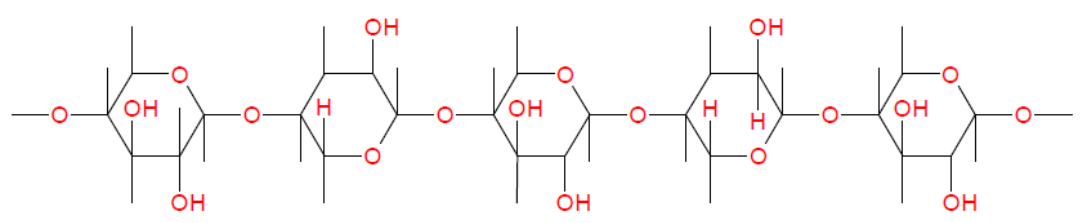

FIGURA 7 - Estrutura molecular parcial da hemicelulose.

FONTE: ALVES, 2011.

A lignina pertence à família dos biopolímeros heterogêneos de estrutura ramificada com ligações cruzadas entre as unidades fenol. Esse biopolímero de estrutura amorfa juntamente com a celulose confere rigidez ao material e encontra-se presente na parte externa dos materiais ligno-celulósicos, agindo como uma proteção contra ataques de micro-organismos aos carboidratos da celulose (McCARTHY E ISLAM, 1999). A estrutura parcial da lignina é apresentada na FIG. 8.

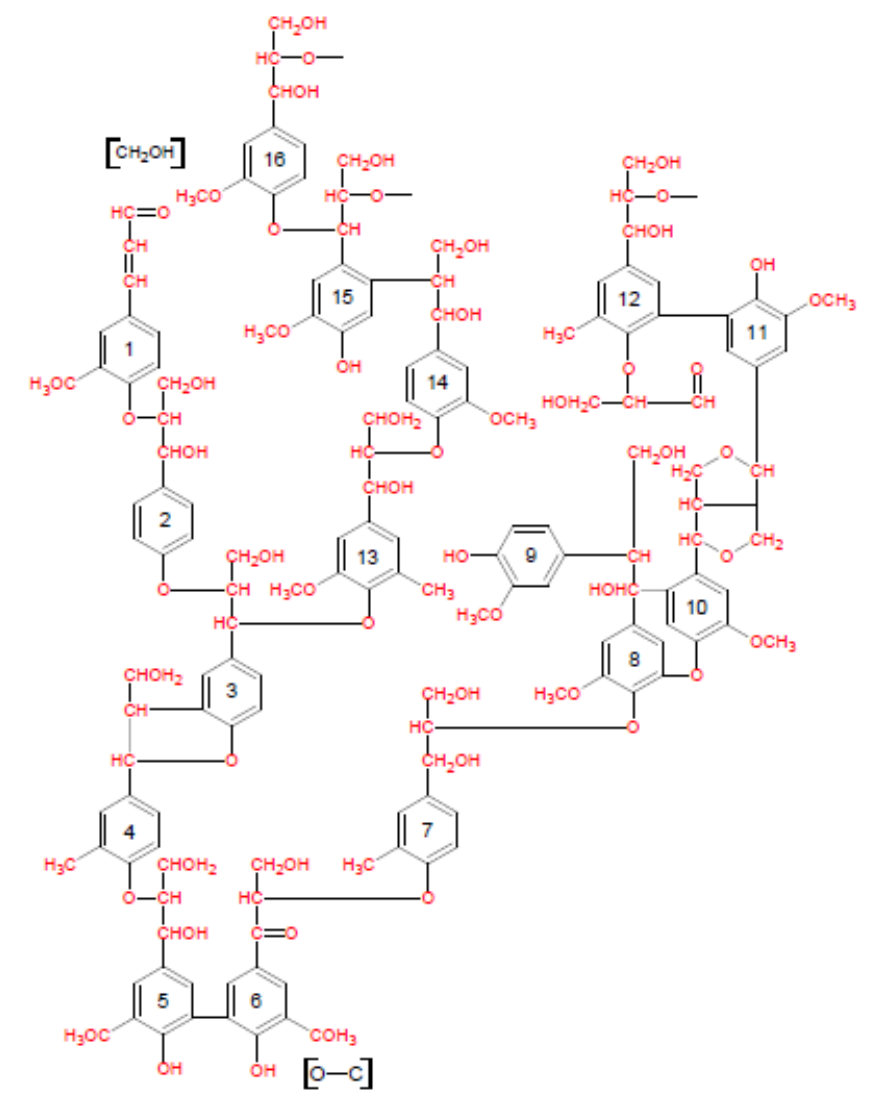

FIGURA 8 - Estrutura parcial da lignina.

FONTE: ALVES, 2011. 
Observa-se que as funções orgânicas comumente encontradas na lignina são os alcoóis alifáticos primários e secundários, as cetonas, os aldeídos, os compostos fenólicos, os radicais metilas e os ácidos carboxílicos (BYKOV, 2008; LAINE, 2005; HARMSEN et al., 2010).

A fibra de coco tem sido frequentemente utilizada em aplicações sustentáveis e de baixo custo (EMBRAPA, 2012). A sua produção é destinada à fabricação de coletes à prova de balas, peças de carro, fios, cordas, tapetes, colchões, escovas, painéis de isolamento e embalagens. Na área civil é utilizada como componente na fabricação de telhados e em produtos de acabamento com a finalidade de melhorar as propriedades mecânicas dos materiais (ALI, 2010).

\subsection{Processo de Ativação das Fibras com Peróxido de Hidrogênio em meio Básico}

A fibra de coco bruta, assim como outros resíduos agrícolas, pode ser utilizada na remoção de metais tóxicos pelo processo de biossorção. Na literatura são descritas modificações químicas e físicas na superfície da biomassa com o objetivo de aumentar as propriedades adsortivas do material e aumentar a quantidade de sítios ativos responsáveis pela remoção de metais tóxicos em meio aquoso (McCABE et al., 1993).

Dentre os processos empregados para essas modificações destacamse os tratamentos térmico, básico e oxidativo, e a modificação química (HUBBE et al., 2011).

No tratamento de oxidação, a degradação de lignina não aumenta utilizando um teor de peróxido de hidrogênio superior a 1\%, mas em teores maiores é possível solubilizar mais macromoléculas de hemicelulose presentes no material ligno-celulósico e (RABELO, 2010).

A lignina também pode ser removida pela reação com hidróxido de sódio conforme descrito por Sangian et al., 2015 (EQ.4). A lignina presente superficialmente na biomassa está ligada à celulose por meio de grupos $-\mathrm{OH}$ que se solubilizam em meio básico. 


$$
\text { Fibra }-\mathrm{OH}+\mathrm{NaOH} \rightarrow \text { Fibra-ONa }{ }^{+}+\mathrm{H}_{2} \mathrm{O}
$$

Acredita-se que o outro possível mecanismo de desprendimento de lignina e hemicelulose após o tratamento com peróxido de hidrogênio em meio básico seja o processo de saponificação intermolecular das ligações cruzadas de ésteres presentes na fibra (RABELO, 2010).

A redução da taxa de lignina e hemicelulose nos materiais lignocelulósicos implica em uma maior porosidade do material resultante (RABELO, 2010), conforme a ilustração da FIG. 9.

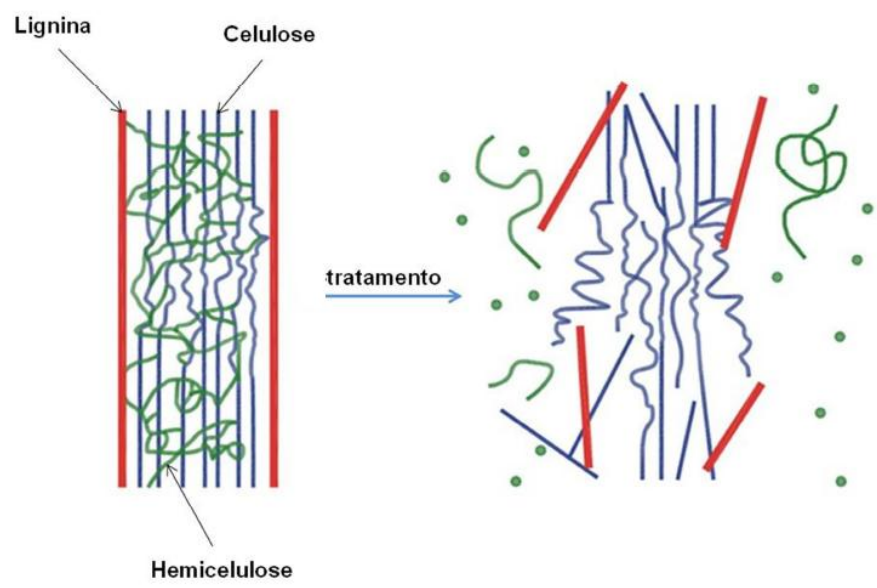

FIGURA 9 - Modificações dos materiais ligno-celulósicos após tratamento. FONTE: HARMSEN, 2010.

Observa-se também que as alterações ocorridas pela remoção desses compostos da biomassa ocasiona o aumento da área superficial do material (RABELO, 2010).

O peróxido de hidrogênio possui um comportamento diferente dependente do meio em que se encontra. Em meio ácido ele é bastante estável, em meio básico, nas condições ótimas de deslignificação e solubilização da hemicelulose $(\mathrm{pH} 10-12)$, ele tende a se degradar. Em solução aquosa, este agente oxidante se decompõe facilmente à medida que se eleva a temperatura. (NICOLL \& SMITH, 1955). 
Os mecanismos de degradação do peróxido de hidrogênio em meio básico são importantes no entendimento deste tratamento e serão apresentados a seguir.

O peróxido de hidrogênio quando dissolvido em solução leva a formação do ânion hipoperóxido (HOO'), como demonstrado na EQ. 5. Com a reação entre o ânion hidroperóxido e o peróxido de hidrogênio remanescentes na solução ocorre à formação dos radicais hidroxilas $\left(\mathrm{OH}^{\circ}\right)$, altamente reativos, e superóxidos $\left(\mathrm{O}_{2}{ }^{\circ}\right)$, conforme apresentado na $\mathrm{EQ} .6$.

$$
\begin{gathered}
5 / 2 \mathrm{H}_{2} \mathrm{O}_{2} \rightleftharpoons 2 \mathrm{HOO}^{-}+\mathrm{H}_{3} \mathrm{O}^{+} \\
\mathrm{H}_{2} \mathrm{O}_{2}+\mathrm{HOO}^{-} \rightleftharpoons \mathrm{OH}^{-}+\mathrm{O}_{2}^{-}+\mathrm{H}_{2} \mathrm{O}
\end{gathered}
$$

Justamente, o radical hidroxila $\left(\mathrm{OH}^{\circ}\right)$, altamente reativo, obtido na EQ. 6, é o responsável pela oxidação dos compostos dos materiais ligno-celulósicos. (LEE, 2005).

AMJED et al. (1992) realizaram um estudo sobre o efeito do tratamento com peróxido de hidrogênio em meio básico na parede celular do bagaço da cana-de-açúcar e da palha de trigo. $O$ experimento foi realizado com uma solução de $\mathrm{H}_{2} \mathrm{O}_{2}(1 \%)$ e em $\mathrm{pH}=11,5$, sob agitação e a temperatura ambiente por 24 horas. Os autores compararam os resíduos insolúveis formados desta solução com o não tratado e foi constatada uma maior quantidade de lignina e hemicelulose nos resíduos da solução proveniente do material tratado indicando, assim, uma maior degradação da lignina e hemicelulose.

O peróxido de hidrogênio em meio básico oxida os grupos hidroxilas presentes na biomassa a ácidos carboxílicos, que possuem grande afinidade por íons metálicos (HO, 2006; BYKOV, 2008; SHUKLA et al., 2009). Em meio básico o ácido carboxílico é desprotonado e forma o carboxilato de sódio com os íons de $\mathrm{Na}^{+}\left(\mathrm{COO}^{-} \mathrm{Na}^{+}\right)$provenientes do hidróxido de sódio $(\mathrm{NaOH})$.

A presença dos íons $\mathrm{Na}^{+}$ligados aos carboxilatos facilita o mecanismo de troca-iônica durante o processo de biossorção devido à maior afinidade dos íons metálicos presentes na solução pelos carboxilatos em relação ao sódio. $O$ cobre $\left(\mathrm{Cu}^{2+}\right)$, por exemplo, é facilmente adsorvido pelos sítios ativos de ácidos 
carboxílicos, resultando na dessorção dos íons $\mathrm{Na}^{+}$para a solução (HUBBE et al, 2011; KADIRVELU E GOEL, 2007; SHUKLA et al., 2009), conforme demonstrado na FIG. 10 abaixo.

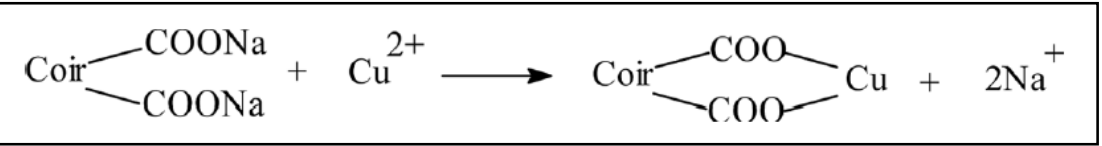

FIGURA 10 - Mecanismo de troca-iônica do Cu pelos sítios ativos de ácidos carboxílicos da biomassa.

FONTE: SHUKLA et al., 2009.

\subsection{Tratamentos de rejeitos radioativos contendo íons de ${ }^{90} \mathrm{Sr}$}

\subsubsection{Rejeitos Radioativos}

Os rejeitos radioativos podem ser definidos, de acordo com a Agência Internacional de Energia Atômica (IAEA), como "qualquer material que contenha ou esteja contaminado com radionuclídeos em concentrações ou níveis de atividade maiores que os limites de isenção estabelecidos pela autoridade competente" (IAEA, 2003).

Atividades em que o material radioativo é manuseado, como as indústrias, a pesquisa, em reatores e a agricultura, durante ou ao final do processo, geram rejeitos radioativos (DELLAMANO, 2005; RADUAN, 1994).

No gerenciamento, a etapa de tratamento tem como objetivo a redução de volume para diminuir despesas com o armazenamento e aumentar a segurança com respeito a aspectos radiológicos. Em alguns casos após a etapa de tratamento, pode ser gerado um rejeito radioativo sólido, com volume menor, porém com atividade maior. (RAHMAN et al., 2011).

A Comissão Nacional de Energia Nuclear (CNEN) é o órgão regulador que determinou as diretrizes acerca do limite de isenção para os diversos radionuclídeos, especificando sua concentração no meio físico em que se encontram.

Os rejeitos líquidos contendo ${ }^{90} \mathrm{Sr}$ provenientes de instalações nucleares ou de laboratório de pesquisa, conforme descrito pela resolução 167/14 
da CNEN, a norma da CNEN NN 8.01, quando em valores de concentração de atividade inferiores ou iguais a $9.300 \mathrm{~Bq} / \mathrm{m}^{3}$ são classificados como Rejeitos Isentos (CNEN, 2014).

$\mathrm{Na}$ Gerência de Rejeitos Radioativos (GRR) do IPEN/CNEN-SP, estão armazenados rejeitos radioativos líquidos mistos provenientes de centros de pesquisa e de atividades do reator, totalizando aproximadamente 910 litros, segundo dados fornecidos em 2013 (JESUS, 2013), sendo que o ${ }^{90} \mathrm{Sr}$ é um dos radionuclídeos presentes nesses rejeitos.

\subsubsection{Técnicas de remoção de íons de estrôncio radioativo}

As quatro principais técnicas que foram desenvolvidas na remoção de ín estrôncio radioativo são as mesmas utilizadas para o tratamento de íons metálicos tóxicos não radioativos, que são a precipitação química, processos com membranas, eletrodeposição e extração em fase sólida ou processo de adsorção (KADIRVELU E GOEL, 2007). Esses quatro métodos disponíveis estão apresentados na FIG. 11.

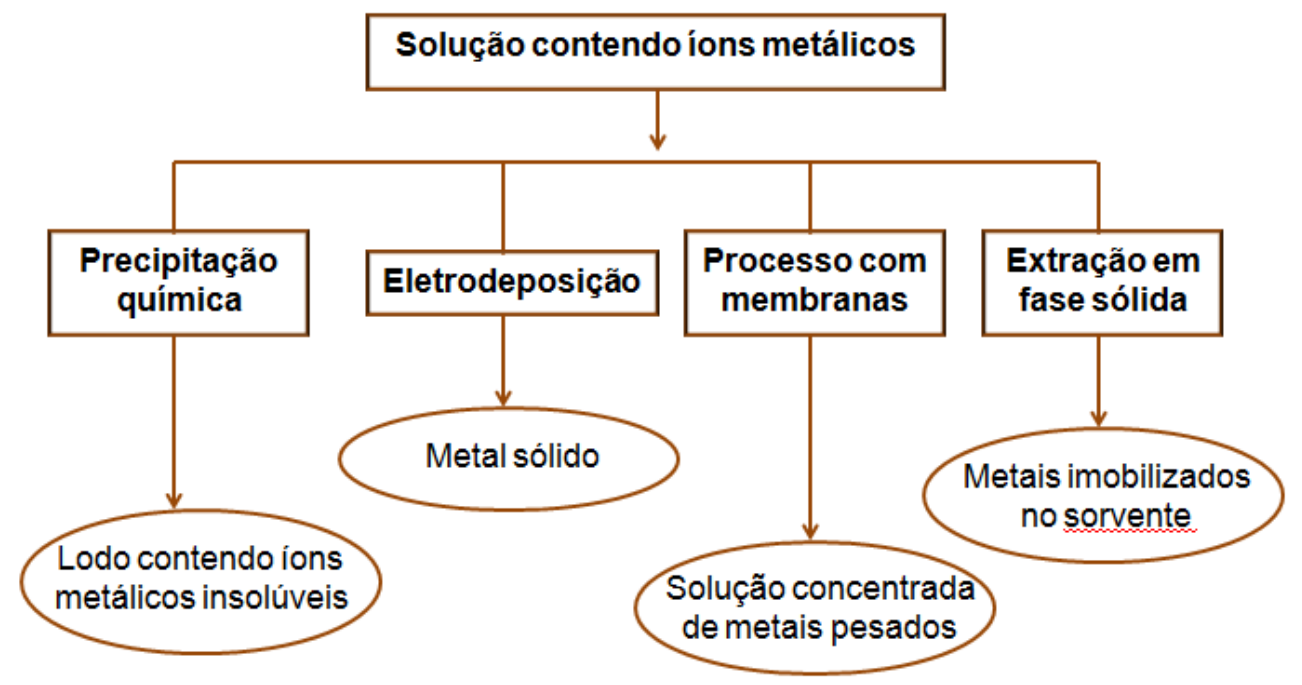

FIGURA 11 - Diferentes métodos para a remoção de metais.

FONTE: Adaptado de KADIRVELU E GOEL, 2007. 


\subsubsection{Processo com membranas}

O tratamento com membranas tem se destacado pelo fato de remover metais tóxicos com boa eficiência em soluções de baixas concentrações e de forma seletiva através de membranas adequadas (KADIRVELU E GOEL, 2007).

Para esse processo por osmose reversa foi utilizada uma membrana de poliamida a uma pressão de 1,0 MPa para o tratamento com $10 \mathrm{~L}$ de solução contendo esses radionuclídeos na faixa de $100-1000 \mu \mathrm{g} . \mathrm{L}^{-1}$. Em pH 9 as porcentagens de íons de ${ }^{90} \mathrm{Sr}$ e ${ }^{137} \mathrm{Cs}$ removidas pela membrana semipermeável foram de $97,25 \%$ e de $87,12 \%$, respectivamente, em pH 3, foram superiores a 99\%. Segundo Ding e col. (2015), o principal responsável pela remoção de cada íon metálico foi o fluxo da solução e não o efeito de pH ou da carga superficial da membrana.

O uso de membranas possui algumas desvantagens, que incluem a baixa durabilidade, custo elevado e suporte técnico especializado (KADIRVELU E GOEL, 2007).

\subsubsection{Precipitação química}

A precipitação química é um processo bastante simples e de baixo custo para a remoção de cátions contidos em soluções aquosas. Os reagentes mais frequentemente utilizados neste processo são hidróxido de sódio, hidróxido de cálcio e carbonato de sódio (EPA, 2000).

O uso da precipitação química é restringido apenas para soluções com íns metálicos em concentrações acima de $100 \mathrm{mg} \cdot \mathrm{L}^{-1}$.

$\mathrm{O}$ íon de ${ }^{90} \mathrm{Sr}$ pode ser removido por precipitação química na forma de carbonato. A quantificação do precipitado obtido pode ser realizada através da dissolução com ácido nítrico seguido da medição com líquido de cintilação como descrito por Amano e Yanase, 1990. 
A principal desvantagem é que em baixas concentrações de metais tóxicos este método torna-se ineficaz (KADIRVELU E GOEL, 2007).

\subsubsection{Eletrodeposição}

Neste método é feita a redução dos íons metálicos sobre eletrodos. A principal vantagem apresentada por este método é a necessidade de uma pequena quantidade de reagentes químicos (KADIRVELU E GOEL, 2007).

Kim et al (2002) estudaram soluções aquosas contendo $\mathrm{Co}^{2+}$ e $\mathrm{Sr}^{2+}$ estáveis pelo processo de eletrodeposição com eletrodo de fibra de carbono ativado para posterior aplicação no tratamento nos rejeitos radioativos líquidos. Esse processo é denominado de eletrossorção e um potencial negativo é aplicado ao eletrodo, favorecendo a deposição dos íons metálicos nos poros deste material. Pode ocorrer a dessorção, para fins de recuperação de íons metálicos, quando é aplicado um potencial positivo. Neste trabalho quase todo o íon cobalto presente na solução de $\mathrm{pH}$ 6,5 e potencial aplicado de -0,2V foi removido após 12 horas de reação. Para a solução contendo íon estrôncio em pH 7,7 foram necessárias aproximadamente 22 horas e um potencial de $0,5 \mathrm{~V}$ para a remoção completa deste ion metálico. Já a dessorção do $\mathrm{Co}^{2+}(+0,7 \mathrm{~V}, \mathrm{pH} 6,7)$ e $\mathrm{Sr}^{2+}$ $(+0,5 \mathrm{~V}, \mathrm{pH} 5)$ foi completa após cerca de 30 e 12 horas, respectivamente.

O investimento inicial para este método é alto, porém o custo de operação é baixo e o tratamento não é recomentado para resíduos com baixa concentração por causa da baixa eficiência nessas condições (KADIRVELU E GOEL, 2007).

\subsubsection{Resina de troca iônica}

O processo de troca-iônica envolve a troca entre os íons do trocador e da solução de forma seletiva até atingir a condição de equilíbrio. Os trocadores de íons iônicos podem ser constituídos por materiais orgânicos ou inorgânicos, como por exemplo, gel ou resinas de troca iônica do tipo catiônico que contém grupos 
de ácidos ou do tipo aniônica que contém grupos básicos (FLORES E MACHADO, 2009; LAVARDA, 2010; SHINZATO, 2007).

Para o estudo da eficiência de remoção de ${ }^{90} \mathrm{Sr}$ e ${ }^{133} \mathrm{Ba}$ foi realizada por Stella et al. (1993) uma simulação com amostras de leite contaminado. Esses radioisótopos foram separados e purificados pelo processo de troca-iônica utilizando a combinação do cromato de cobre e um material amorfo de dióxido de estanho parcialmente reduzido. Com o uso deste material, foi possível obter uma boa eficiência de remoção do ${ }^{90} \mathrm{Sr}$. Ao final do processo restaram, a partir das amostras contendo 200 Bq. $\mathrm{L}^{-1}$ de ${ }^{90} \mathrm{Sr}$ e 500 Bq. $\mathrm{L}^{-1}$ de ${ }^{133} \mathrm{Ba}$, uma concentração,respectivamente, de cerca de $140 \mathrm{~Bq} \cdot \mathrm{L}^{-1}$ e $10 \mathrm{~Bq} \cdot \mathrm{L}^{-1}$,

\subsubsection{Processo de sorção}

O processo de sorção está dividido em dois fenômenos que são a adsorção e a absorção. Quando o adsorvato se encontra retido externamente na partícula do material sorvente o processo é denominado de adsorção. No processo de absorção as partículas são assimiladas no interior do material sorvente. Na FIG. 12 é ilustrado o processo de adsorção e absorção.

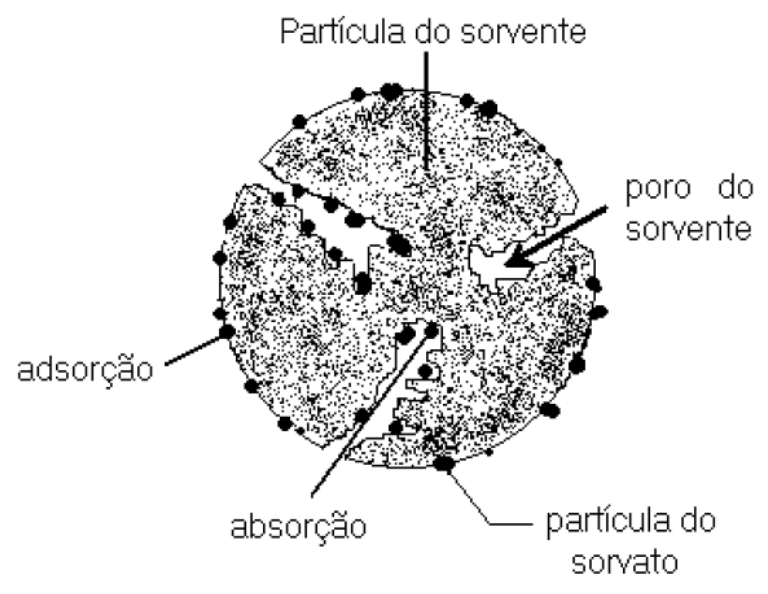

FIGURA 12 - Processo de adsorção e absorção.

FONTE: MONTANHER, 2009. 
O processo de adsorção apresenta uma excelente eficiência na remoção de íons de metais tóxicos em soluções com baixas concentrações, assim, constituindo a principal vantagem oferecida por meio deste método. Por outro lado, a principal desvantagem está associada à disposição final do material sorvente gasto ao final do tratamento, o qual apresenta metais tóxicos em sua estrutura (KADIRVELU E GOEL, 2007).

O processo de adsorção pode ocorrer por meio de dois tipos de mecanismos, ou simultaneamente: adsorção química ou adsorção física. As características gerais estão resumidas na TAB. 1 .

TABELA 1. Diferenças entre os tipos de processo de adsorção

\begin{tabular}{ll}
\hline \multicolumn{1}{c}{ Fisiossorção } & \multicolumn{1}{c}{ Quimiossorção } \\
\hline Baixo calor de adsorção. & Alto calor de adsorção. \\
Não especifica. & Altamente específica. \\
$\begin{array}{l}\text { Pode ocorrer monocamada ou } \\
\text { multicamada. }\end{array}$ & Apenas monocamada. \\
$\begin{array}{l}\text { Sem dissociação das espécies do } \\
\text { adsorbato. }\end{array}$ & $\begin{array}{l}\text { Pode envolver a dissociação das } \\
\text { espécies do adsorbato. }\end{array}$ \\
$\begin{array}{l}\text { Não há transferência de elétrons embora } \\
\text { possa ocorrer polarização do adsorbato. }\end{array}$ & $\begin{array}{l}\text { Há transferência de elétrons e } \\
\text { formação de ligação química. }\end{array}$ \\
\hline
\end{tabular}

FONTE: Adaptado de KADIRVELU E GOEL, 2007.

$\mathrm{Na}$ adsorção química ou quimiossorção ocorre a formação de uma monocamada devido às interações com grupos funcionais contidos superficialmente no sorvente. $\mathrm{Na}$ adsorção física ou fisiossorção ocorre uma deposição do adsorbato sobre a superfície do sorvente. A ligação entre as espécies do adsorbato e o adsorvente, pela fisiossorção, envolve, 
essencialmente, forças intermoleculares e, pela quimiossorção, essa ligação se dá apenas por ligações químicas do adsorbato por grupos funcionais existentes no sorvente.

\subsection{Biossorção}

O termo "biossorção" é definido como um processo em que um sorvente composto por uma biomassa é utilizado na remoção ou recuperação de metais tóxicos presentes em soluções aquosas.

Geralmente, a biomassa composta por micro-organismos vivos envolve o metabolismo na remoção de íons metálicos e na biomassa vegetal, por exemplo, os resíduos agrícolas, o mecanismo de adsorção é frequentemente observada na superfície da biomassa (MOREIRA, 2007).

Resíduos são comumente utilizados como adsorventes na biossorção devido ao seu baixo custo (VIEIRA E VOLESKY, 2000).

O mecanismo de biossorção utilizando o resíduo vegetal pode envolver diferentes interações físico-químicas simultaneamente entre os íons metálicos e os grupos funcionais contidos superficialmente no material biossorvente (PINO, 2005). Os mecanismos que englobam o processo de biossorção são os mesmos que envolvem o de sorção: complexação, quelação, adsorção superficial por forças físicas, troca iônica, precipitação (VOLESKY, 2004).

$\mathrm{Na}$ adsorção, as espécies do adsorbato são aderidas na superfície da biomassa por ligações intramoleculares: iônica e covalente ou ligações intermoleculares do tipo dipolo-dipolo, dipolo-induzido e íon-íon. No processo de quelação o íon metálico é ligado por coordenação à biomassa por meio de dois ou mais ligantes que doam elétrons para o íon metálico; na troca-iônica ocorrem diferentes afinidades entre os íons metálicos da fase líquida com outros da fase sólida do biossorvente; no mecanismo de precipitação ocorre à formação de compostos insolúveis que ficam retidos no exterior ou interior da superfície do material biossorvente e na complexação ocorre à ligação iônica do íon com os 
grupos funcionais negativamente ou parcialmente carregados presentes na superfície da biomassa (VOLESKY, 1990).

O processo de biossorção ocorre até atingir o equilíbrio. Nesta etapa, a quantidade de íons metálicos adsorvidos na biomassa é a mesma dissolvida na solução remanescente, denominado de equilíbrio dinâmico. A distribuição da quantidade de adsorbato retida na fase sólida e líquida é determinada pelo grau de afinidade existente entre o material biossorvente e o adsorbato (DAS et al., 2008).

Os cálculos para a determinação da capacidade de biossorção $\left(q_{e}\right)$ e da eficiência de remoção $E(\%)$ são descritos pelas $E Q .7$ e 8, respectivamente.

$$
\begin{aligned}
q_{e} & =\frac{(C i-C f)}{m} V \\
E(\%) & =\frac{(C i-C f)}{C i} X 100
\end{aligned}
$$

Onde:

$\mathrm{q}_{\mathrm{e}}$ é a quantidade de metal biossorvido por grama de biomassa $\left(\mathrm{mg} \cdot \mathrm{g}^{-1}\right)$;

E é a eficiência de biossoção (\%);

$C_{i}$ e $C_{f}$ são as concentrações inicial e final do adsorbato, respectivamente;

m é a massa da biomassa $(\mathrm{g}) \mathrm{e}$;

V é o volume da solução (L).

Existem diversos parâmetros que afetam na eficiência de remoção de íons metálicos pela biomassa, tais como a temperatura, $\mathrm{pH}$, quantidade de biomassa, afinidade do íon metálico pelos grupos funcionais do material biossorvente, tamanho de partícula, concentração de metais, tempo de contato e as características da biomassa. 
Para uma pequena faixa de temperatura entre 20 a $35^{\circ} \mathrm{C}$, a variação de eficiência de biossorção pode ser pequena, porém em alguns casos a temperaturas mais altas, por exemplo, 50ํㅡ essa eficiência pode aumentar consideravelmente.

O pH é um parâmetro de grande importância na biossorção. As biomassas são constituídas por ácidos fracos e por grupos básicos e dependendo do valor de $\mathrm{pH}$ podem ocorrer variações no grau de dissociação desses sítios ativos, além da solubilidade dos cátions presentes no meio.

No processo de biossorção, a capacidade de adsorção tende a aumentar conforme o aumento da concentração de metais, embora o processo seja eficiente em faixas de concentrações baixas de íons metálicos.

A natureza da biomassa ou produtos derivados obtidos por tratamentos físico-químicos pode ser considerada como um fator importante a ser estudado. $O$ tratamento empregado para um determinado tipo de biomassa tem como objetivo aumentar a capacidade de adsorção do material. $O$ tratamento da biomassa com agentes básicos, por exemplo, faz aumentar a permeabilidade da solução metálica no interior do biossorvente tornando os sítios ativos mais acessíveis aos metais dissolvidos em solução. Estes pré-tratamentos podem ser efetuados com agentes alcalinos, por diferentes tipos de ácidos e por aquecimento. A quantidade de determinado grupo funcional contido na biomassa também pode ser alterado após o tratamento, bem como um novo tipo de ligante com afinidade por íons metálicos (ABBAS et al., 2014).

Na literatura são descritos poucos estudos de biossorção de estrôncio radioativo por biomassa como apresentado a seguir.

De acordo com Dabbagh et al. (2007), íons de estrôncio tanto estável como radioativo $\left({ }^{90} \mathrm{Sr}\right)$ foram removidos utilizando-se biomassa viva do fungo Oscillatoria homogenea. Uma solução de 1000 mol.L $\mathrm{L}^{-1}$ do metal foi removido a 43,8 mol.L $\mathrm{L}^{-1}$ após 240 horas de tempo de contato. O longo período de sorção foi devido ao tempo de crescimento desse fungo. 
Barot e Bagla (2012), descreveram a utilização de esterco bovino em pó sem qualquer pré-tratamento como biomassa na biossorção de ${ }^{90} \mathrm{Sr}$ contido em meio aquoso. A eficiência de remoção foi de aproximadamente $50 \%$ utilizando-se $350 \mathrm{mg}$ de biomassa em uma solução de ${ }^{90} \mathrm{Sr}^{2+}$ de $20 \mathrm{mg} \cdot \mathrm{mL}^{-1}, \mathrm{pH} 6$, tempo de contato de 10 minutos e à temperatura ambiente. Segundo os autores, essa biomassa possui uma vantagem sobre os outros materiais, no caso, seu custo de produção.

Mimura et al. (2001) estudaram a afinidade de adsorção do ácido algínico granulado como sorvente no seguintes radionuclídeos ${ }^{22} \mathrm{Na}^{+},{ }^{137} \mathrm{Cs}^{+}$, ${ }^{85} \mathrm{Sr}^{2+},{ }^{60} \mathrm{Co}^{2+},{ }^{59} \mathrm{Fe}^{3+},{ }^{152} \mathrm{Eu}^{3+}$ e ${ }^{241} \mathrm{Am}^{3+}$. Os coeficiente de distribuição $\left(K_{D}\right)$ na ordem crescente de adsorção para os íons metálicos foram ${ }^{22} \mathrm{Na}^{+}<{ }^{137} \mathrm{Cs}^{+}<$ ${ }^{60} \mathrm{Co}^{2+}<{ }^{85} \mathrm{Sr}^{2+},{ }^{59} \mathrm{Fe}^{3+}<{ }^{152} \mathrm{Eu}^{3+},{ }^{241} \mathrm{Am}^{3+}$, indicando a afinidade de remoção de cada radionuclídeo pelo ácido algínico, comprovando a eficiência de seu uso no tratamento de rejeitos radioativos líquidos. $O \mathrm{~K}_{\mathrm{D}}$ do ${ }^{85} \mathrm{Sr}$ em uma solução 0,5 mol. $\mathrm{L}^{-1}$ em meio ácido foi de $1.10^{4} \mathrm{~mL} \cdot \mathrm{g}^{-1}$ utilizando-se $0,07 \mathrm{~g}$ de material sorvente e 3 dias de tempo de contato.

Gok et al. (2013) utilizaram esferas de alginato de sódio para a remoção do radioisótopo ${ }^{85} \mathrm{Sr}^{2+}$ presente em meio aquoso. A remoção deste radionuclídeo presente em $50 \mathrm{~mL}$ de uma solução $20 \mathrm{~Bq} \cdot \mathrm{mL}^{-1}$ de ${ }^{85} \mathrm{Sr}^{2+}$ foi de cerca de $85 \%$ após 90 minutos de tempo de contato em $\mathrm{pH} 7$ à temperatura ambiente.

Recentemente, Fuks et al. (2015) investigaram a remoção de íons ${ }^{85} \mathrm{Sr}$ pelo alginato de cálcio comercial. $O \mathrm{~K}_{\mathrm{D}}$ obtido foi de aproximadamente $100 \mathrm{~mL} \cdot \mathrm{g}^{-1}$, em pH 5,6 e tempo de contato de 4 horas à $25^{\circ} \mathrm{C}$. De acordo com este estudo, o biopolímero apresenta ácidos carboxílicos em sua superfície que facilitam a remoção de íons de estrôncio presentes em meio aquoso.

\subsection{Isotermas de Adsorção}

As isotermas de adsorção são definidas como modelos matemáticos que descrevem a distribuição do adsorbato entre as fases sólida e líquida (SEKER et al., 2008; MAMMAN et al., 2011), a temperatura e pH constantes. 
Esses modelos matemáticos são amplamente utilizados para a avaliação da força de sorção, capacidade máxima de biossorção (MONTANHER et al., 2005; MONTANHER, 2009) e também na determinação das condições de operação de um processo de tratamento com a respectiva eficiência de remoção para cada valor de concentração inicial (YAMAMURA E YAMAURA, 2005).

No cálculo das isotermas são consideradas a heterogeneidade/homogeneidade e outras características de superfície da biomassa, bem como as interações das espécies do adsorbato pela biomassa (KALALAGH et al., 2011).

As isotermas são avaliadas por meio de gráficos envolvendo a capacidade de biossorção $\left(q_{e}\right)$ em função da concentração inicial. Os processos de adsorção podem ser identificados pelo formato das isotermas. As isotermas côncavas, por exemplo, designa um processo de adsorção favorável, já o formato convexo da isoterma indica um processo desfavorável em toda sua extensão e a linear, indica que o processo de remoção de metais é proporcional ao aumento da concentração de adsorbato. As isotermas são ditas favoráveis porque alcançam altas capacidades de remoção mesmo em baixas concentrações (MONTANHER, 2009). Os formatos das isotermas estão apresentados na FIG. 13.

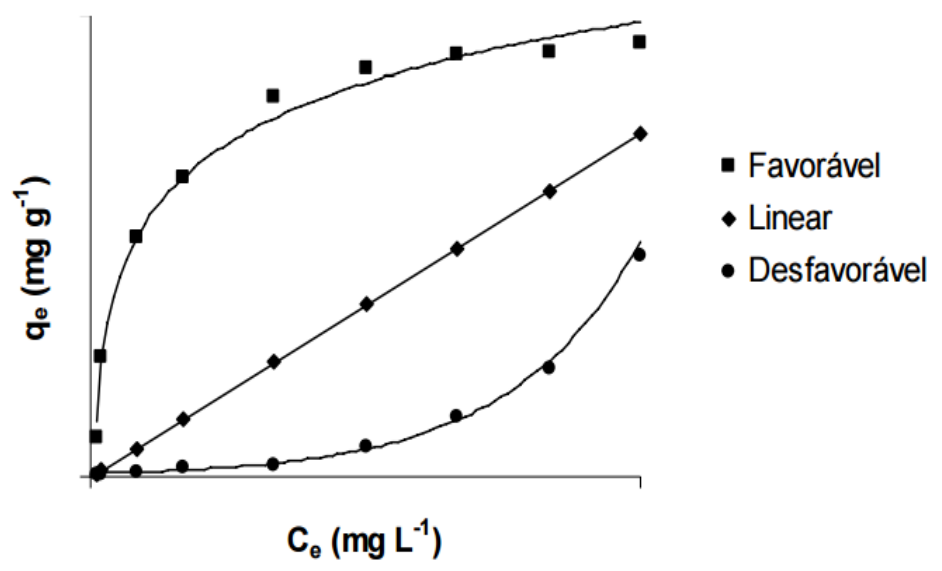

FIGURA 13 - Forma das isotermas.

FONTE: MONTANHER, 2009.

Nos processos em batelada, os modelos matemáticos mais utilizados para descrever o processo de sorção de metais pela biomassa são as isotermas 
de Langmuir e Freundlich (YAMAMURA E YAMAURA, 2005; SALEHI et al., 2010).

\section{Modelo de Langmuir}

As isotermas de Langmuir foram desenvolvidas em 1926 para descrever o fenômeno de gases sobre a superfície de carvão ativado (FOO, 2010), e atualmente tem sido empregada para quantificar a eficiência em processos envolvendo a remoção de compostos orgânicos ou inorgânicos em meios líquidos por uma variedade de materiais adsorventes.

Este modelo presume que há a formação de uma monocamada de adsorbato em sítios ativos de mesma energia. Esta energia é constante na superfície homogênea e não ocorrem interações entre as espécies do adsorbato com outros sítios ativos ou adsorbatos laterais (GHAEDI et al., 2013). O modelo de Langmuir é apresentado na EQ. 9.

$$
Q_{e q}=\frac{Q K_{L} C_{e q}}{1+K_{L} C_{e q}}
$$

Sua forma linearizada na EQ. 10:

$$
\frac{C_{e q}}{Q_{e q}}=\frac{C_{e q}}{\mathbf{Q}}+\frac{1}{\left(\mathbf{Q} K_{L}\right)}
$$

Onde:

$\mathrm{C}_{\text {eq }}=$ concentração de adsorvato na solução $\left(\mathrm{mg} \cdot \mathrm{L}^{-1}\right)$;

$Q_{\text {eq }}=$ é a quantidade de soluto adsorvido na biomassa $\left(\mathrm{mg} \cdot \mathrm{g}^{-1}\right)$;

$\mathrm{Q}=$ capacidade máxima de adsorção $\left(\mathrm{mg}^{\left.-\mathrm{g}^{-1}\right)}\right.$;

$\mathrm{K}_{\mathrm{L}}=$ constante de adsorção de Langmuir $\left(\mathrm{L} \cdot \mathrm{mg}^{-1}\right)$. 
As constantes $\mathrm{Q}$ e $\mathrm{K} \mathrm{L}$ são obtidas respectivamente pelo coeficiente angular e coeficiente linear na forma linearizada (EQ 10). Os valores dessas constantes serão utilizados na obtenção da curva teórica da isoterma de Langmuir (EQ.9).

Quanto maior os valores de $Q$ e $K_{L}$ melhor será a eficiência de remoção apresentada pela biomassa e maior a afinidade dos íons metálicos pela biomassa, respectivamente (FIGUEIREDO, 2013). Geralmente quando o mecanismo envolvido no processo de adsorção se dá por meio de ligações químicas, atribui-se a isoterma de Langmuir.

Um importante parâmetro de dimensionamento que prevê a forma da isoterma de Langmuir é o parâmetro de equilíbrio $\left(R_{L}\right)$. $O R_{L}$ é calculado pela $E Q$. 11.

$$
R_{L}=\frac{1}{1+K_{L} C_{i}}
$$

Onde:

$\mathrm{R}_{\mathrm{L}}=$ parâmetro de equilíbrio (adimensional);

$\mathrm{K}_{\mathrm{L}}=$ constante relacionada à energia de adsorção (constante de Langmuir);

$\mathrm{C}_{\mathrm{i}}=$ concentração inicial da solução $\left(\mathrm{mg} \cdot \mathrm{L}^{-1}\right)$.

Por meio dos valores de $R_{L}$, é possível classificar se o processo é desfavorável $\left(R_{L}>1\right)$, linear $\left(R_{L}=1\right)$, favorável $\left(0<R_{L}<1\right)$ ou irreversível $\left(R_{L}=0\right)$ (DADA et al., 2012; AHALYA et al., 2007).

\section{Modelo de Freundlich}

A isoterma de Freundlich é um modelo empírico que prevê o processo de adsorção em multicamadas. Esse modelo assume que os adsorbatos são 
capturados com o auxílio de outros sítios ativos adjacentes, ocupados ou não (MONTANHER, 2009). A equação do modelo de Freundlich é apresentada na EQ. 12 abaixo.

$$
Q_{e q}=K_{F} C_{e q}^{1 / n}
$$

Sua forma linearizada na EQ. 13:

$$
\log Q_{e q}=\frac{1}{n} \cdot \log C_{e q}+\log K_{F}
$$

Onde:

$\mathrm{Q}_{\mathrm{eq}}=$ capacidade máxima de adsorção $\left(\mathrm{mg} \cdot \mathrm{g}^{-1}\right)$;

$\mathrm{C}_{\text {eq }}=$ é a concentração de adsorvente na solução $\left(\mathrm{mg} \cdot \mathrm{L}^{-1}\right)$;

$1 / \mathrm{n}=$ fator de heterogeneidade (adimensional);

$\mathrm{K}_{\mathrm{F}}=$ constante de adsorção de Freundlich $\left(\mathrm{L} \cdot \mathrm{g}^{-1}\right)$.

Os valores de $K_{F}$ e de $1 / n$ são dados pela reta da $E Q 13$ pelo coeficiente linear e coeficiente angular, respectivamente.

A isoterma de Freundlich demonstra a heterogeneidade da superfície do adsorvente, onde os sítios ativos possuem diferentes tipos de energia de adsorção (BULGARIU E BULGARIU, 2012).

Esta isoterma de Freundlich foi desenvolvida para descrever a remoção de adsorbato utilizando carvão animal, demonstrando que a remoção de adsorvato por uma dada quantidade de adsorvente pode variar a diferentes valores de concentração. Esta suposição pode ser explicada considerando que os sítios ativos possuem energias distintas de adsorção e durante o andamento do processo de adsorção os sítios que possuem maior energia são ocupados primeiro, até que a energia de ligação entre os sítios ativos e o adsorbato diminua exponencialmente e as espécies do adsorbato são então continuamente 
adsorvidas até o término do processo de adsorção, admitindo a formação de multicamadas (FOO E HAMEED, 2010).

\subsection{Cinética de Adsorção}

A cinética de adsorção ou velocidade de reação é essencial na compreensão do comportamento dos mecanismos envolvidos no processo de adsorção. Por meio da cinética de adsorção é possível calcular o tempo de retenção em sistemas de tratamento de remoção de íons metálicos (ASIAGWU, 2012; GHAEDI et al., 2014).

Os principais fatores que influenciam na velocidade de adsorção são as características físico-químicas do sistema, que incluem a temperatura, o pH e a concentração de íons metálicos em solução, o tipo de biomassa e seus derivados e suas características, como natureza do material e sua porosidade; e a natureza do adsorbato, o qual possui propriedades distintas, como peso molecular, solubilidade e carga iônica (LAVARDA, 2010).

Normalmente, a cinética de adsorção depende do fenômeno de transporte e das reações químicas envolvidas na adsorção.

O transporte do adsorbato a posterior adsorção nos grupos funcionais contidos superficialmente no material adsorvente é conduzido por etapas bem definidas. Inicialmente, o adsorbato presente na solução é direcionado até a interface que envolve o material adsorvente. As espécies do adsorbato são então conduzidas à superfície do adsorvente por difusão externa, em seguida, são dispersas entre os poros existentes em seu interior por difusão intrapartícula e finalmente por adsorção física ou química o adsorbato é assimilado pelos sítios ativos do adsorvente (CHEN E WANG, 2004).

Os passos empregados até a adsorção das espécies do adsorbato no biossorvente são apresentados na FIG. 14. 


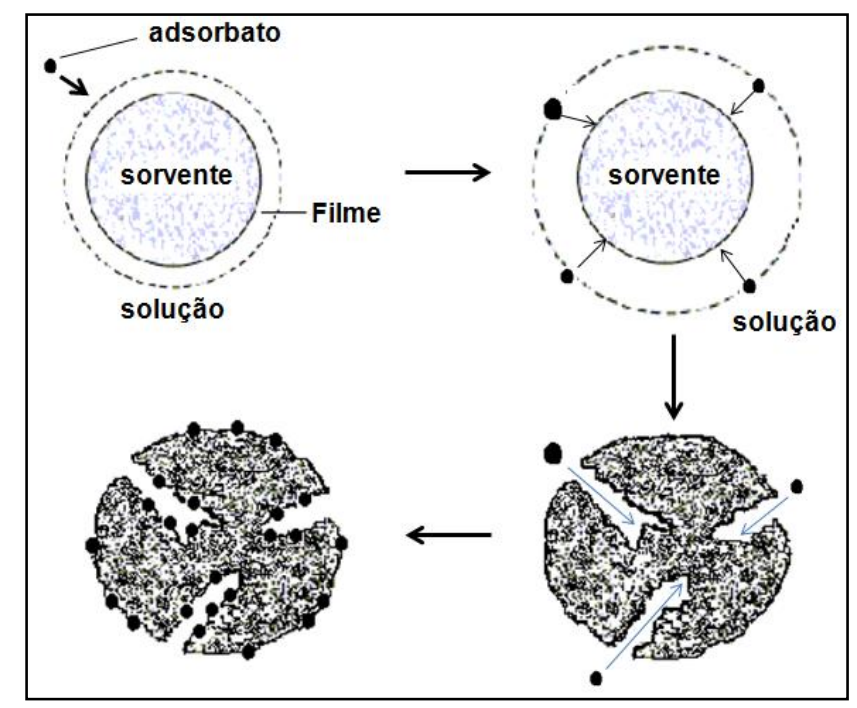

FIGURA 14 - Esquema das etapas de transporte do adsorbato ao biossorvente.

FONTE: Adaptado de MONTANHER et al., 2009.

As etapas limitantes da velocidade de reação de adsorção são a difusão intrapartícula e o processo de ligação química. Já o transporte do adsorbato e sua dispersão na interface do adsorvente são etapas que ocorrem rapidamente (MIRETZKY et al., 2010).

Os modelos desenvolvidos por Lagergren e Ho são os mais utilizados na estimação da velocidade de reação de primeira ordem e segunda ordem.

\section{Modelo de pseudo-primeira ordem}

O modelo de Lagergren foi desenvolvido para estimar a cinética de adsorção de primeira ordem apenas em sistemas de adsorção sólido-líquido. O cálculo da cinética de adsorção de pseudo-primeira ordem é dado conforme a $E Q$ 14 (EDRIS et al., 2014).

$$
\ln \left(\mathbf{q}_{e q}-\mathbf{q}_{t}\right)=\ln \mathbf{q}_{e q}-K_{1} \cdot \mathbf{t}
$$


Onde:

$\mathrm{K}_{1}=$ constante de velocidade da reação $\left(\min ^{-1}\right)$;

$q_{\text {eq }}=$ capacidade de remoção do adsorbato no equilíbrio $\left(\mathrm{mg} \mathrm{g}^{-1}\right)$;

$\mathrm{q}_{\mathrm{t}}=$ capacidade de remoção do adsorbato em um dado tempo $\mathrm{t}\left(\mathrm{mg} \cdot \mathrm{g}^{-1}\right)$;

$\mathrm{t}=$ tempo de contato (minuto).

Os valores experimentais no gráfico de $\ln (q e$ - qt) em função do tempo (t) dão origem a uma reta, em que os coeficientes linear e angular fornecem, respectivamente. a capacidade de remoção de adsorbato no equilíbrio $\left(q_{\mathrm{eq}}\right)$ e a constante de velocidade da reação $\left(\mathrm{K}_{1}\right)$.

No modelo de pseudo-primeira ordem a velocidade de ocupação dos sítios ativos é proporcional à quantidade de sítios ativos desocupados e para cada sítio pode ocorrer à adsorção por um único adsorbato (TARLEY et al., 2012).

\section{Modelo de pseudo-segunda ordem}

O modelo pseudo-segunda ordem foi proposto por Ho \& Mckay para o estudo de cinética de adsorção envolvendo reação com velocidade de reação de segunda ordem, conforme apresentado na EQ.15 (STERNBERG E DORN, 2002).

$$
\frac{t}{\mathbf{q}_{t}}=\frac{1}{\mathbf{K}_{2}(\mathbf{q})^{2}}+\frac{1}{\mathbf{q}} \mathbf{t}
$$

Onde:

$\mathrm{K}_{2}=$ constante de velocidade da reação $\left(\mathrm{g} \cdot \mathrm{mg}^{-1} \cdot \mathrm{min}^{-1}\right)$;

$\mathrm{q}=$ capacidade de remoção teórica $\left(\mathrm{mg} \cdot \mathrm{g}^{-1}\right)$;

$\mathrm{qt}=$ capacidade de remoção em um dado tempo $\mathrm{t}\left(\mathrm{mg} \cdot \mathrm{g}^{-1}\right)$;

$\mathrm{t}=$ tempo de contato $(\min )$. 
Por meio dos dados contidos no gráfico de $t / q_{t}$ em função de tempo (t), são obtidos pelo coeficiente angular e linear da reta, a capacidade de remoção teórica (q) e a constante de velocidade da reação $\left(\mathrm{K}_{2}\right)$, respectivamente (GHAEDI et al., 2013). A velocidade de sorção inicial pode ser obtida no gráfico mediante o valor de $t / q_{t}$ tendendo a zero (OLADOJA, et al., 2008).

A taxa de ocupação dos sítos ativos também é proporcional ao número de sítios ativos disponíveis superficialmente na biomassa. O modelo de pseudosegunda ordem admite dois sítios ativos para a captação de uma espécie do adsorbato (TARLEY et al., 2012). Este modelo é baseado na suposição de que a velocidade de adsorção é controlada especialmente pela interação dos grupos funcionais do biosorvente com os íons metálicos (BULGARIU E BULGARIU, 2012).

\subsection{Energia livre de Gibbs}

Os parâmetros termodinâmicos são importantes para indicar a espontaneidade e viabilidade do processo de adsorção. Dentre os parâmetros termodinâmicos está à energia livre de Gibbs que prevê a espontaneidade de uma reação química e da adsorção.

Por meio da variação da energia livre de Gibbs $(\Delta G)$ é possível verificar se em um sistema ocorreu reação química, em um dado sistema com valores de temperatura e pressão conhecidos (SALEEM E BHATTI, 2011). A variação da energia livre de Gibbs é calculada por meio da EQ.16 (JAIKUMAR, 2009).

$$
\Delta \mathbf{G}=-R T \cdot \ln \mathbf{K}_{e q}
$$

Onde:

$\mathrm{R}=$ constante universal dos gases perfeitos $8,314 \mathrm{~J} \cdot \mathrm{K}^{-1} \cdot \mathrm{mol}^{-1}$;

$\mathrm{T}=$ temperatura absoluta $(\mathrm{K})$;

$\mathrm{K}_{\mathrm{eq}}=$ constante de equilíbrio da reação $\left(\mathrm{L} \cdot \mathrm{mol}^{-1}\right)$. 
A constante de equilíbrio da reação $\left(K_{\text {eq }}\right)$ pode ser substituída pela constante de Langmuir $\left(\mathrm{K}_{\mathrm{L}}\right)$ para se estimar a energia livre de Gibbs padrão $\left(\Delta \mathrm{G}^{0}\right)$ no processo de adsorção no equilíbrio (ZHANG, 2014; FREITAS, 2005).

Em um processo de adsorção de íons metálicos $\circ \Delta G<0$ indica que o processo de adsorção é espontâneo. Essas reações ditas espontâneas ocorrem em um processo exotérmico, na qual há liberação de energia (OSASONA et al., 2013; NUHOGLU E MALKOC, 2009). Por outro lado, em sistemas não espontâneos, $\Delta G>0$, ocorre a absorção de energia, ou seja, é necessário um fornecimento de energia ao sistema para ocorrer a reação química de maneira a vencer a energia de ativação para a formação de produtos. Quando o $\Delta G=0$, a quantidade de produtos formados é igual ao de reagentes.

\subsection{Coeficiente de distribuição}

O coeficiente de distribuição $\left(K_{D}\right)$ é um parâmetro termodinâmico que expressa o potencial de adsorção em uma dada temperatura. Essa constante expressa à distribuição existente entre as espécies do adsorbato e o adsorvente na fase líquida (YANTASEE, et al., 2007). Quanto maior o valor de $K_{D}$ melhor será a eficiência do processo, indicando que houve uma maior fração adsorvida de adsorbato na biomassa após a biossorção. $A$ equação de $K_{D}$ é apresenta na EQ.17.

$$
\mathrm{K}_{D}=\frac{\mathrm{C}_{i}-\mathrm{C}_{f}}{\mathrm{C}_{f}} x \frac{V}{m}
$$

Onde:

$\mathrm{Ci}=$ concentração inicial da solução $\left(\mathrm{mg} \cdot \mathrm{L}^{-1}\right)$;

$\mathrm{Cf}=$ concentração final da solução $\left(m g \cdot \mathrm{L}^{-1}\right)$;

V = volume da solução $(\mathrm{L})$;

$\mathrm{m}=$ massa do material biossorvente $(\mathrm{Kg})$. 
Em relação à Equação $17, \mathrm{Ci}-\mathrm{Cf}$ representa a porção de adsorbato que foi adsorvida pela fase sólida e o Cf é a porção de adsorbato remanescente na solução. A fração adsorvida também pode variar dependendo da taxa de $\mathrm{V} / \mathrm{m}$ escolhida para o processo. $O$ valor de $K_{D}$ pode variar em relação à massa e 0 volume admitidos como constante no processo de biossorção. Esse conhecimento é de grande valia na comparação de resultados (WAHLBERG E DEWAR, 1965). 


\section{METODOLOGIA}

\subsection{Materiais}

A determinação das concentrações das soluções de $\mathrm{Sr}^{2+}$ foi realizada na Gerência de Rejeitos Radioativos (GRR) No Centro de Tecnologia das Radiações (CTR) foram realizadas as Análises Termogravimétricas (TGA/DTG) As análises de Microscopia Eletrônica de Varredura (MEV) foram realizadas no Centro de Ciência e Tecnologia dos Materiais (CCTM). As análises por Difração de Raio X (DRX) foram realizadas no Centro de Combustível Nuclear (CCN). As análises de espectroscopia de infravermelho (FT-IR) foram realizadas no Instituto de Química (IQ - USP)

\subsubsection{Reagentes}

Os reagentes utilizados foram hidróxido de sódio (Vetec), nitrato de estrôncio (Merck), , peróxido de hidrogênio - 30\% (Merck), ácido nítrico P. A. (Alphatec), permanganato de potássio P. A. (Vetec), nitrato de estrôncio P. A. (Merck), bicarbonato de sódio (Merck), ácido clorídrico - 65\% (CAAL) e ácido sulfúrico concentrado - 95 a 97\% (CAAL).

\subsubsection{Biomassa}

A fibra de coco bruta foi obtida em comércio local (West Garden).

\subsubsection{Vidrarias}

As vidrarias utilizadas foram, balões volumétricos, bureta de $50 \mathrm{~mL}$, Béqueres, espátula, filtro qualitativo, estante para tubos de ensaio, frascos de vidro e plástico com tampa de $20 \mathrm{~mL}$, funil de haste longa, garra metálica, pipeta de Pasteur, pipeta volumétrica de $25 \mathrm{~mL}$, pipetas graduadas, provetas, suporte universal, termômetro, tubos Falcon de $10 \mathrm{~mL}$, tubo secante e Erlenmeyers.

\subsubsection{Equipamentos}

A determinação das concentrações das soluções de $\mathrm{Sr}^{2+}$ foi realizada no Espectrômetro de Emissão Óptica por Plasma Acoplado Indutivamente (ICP- 
OES) da marca Perkim Elmer modelo Optima 7000 DV. As análises Termogravimétricas (TGA/DTG) foram efetuadas no equipamento TA, modelo SDT Q600 e os experimentos de biossorção foram efetuadas na mesa agitadora da marca SP Labor, modelo SP-180/A. As análises de Microscopia Eletrônica de Varredura (MEV) foram realizadas no equipamento da marca $\mathrm{FEl}$, modelo INSPECT S50 acoplado a um Espectrômetro de Energia Dispersiva (EDS). As análises por Difração de Raio $X(D R X)$ foram realizadas em um difratômetro da marca Bruker, modelo D8ADVICE. As análises de espectroscopia de infravermelho (FT-IR) foram realizadas no equipamento da marca Perkin Elmer, modelo Spectrum 100 .

\subsection{EXPERIMENTAL}

Os seguintes experimentos foram realizados nas instalações no Centro de Tecnologia das Radiações (CTR)

\subsubsection{Tratamento da fibra de coco bruta}

A fibra de coco bruta foi lavada com água deionizada para a retirada de impurezas. Em seguida, seca em estufa a $80^{\circ} \mathrm{C}$ por 24 horas, esterilizada com luz UV por 2 horas, cortada em comprimentos de $2-5 \mathrm{~mm}$ e finalmente separada em diâmetros menores de 80 mesh $(0,177 \mathrm{~mm}$ a $0,297 \mathrm{~mm})$ utilizando-se peneiras granulométricas. O esquema do pré-tratamento da fibra de coco bruta está apresentado na FIG. 15. 


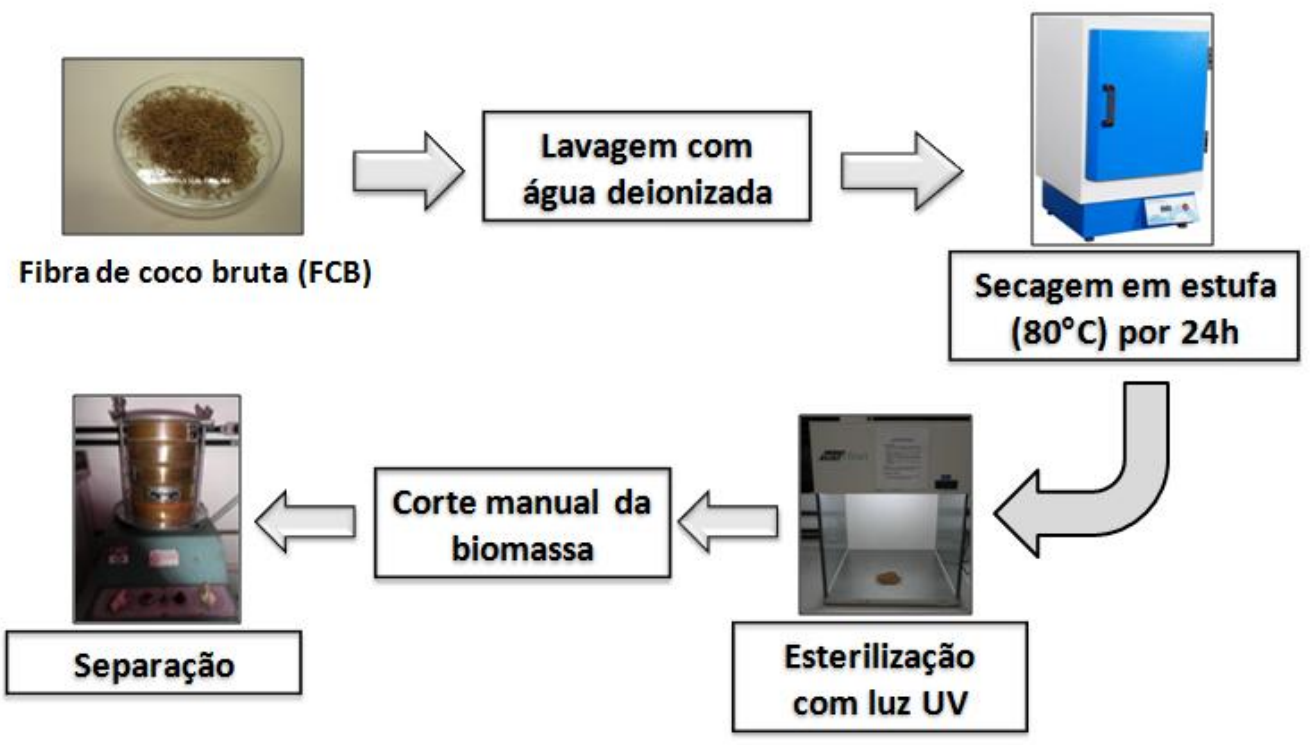

FIGURA 15 - Etapas do processo de pré-tratamento da fibra de coco bruta.

\subsubsection{Determinação do teor de peróxido de hidrogênio}

O teor do peróxido de hidrogênio na solução comercial foi determinado por titulação de óxido-redução. Em um Béquer foram adicionados cerca de $5 \mathrm{~g}$ de solução de peróxido de hidrogênio, em seguida transferida para um balão volumétrico de $250 \mathrm{~mL}$ contendo aproximadamente $100 \mathrm{~mL}$ de água deionizada e $2 \mathrm{~mL}$ de ácido sulfúrico - (1:3) e finalmente avolumado com água deionizada para $250 \mathrm{~mL}$. Uma alíquota de $20 \mathrm{~mL}$ desta solução foi retirada do balão volumétrico com uma pipeta e transferida para um Erlenmeyer de $250 \mathrm{~mL}$ contendo uma solução de $60 \mathrm{~mL}$ de água deionizada e $15 \mathrm{~mL}$ de $\mathrm{H}_{2} \mathrm{SO}_{4}$ (1:3). A titulação foi realizada com uma solução de $0,1 \mathrm{~mol} . \mathrm{L}^{-1}$ de permanganato de potássio $\left(\mathrm{KMnO}_{4}\right)$ previamente padronizado até o aparecimento de cor rosa (SOLVAY CHEMICALS, 2004).

\subsubsection{Ativação da fibra de coco com $\mathrm{H}_{2} \mathrm{O}_{2}$ em meio básico}

O método utilizado na ativação da biomassa foi realizado conforme descrito por Shukla et al. (2009) com algumas modificações. Parte da fibra de coco bruta obtida após o pré-tratamento foi tratada em uma solução contendo 60 $\mathrm{mL}$ de água deionizada, com a adição de 2 e $8 \mathrm{~mL}$ de $\mathrm{H}_{2} \mathrm{O}_{2}$ para a obtenção de, respectivamente, FCA 1 e FCA 2, em pH 11,5 para cada $3 \mathrm{~g}$ de biomassa, sob 
agitação constante por 2 horas a $70^{\circ} \mathrm{C}$. Após este tempo de contato, a biomassa foi filtrada a vácuo, lavada com água deionizada quente e água destilada fria até apresentar $\mathrm{pH} 7$, sendo seca posteriormente em estufa por 24 horas a $70^{\circ} \mathrm{C}$. A FIG. 16 demonstra a aparelhagem utilizada no processo de ativação da biomassa.
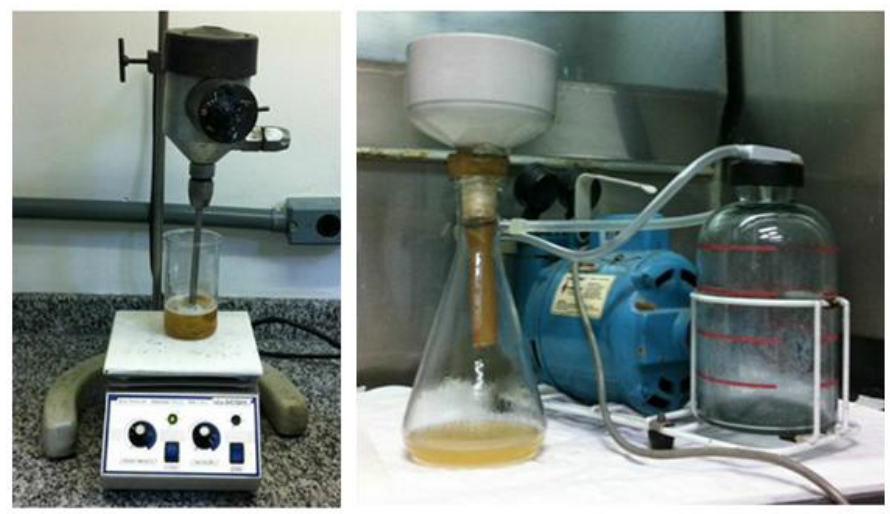

FIGURA 16 - Aparelhagem utilizada no processo de ativação e filtragem a vácuo da fibra de coco ativada.

\subsubsection{Caracterização do ponto de carga zero das fibras}

A metodologia empregada para a determinação do ponto de carga zero é denominada de "experimento dos onze pontos". Inicialmente mistura-se $25 \mathrm{mg}$ de biomassa em $50 \mathrm{~mL}$ de solução aquosa com onze valores distintos de $\mathrm{pH}$,

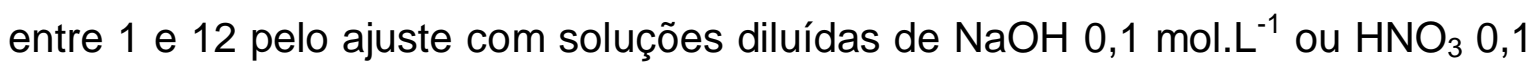
mol.L-1 . Finalmente após 24 horas de equilíbrio, foi medido o pH final da solução. O gráfico foi plotado com os valores de $\mathrm{pH}$ final em função do $\mathrm{pH}$ inicial, e o ponto de carga zero é o valor de $\mathrm{pH}$ a partir da qual a curva manteve-se constante (MINURA, 2010).

\subsection{Preparação das soluções estoque de $\mathrm{Sr}\left(\mathrm{NO}_{3}\right)_{2}$ para a curva de calibração}

Para a curva de calibração do Espectrômetro Óptico de Emissão Atômica com Plasma Indutivamente Acoplado (ICP-OES) foram preparadas soluções de $\operatorname{Sr}\left(\mathrm{NO}_{3}\right)_{2}$ com $2 \%$ de $\mathrm{HNO}_{3}$ de 0,$2 ; 0,5 ; 1,0 ; 2,0$ e $5,0 \mathrm{mg} \cdot \mathrm{L}^{-1}$, foi utilizada uma solução de nitrato de estrôncio de $1000 \mathrm{mg} \cdot \mathrm{g}^{-1}$, em água deionizada. Para a curva de calibração do estrôncio o comprimento de onda utilizado foi de 460,733 nm e é apresentada na FIG. 17. 


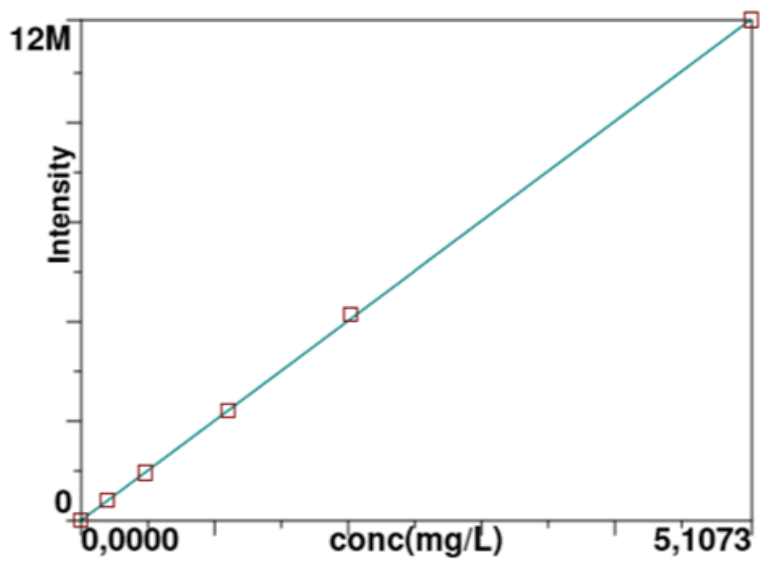

FIGURA 17 - Curva de calibração do $S r^{2+}$ obtida por ICP-OES no comprimento de onda de 460,733 $\mathrm{nm}$.

\subsection{Experimentos de biossorção de $\mathrm{Sr}^{2+}$}

As soluções de nitrato de estrôncio (estável) utilizadas nos experimentos de biossorções foram feitas a partir de uma solução estoque de $100 \mathrm{mg} \cdot \mathrm{g}^{-1}$. Os valores de $\mathrm{pH}$ das soluções foram ajustados para 3, 6 e 9, com solução de $\mathrm{HNO}_{3}\left(0,1 \mathrm{~mol} . \mathrm{L}^{-1}\right)$ ou com $\mathrm{NaOH}\left(0,1 \mathrm{~mol} . \mathrm{L}^{-1}\right)$.

Em frasco de polietileno de $20 \mathrm{~mL}$ foram adicionados $10 \mathrm{~mL}$ de solução de estrôncio e 10 ou $5 \mathrm{mg}$ de biomassa. A mistura foi mantida sob uma agitação constante de 100 rpm em uma mesa agitadora nos diferentes tempos de contato de $2,5,10,30,60,90,150,200$ e 250 minutos. Ao término do experimento a solução foi separada da biomassa por filtração simples e a solução remanescente foi analisada por ICP-OES. A FIG. 18 apresenta o esquema do experimento de biossorção. Todos os experimentos de biossorção foram realizados em triplicata.

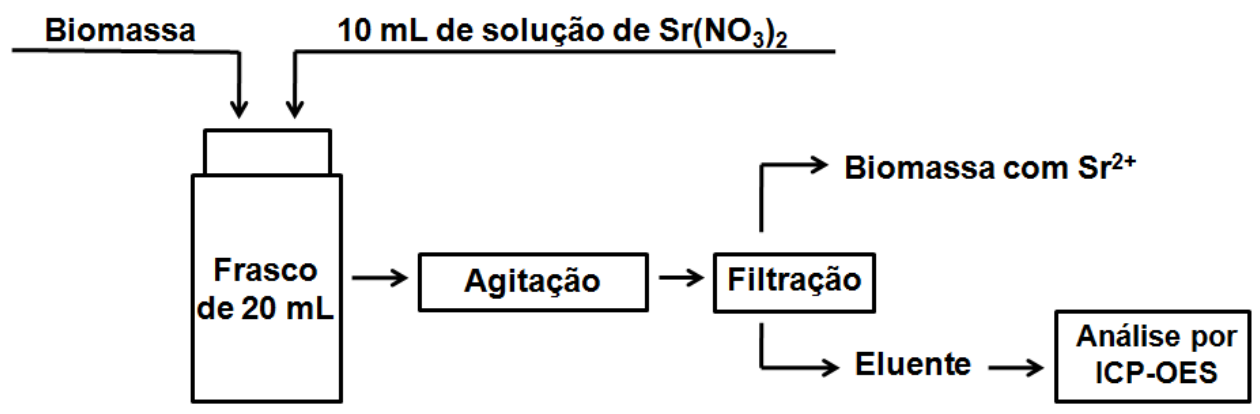

FIGURA 18 - Esquema do experimento de biossorção. 
Para os estudos das isotermas tanto para as fibras bruta como ativada, as soluções de nitrato de estrôncio foram obtidas a partir da diluição com água deionizada de uma solução estoque de nitrato de estrôncio de $100 \mathrm{mg} \cdot \mathrm{L}^{-1}$, com $\mathrm{pH}$ 6. As concentrações das soluções de $\mathrm{Sr}^{2+}$ preparadas foram de 1,9; 5,5; 9,9; 22,2; 34,3 e 46,5 mg. $\mathrm{L}^{-1}$. As isotermas de adsorção, tanto para a fibra de coco bruta quanto para a fibra de coco ativada, foram realizadas nas melhores condições obtidas nos experimentos de biossorção que são: $5 \mathrm{mg}$ de biomassa, em $\mathrm{pH} 6$, tempo de contato de 90 minutos a temperatura ambiente $\left(25^{\circ} \mathrm{C}\right)$, sob agitação constante de $100 \mathrm{rpm}$. No estudo de cinética, utilizaram-se $5 \mathrm{mg}$ de biomassa, $10 \mathrm{~mL}$ de solução de $\mathrm{Sr}^{2+}\left(2 \mathrm{mg} \cdot \mathrm{L}^{-1}\right)$, em pH 6, com tempos de contato de $10,30,60,90,120$ e 200 minutos.

\subsubsection{Análise de estrôncio $\left(\mathrm{Sr}^{2+}\right)$ por Espectrometria de Emissão Óptica}

As amostras de solução de estrôncio antes após cada experimento de biossorção foram acidificadas $\left(2 \% \mathrm{HNO}_{3}\right)$ e analisadas no ICP-OES. O Espectrômetro de ICP-OES e o sinal obtido em um comprimento de onda de 460, 733 nm estão apresentados na FIG. 19.

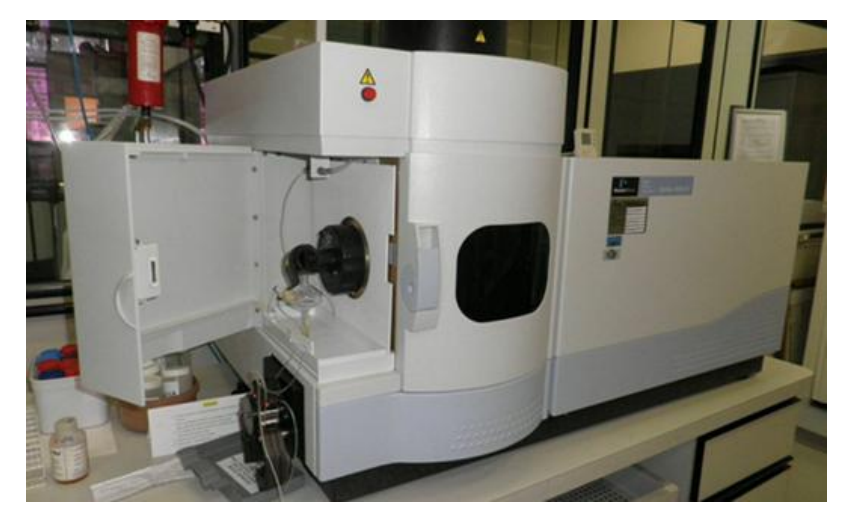

FIGURA 19 - Espectrômetro de ICP-OES e o sinal de $\mathrm{Sr}^{2+}$ no ICP-OES

$$
(\Lambda=460,733 \mathrm{~nm}) \text {. }
$$

\subsection{Análise das Fibras por Microscopia Eletrônica de Varredura (MEV) e por Espectroscopia de Energia Dispersiva (EDS)}

As características morfológicas das fibras de coco bruta e ativada foram analisadas por Microscopia de Varredura Eletrônica acoplada ao 
Espectrômetro de Energia Dispersiva (MEV/EDS). As fibras foram analisadas em um porta amostra de matriz de carbono sob feixe de elétrons de $10 \mathrm{kV}$ com ampliações de até 500 vezes.

\subsection{Análise de Infravermelho com Transformada de Fourier}

A espectrometria de Infravermelho por ATR (Attenuated Total Reflectance) é uma técnica que fornece evidência da presença de grupos funcionais contidos superficialmente nas amostras.

\subsection{Análise Térmica (TGA/DTG)}

A presença de estrôncio das fibras de coco bruta e ativada foi verificada por análise termogravimétrica (FIG. 20). Os experimentos foram realizados com cerca de $10 \mathrm{mg}$ da amostra, com uma faixa de temperatura de 30 a $550^{\circ} \mathrm{C}$, taxa de aquecimento de $10^{\circ} \mathrm{C} \cdot \mathrm{min}^{-1}$ e uma vazão de e ar sintético de 100 $\mathrm{mL} \cdot \mathrm{min}^{-1}$ (MOTHÉ E MIRANDA, 2009).

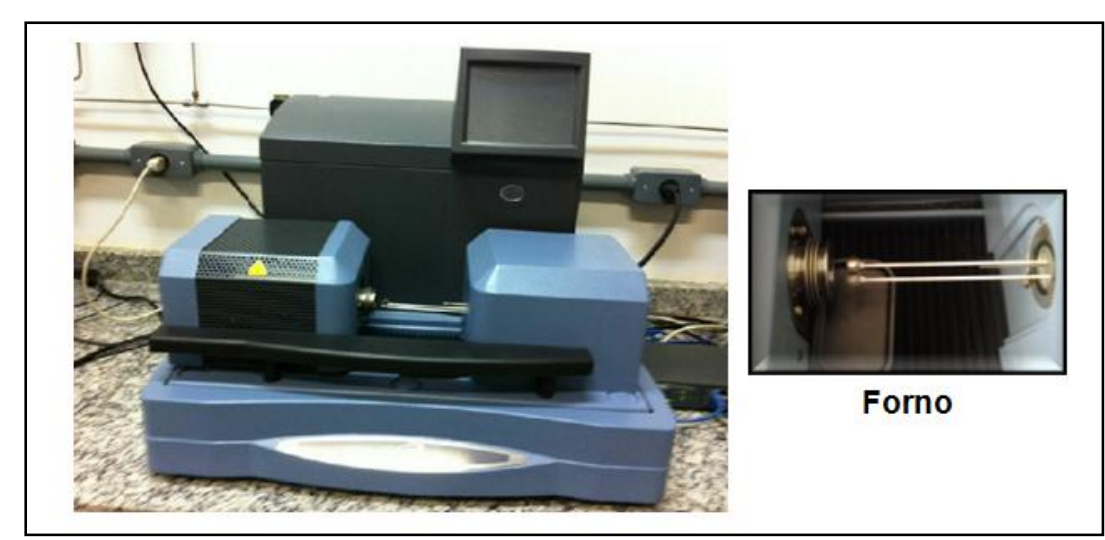

FIGURA 20 - Equipamento SDTQ 600 (TA Instruments) e a imagem interna do forno.

\subsection{Caracterização por Difratometria de Raios X}

Para as análises por raios $\mathrm{X}$ foi utilizado um difratometro de raios $\mathrm{X} e$ um porta amostra que estão apresentados na FIG. 21. 


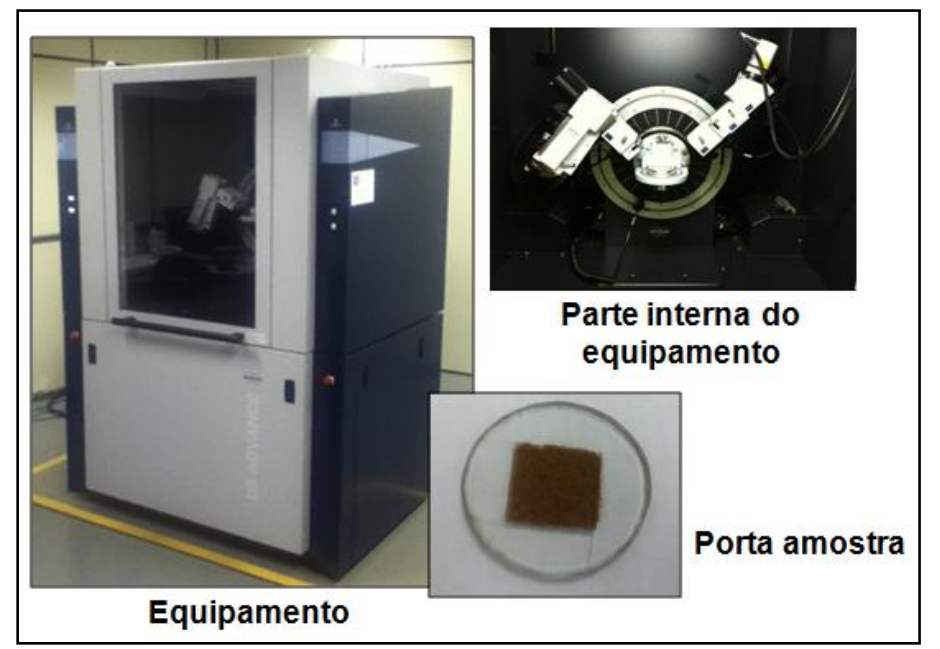

FIGURA 21 - Difratômetro de Raios Xe amostra da fibra de coco bruta no porta amostra.

Os difratogramas da análise por difração de raios $X$ foram obtidos a partir da metodologia conforme descrita por Park et al. (2010). A radiação empregada foi a de Cu-Ka com filtro de níquel de 1,5406 $\AA$ e as condições de medidas foram de $40 \mathrm{KW}$ e $30 \mathrm{~mA}$. A varredura foi obtida em uma faixa de $5-65$ (ângulo de Bragg, 20) de 0,05 em 0,05 graus a cada 15 segundos. Todas as amostras das fibras foram analisadas na forma de pó (cerca de 100 mesh).

Entretanto, para as análises por difração de raios $X$ das fibras de coco bruta antes e após os experimentos de biossorção foi necessário o preparo das amostras em uma mufla a uma temperatura de $600^{\circ} \mathrm{C}$ até a formação das cinzas das fibras, aproximadamente 1,5 horas. As cinzas são apresentadas na FIG. 22.

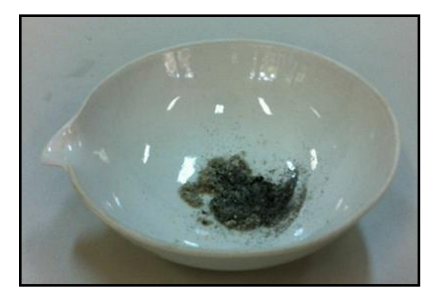

FIGURA 22 - Imagem das cinzas de fibra de coco bruta.

Esta técnica foi utilizada para determinar a presença de estrôncio adsorvido na fibra após a biossorção. As condições da análise no Difratômetro de Raios $X$ utilizadas nas fibras foram semelhantes as condições anteriores, porém a variação dos ângulos no equipamento foi de 0,04 em 0,04 (graus de Bragg, 2 $\theta$ ) a cada 8 segundos. 


\section{RESULTADOS E DISCUSSÃO}

\subsection{Biossorção de metais com fibra de coco}

A remoção dos íons $\mathrm{Sr}^{2+}$ da solução aquosa pelas fibras de coco bruta ( $F C B$ ) e ativadas com $2 \mathrm{~mL}$ e $8 \mathrm{~mL}$ de peróxido de hidrogênio em meio básico (FCA 1 e FCA 2) foram avaliadas em função quantidade de adsorvente, $\mathrm{pH}$, e também foram estudados os tempos de contato, modelos de isotermas e cinética de adsorção.

\subsection{Ativação da fibra de coco com $\mathrm{H}_{2} \mathrm{O}_{2}$ em meio básico}

\subsubsection{Determinação do teor de peróxido de hidrogênio}

O teor de peróxido de hidrogênio contido no reagente comercial foi determinado por titulação de óxido-redução com permanganato de potássio $\left(\mathrm{KMnO}_{4}\right)$. Na EQ.18 é apresentado o cálculo para a verificação do teor de $\mathrm{H}_{2} \mathrm{O}_{2}$ em porcentagem.

$$
\% \mathrm{H}_{2} \mathrm{O}_{2}=\frac{(\mathrm{V})(\mathrm{N})(1,701)(25)}{\mathrm{M}}
$$

Onde:

V é o volume de $\mathrm{KMnO}_{4}$ gasto na titulação $(\mathrm{mL})$;

$\mathrm{N}$ é a concentração de $\mathrm{KMnO}_{4}\left(\mathrm{~mol} . \mathrm{L}^{-1}\right)$;

M é a massa da amostra de $\mathrm{H}_{2} \mathrm{O}_{2}$ pesada no Béquer (g);

1,701 é a massa em miliequivalente do $\mathrm{H}_{2} \mathrm{O}_{2} \times 100$;

25 é o fator de diluição.

O peróxido de hidrogênio é quantitativamente oxidado pelo reagente permanganato de potássio (VOGEL, 1971). A reação do $\mathrm{H}_{2} \mathrm{O}_{2}$ com $\mathrm{KMnO}_{4}$ ocorre em meio ácido com ácido sulfúrico $\left(\mathrm{H}_{2} \mathrm{SO}_{4}\right)$, conforme a EQ.19. 


$$
2 \mathrm{MnO}_{4}{ }^{-}+5 \mathrm{H}_{2} \mathrm{O}_{2}+6 \mathrm{H}^{+} \rightarrow 2 \mathrm{Mn}^{2+}+5 \mathrm{O}_{2}+8 \mathrm{H}_{2} \mathrm{O}
$$

$\mathrm{Na}$ titulação, para $4,8 \mathrm{~g}$ de amostra de solução de $\mathrm{H}_{2} \mathrm{O}_{2}$ foram gastos $32,7 \mathrm{~mL}$ de $\mathrm{KMnO}_{4}$. Pelos cálculos apresentados na EQ 18, o teor do peróxido de hidrogênio do reagente comercial foi de $29,5 \%$.

\subsection{Análise das fibras de coco por Microscopia de Varredura Eletrônica}

As análises de Microscopia de Varredura Eletrônica (MEV) demonstram as características morfológicas da fibra de coco bruta e das fibras ativadas 1 e 2, conforme apresentado na FIG. 23.
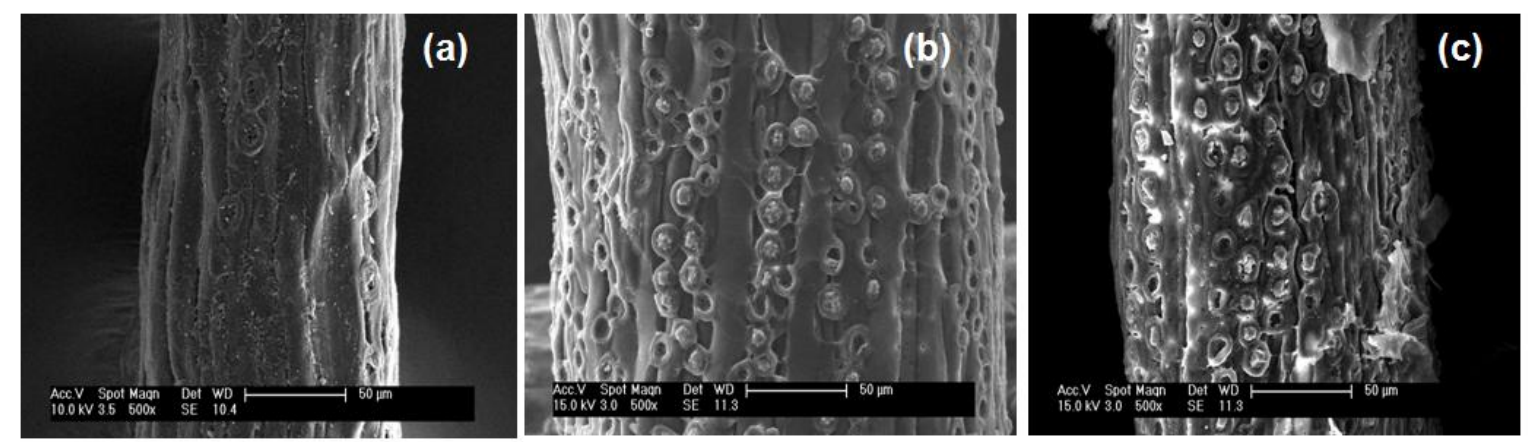

Figura 23 - Micrografias obtidas por MEV da FCB (a), FCA 1 (b) e FCA 2 (c).

Na FIG. 23, observa-se que a porosidade na superfície das FCA 1 e FCA 2 são maiores do que na FCB. Para o tratamento da FCA 2 foi utilizado um teor de $4 \%$ de $\mathrm{H}_{2} \mathrm{O}_{2}$ no meio reacional, enquanto que para a $\mathrm{FCA} 1$ o teor de $\mathrm{H}_{2} \mathrm{O}_{2}$ utilizado foi de $1 \%$. A maior porosidade nas fibras deve-se a degradação de parte da matéria orgânica após o processo de oxidação com peróxido de hidrogênio em meio básico.

Segundo Shukla et al. (2009), no tratamento, ocorre um aumento no diâmetro do material que juntamente com a maior porosidade confere ao material uma maior área superficial.

Observou-se também que a superfície da FCA 2 apresenta uma superfície mais irregular, provavelmente devido ao maior grau de oxidação.

Essa irregularidade dos materiais biossorventes pode auxiliar no processo de biossorção de metais. No estudo de remoção de íons de 
urânio $\left(\mathrm{UO}_{2}{ }^{2+}\right)$, por exemplo, foi relatado que a natureza fibrosa, pouco regular da fibra de coco bruta, favoreceu na remoção desses íons (BONIOLO, 2008).

\subsection{Análise das fibras de coco por Espectroscopia de Energia Dispersiva}

As análises das fibras antes e após o processo de ativação também foram realizadas por Espectroscopia de Energia Dispersiva (EDS), para a identificação qualitativa dos elementos presentes nas biomassas, conforme apresentado nas FIG. 24, 25 e 26.

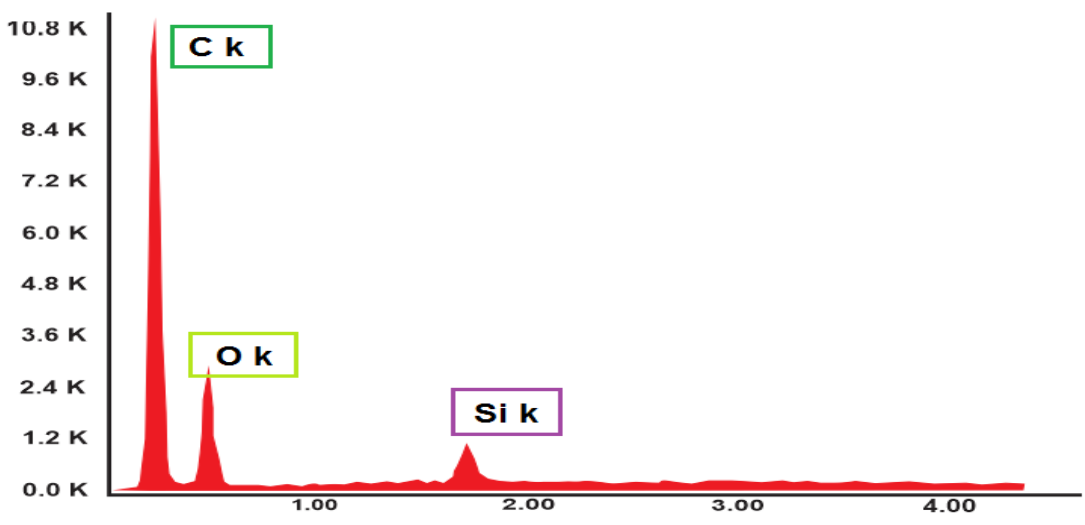

FIGURA 24 - Análise de EDS da FCB.

Observa-se no espectro de EDS da fibra de coco bruta, a presença de carbono e oxigênio em virtude da natureza orgânica das fibras e a presença de silício que é frequentemente encontrado na estrutura das fibras de coco (KODAMA, 2011). Vale ressaltar que não foi observada a presença de estrôncio. Nas FIG. 25 e 26 são apresentados as análises de EDS das FCA 1 e FCA 2 que em relação a análise de EDS da FCB apresentam sódio. A presença de sódio nas fibras ativadas é devido ao uso de $\mathrm{NaOH}$ no processo de oxidação. 


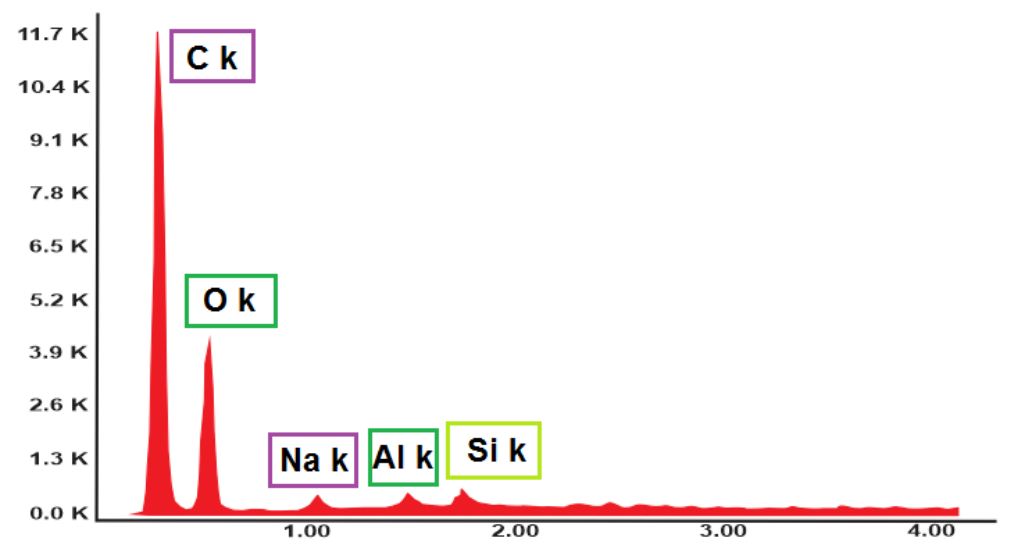

FIGURA 25 - Análise de EDS da FCA 1.

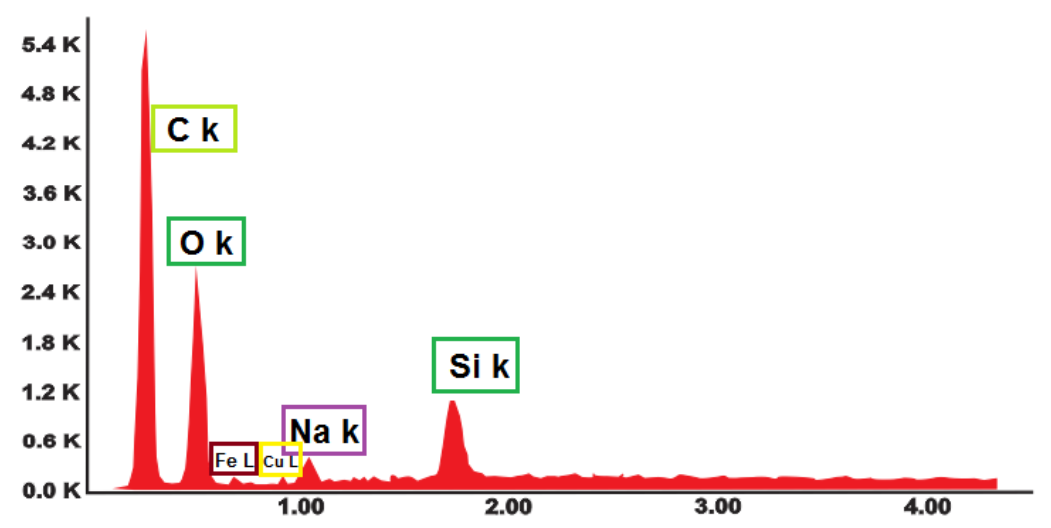

FIGURA 26 - Análise de EDS da FCA 2.

\subsection{Análise de Infravermelho por ATR das fibras}

As análises de infravermelho foram realizadas para identificar os grupos funcionais contidos superficialmente nas fibras de coco antes e após o processo de oxidação. Os espectros de infravermelho da fibra de coco bruta e das fibras de coco ativada, FCA 1 e FCA 2, estão apresentados na FIG. 27. 


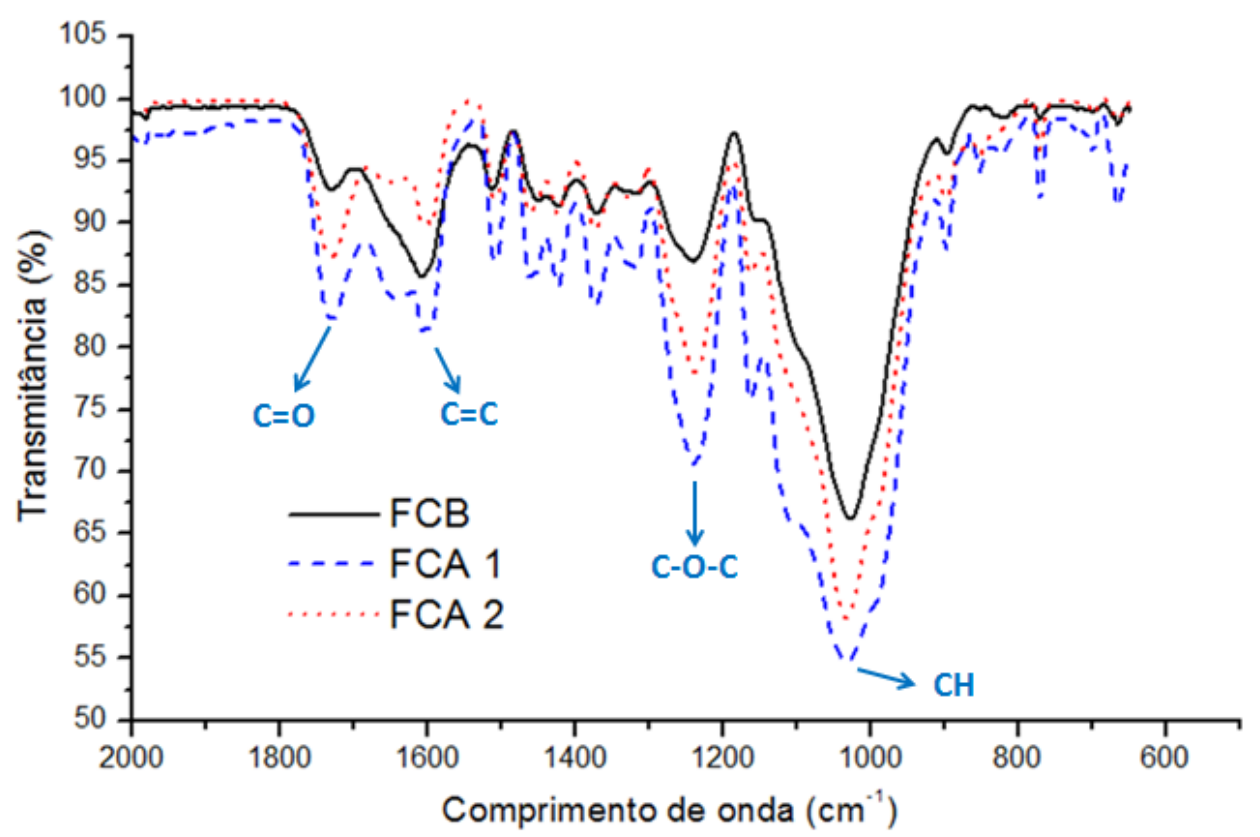

FIGURA 27 - Espectros de Infravermelho da fibra de coco bruta e das fibras ativadas (FCA 1 e FCA 2).

Os espectros vibracionais das fibras apresentaram bandas bem características de compostos lignocelulósicos (HAMEED et al., 2008).

O grupo C-O-C da cadeia celulósica apresenta banda em $1245 \mathrm{~cm}^{-1}$, um sinal de absorção em $1745 \mathrm{~cm}^{-1}$ associado à presença de grupos $\mathrm{C}=\mathrm{O}$ e em característico do grupo de ácido carboxílico (MOTHÉ E MIRANDA, 2009). As frequências vibracionais das fibras de coco bruta $(F C B)$ e das fibras de coco ativada (FCA 1 e FCA 2) $c$ com $\mathrm{H}_{2} \mathrm{O}_{2}(\mathrm{pH}=11,5)$ estão demonstradas na Tab.2. 
TABELA 2. Frequências de vibração das fibras no Infravermelho

\begin{tabular}{|c|c|c|c|}
\hline \multicolumn{3}{|c|}{ Número de onda $\left(\mathrm{cm}^{-1}\right)$} & \multirow{2}{*}{ Grupo funcional } \\
\hline FCB & FCA 1 & FCA 2 & \\
\hline$\overline{1734,11}$ & 1732,87 & 1729,04 & $\mathrm{C}=\mathrm{O}$ est $\mathrm{HCe}$ e $\mathrm{L}$ \\
\hline 1611,51 & 1641,73 & - & $\mathrm{C}=\mathrm{C}$ arom vibr esqueleto da $\mathrm{L}$ \\
\hline - & 1595,19 & 1594,19 & $\mathrm{C}=\mathrm{C}$ arom vibr esqueleto da $\mathrm{L}$ \\
\hline 1515,6 & - & 1506,94 & $\mathrm{C}=\mathrm{C}$ arom vibr esqueleto da $\mathrm{L}$ \\
\hline 1451,54 & 1460,97 & 1454,46 & $\begin{array}{c}\mathrm{C}=\mathrm{C} \text { arom vibr esqueleto }(\mathrm{L}) ; \mathrm{C}-\mathrm{H} \\
\text { dobr. }(\mathrm{HCe}) \text { e }(\mathrm{L})\end{array}$ \\
\hline- & 1422,99 & 1422,69 & C-H dobr da Ce e L \\
\hline 1375,87 & 1373,76 & 1370,96 & $\mathrm{C}-\mathrm{H}$ dobr da HC, Ce e L \\
\hline 1318,92 & 1319,43 & 1318,44 & $\mathrm{CH}_{2}$ est da Ce \\
\hline 1265,27 & 1238,64 & 1235,46 & $\mathrm{C}-\mathrm{O}$ est $\mathrm{Ce}$ \\
\hline- & 1162,63 & 1161,56 & C-O-C est ass da $\mathrm{HCe}, \mathrm{Ce}$ e L \\
\hline 1053,2 & 1032,2 & 1031,82 & C-H est da HCe, Ce e L \\
\hline 896,32 & 897,81 & 897,41 & est anel glicose, $\mathrm{C} 1-\mathrm{H}, \mathrm{def}(\mathrm{HCe}, \mathrm{Ce})$ \\
\hline 820,36 & 852,19 & 851,88 & def $\mathrm{C}-\mathrm{H}$ da $\mathrm{L}$ fora do plano \\
\hline 770,87 & 770,84 & 770,05 & def $\mathrm{C}-\mathrm{H}$ da $\mathrm{L}$ fora do plano \\
\hline
\end{tabular}

est: estiramento; est assim: estiramento assimétrico; arom: aromático; vibr: vibração; dobr: dobramento; HCe: hemicelulose; Ce: celulose e L: lignina. FONTE: PAVIA et al. (2010); MOTHÉ et al. (2009); ROSA et al. (2010).

Os ácidos carboxílicos apresentam uma banda característica da vibração da carbonila $(\mathrm{C}=\mathrm{O})$ entre $1730 \mathrm{~cm}^{-1}$ a $1700 \mathrm{~cm}^{-1}$ dos ácidos carboxílicos alifáticos simples na forma de dímeros da lignina e hemicelulose. $O$ estiramento 
C-O dos ácidos carboxílicos, geralmente ocorre com intensidade média entre $1320 \mathrm{~cm}^{-1}$ a $1210 \mathrm{~cm}^{-1}$ (PAVIA et al., 2010).

Na FIG. 27, verifica-se que a carbonila dos ácidos carboxílicos das FCB, FCA1 e FCA 2 estão nas regiões de 1734,11; 1732,87 e 1729,04 (Tab. 2), respectivamente. $A$ intensidade do espectro de absorção nessa região ordena-se da seguinte forma, FCA $1>$ FCA $2>$ FCB.

No geral, as fibras que passam pelo tratamento com peróxido de hidrogênio em meio básico possuem uma maior quantidade de ácidos carboxílicos devido à oxidação dos alcoóis e cetonas presentes na estrutura da fibra, conforme descrito por Shukla et al. (2009). A maior intensidade da banda referente à carbonila de ácidos carboxílicos na FCA 1 significa uma maior quantidade deste grupo em comparação a FCB e FCA 2, assim, observa-se que ocorreu o processo de ativação das fibras por meio do tratamento com peróxido de hidrogênio em meio básico.

\subsection{Difração de Raios X das Fibras}

As análises por difração de raios $\mathrm{X}$ foram realizadas na fibra bruta $\mathrm{e}$ nas fibras de coco ativada, FCA 1 e FCA 2, afim de caracterizar a estrutura cristalina de cada fibra. Todas as amostras foram analisadas na forma de pó, previamente segregados em peneira de 100 mesh. Na FIG. 28 são apresentados os padrões de difração das FCB, FCA 1 e FCA 2. 


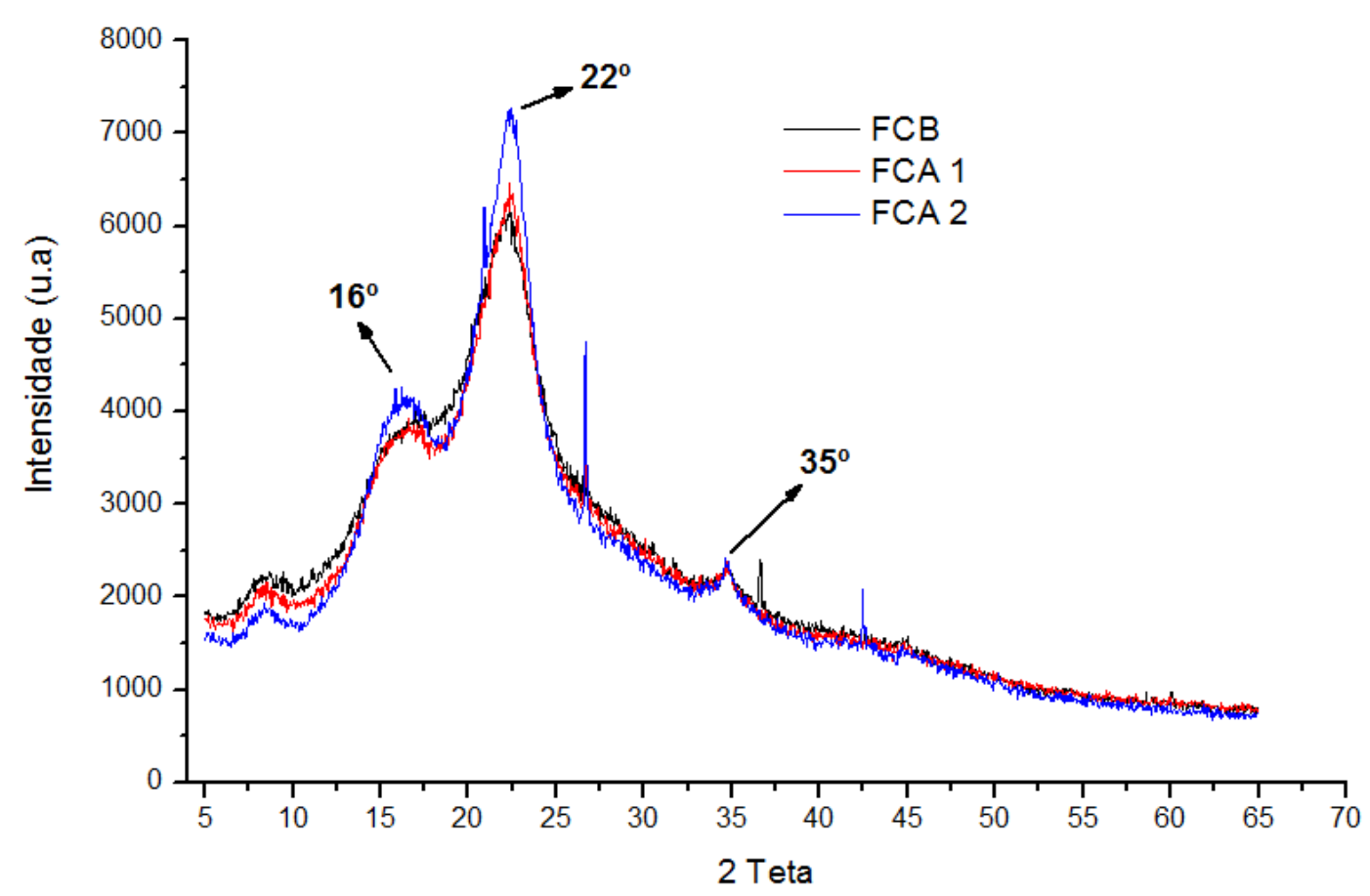

FIGURA 28 - Perfis de difração de raios $X$ das fibras FCB, FCA1 e FCA2.

Nos padrões de difração obtidos, os picos mais estreitos indicam a parte cristalina do material, enquanto que a parte amorfa das fibras envolve os picos mais largos (RAMIREZ, 2011).

Nos difratogramas das FCB, FCA 1 e FCA 2 observa se predominantemente uma característica amorfa.

No padrão de difração da fibra de coco bruta, verificam-se três picos que são característicos da celulose (FIG. 28) em ângulos de Bragg de $2 \theta=16^{\circ}$, $22^{\circ}$ e $35^{\circ}$ (PARK et al., 2010; HE et al., 2008), o pico correspondente à região cristalina encontra-se em um ângulo de Bragg $2 \theta$ de $22^{\circ}$ (TOMCZAK et al, 2007).

A taxa de cristalinidade das fibras (T.Cr.) foi estimada de acordo com o cálculo dado pela EQ.20 (BUSCHLE-DILLER e ZERONIAN, 1992).

$$
\text { T.Cr. }=1-\frac{I_{1}}{I_{2}}
$$


Onde:

$l_{1}$ é a intensidade do pico mínimo em um angulo $2 \theta=18-19^{\circ}$ (para a celulose l);

$\mathrm{I}_{2}$ corresponde a intensidade do pico máximo que corresponde a região cristalina, em um ângulo de $2 \theta=22-23^{\circ}$ (para a celulose $\mathrm{I}$ ).

As taxas de cristalinidade (T.Cr.) das fibras foram apresentadas na Tab. 3. Os valores de cristalinidade em porcentagem são apresentados com o intuito de verificar a grau de cristalinidade de cada fibra obtida antes e após o processo de oxidação.

TABELA 3. Taxa de cristalinidade das fibras

\begin{tabular}{cc}
\hline Biomassas & T. Cr. \\
\hline FCB & $38,0 \%$ \\
FCA 1 & $45,4 \%$ \\
FCA 2 & $50,6 \%$ \\
\hline Software: Bruker, DIFFRAC.EVA versão 3.1
\end{tabular}

A taxa de cristalinidade da fibra de coco bruta foi de $38,0 \%$ (Tab. 3). Segundo a literatura consultada, geralmente a cristalinidade da celulose (nos materiais ligno-celulósicos) é de cerca de $40 \%$, dependendo do tipo de tratamento empregado na amostra (KLEMM et al., 2005).

Pelos valores de cristalinidade de cada fibra foi possível verificar que as condições de tratamento podem afetar a cristalinidade do material (ROSA et al., 2010). Os difratogramas das fibras ativadas 1 e 2 possuem taxa de cristalinidade de $45,4 \%$ e $50,6 \%$, respectivamente, com picos mais bem definidos e mais intensos do que a fibra de coco bruta, sobretudo na região com ângulo de Bragg $2 \theta$ a $22^{\circ}$ (região cristalina). A maior cristalinidade nas fibras ativadas ocorreu por causa da remoção de lignina e hemicelulose. Segundo Abraham et al. (2013) admite-se que a remoção de constituintes com estruturas amorfas, como a lignina e a hemicelulose faz aumentar a cristalinidade dos materiais ligno- 
celulósicos. Em vista disso, a cristalinidade da FCA 2 foi maior em relação a FCA 1 em razão da maior quantidade de hemicelulose removida.

Pesquisadores que estudaram a biomassa ativada por difração de raios $\mathrm{X}$ constataram que a biomassa ativada geralmente é considerada como material pouco cristalino e que possui alta área superficial, bem como alto volume de poros (KHALIL et al., 2013). Essa suposição foi consistente quando comparada com as micrografias de MEV apresentadas na FIG 23.

\subsection{Ponto de carga zero}

A determinação do ponto zero de carga (PCZ) indica o comportamento ácido-base da superfície das fibras. O ponto de carga zero é obtido quando o $\mathrm{pH}$ inicial menos o pH final é igual a zero. Com esta condição estabelecida, a carga líquida da biomassa é igual à zero, e ocorre o efeito tampão da superfície do material (SOUZA, 2009). Em vista dos outros valores de $\mathrm{pH}$ da análise de ponto de carga zero, acima do valor de $\mathrm{pH}_{\mathrm{PCZ}}$ a carga superficial da biomassa é predominantemente negativa, consequentemente abaixo do $\mathrm{pH}_{\mathrm{PCZ}}$ a carga superficial é positiva (BOAS et al., 2012).

Os mecanismos envolvidos com os grupo carboxilatos contido nos materiais lignocelulosicos em meio ácido e básico estão demonstrados nas EQ.21 e 22 abaixo (MONTANHER, 2009).

Reações em meio ácido:

$$
\mathrm{R}-\mathrm{COO}^{-}+\mathrm{H}_{3} \mathrm{O}^{+} \rightarrow \mathrm{R}-\mathrm{COOH}+\mathrm{H}_{2} \mathrm{O}
$$

Reação em meio básico:

$$
\mathrm{R}-\mathrm{COOH}+\mathrm{NaOH} \rightarrow \mathrm{R}-\mathrm{COO}^{-} \mathrm{Na}^{+}+\mathrm{H}_{2} \mathrm{O}
$$

A remoção de cátions é favorecida quando a carga superficial do material biossorvente é negativa e em soluções com altos valores de $\mathrm{pH}$ há a precipitação dos íons metálicos na forma de hidróxidos tanto na solução quanto 
sobre a biomassa durante a biossorção ocorrendo a adsorção física. Por isso, faz se necessário apenas avaliar a carga superficial da biomassa, mas também a especiação do metal a ser adsorvido.

Encontrado o $\mathrm{pH}_{\mathrm{PCZ}}$, é importante salientar que neste valor a carga superficial da biomassa é igual a zero e abaixo deste valor de $\mathrm{pH}$ a carga liquida do biossorvente é positiva, nessas condições ocorre a repulsão das espécies metálicas no meio reacional. Em valores de $\mathrm{pH}$ acima do ponto de $\mathrm{pH}_{\mathrm{PCZ}}$ a carga superficial do adsorvente é negativa, no processo de biossorção, a ligação entre os íons metálicos e a biomassa é facilitada tanto por forças eletrostáticas como pelo mecanismo de troca iônica (MIMURA et al., 2001).

As análises de ponto de carga zero foram realizadas com as FCB e FCA 1 porque elas possuem boa eficiência na remoção de estrôncio em soluções aquosas. Nos experimentos foram medidos os valores de $\mathrm{pH}$ inicial e final a fim de encontrar a medida do PCZ de cada fibra, conforme a FIG. 29.

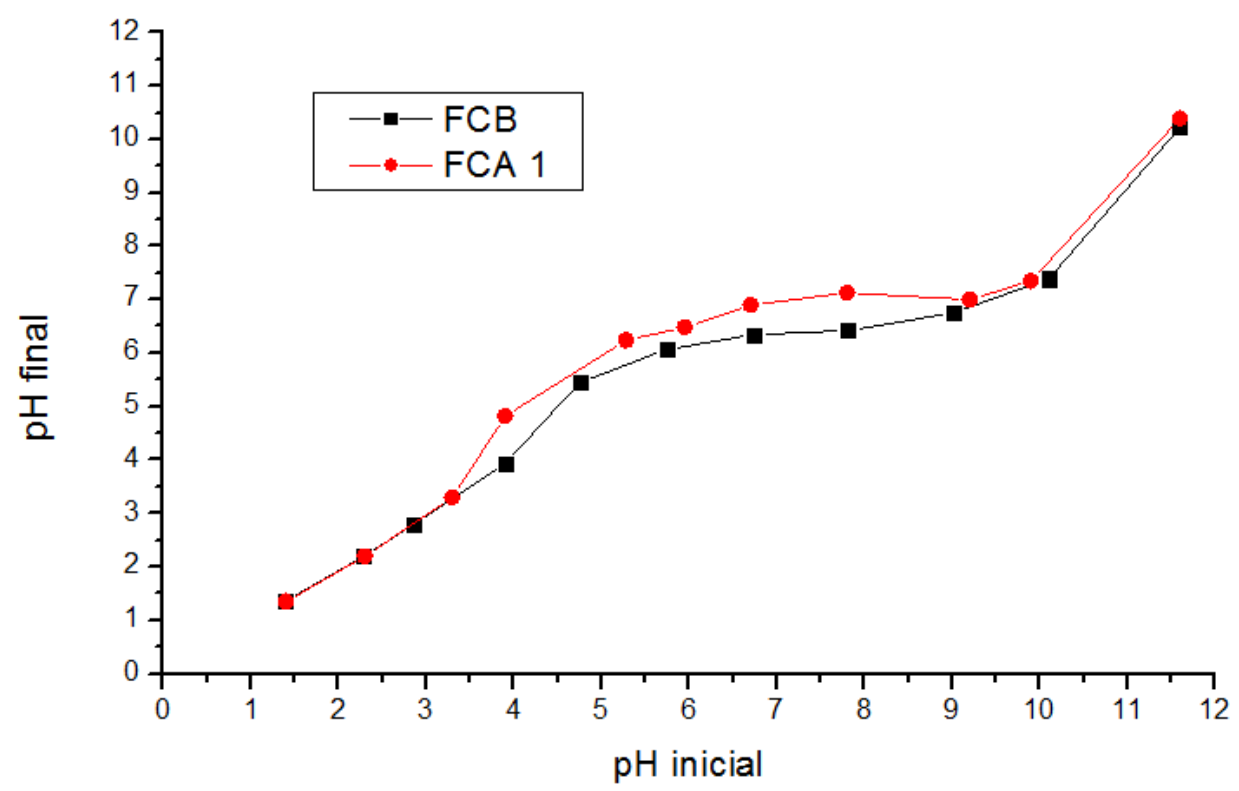

FIGURA 29 - Valores do pH inicial e final da fibra de coco bruta e ativada (FCA 1).

De acordo com a FIG. 29, o valor $\mathrm{pH}_{\mathrm{PCZ}}=4$ é atribuído a fibra de coco bruta. Segundo Santos (2009), também foi verificado que o valor de $\mathrm{pH}_{\mathrm{PCZ}}$ do pó de mesocarpo de coco, in natura, é de aproximadamente 4,1 . 
O grupo funcional ácido carboxílico possui um pKa entre 2 - 6 e em pH 4,5 cerca de $50 \%$ desses grupos são dissociados (FUKS et al., 2015; BAYRAMOGLU et al., 2009).

A partir dos dados obtidos (FIG. 29) verifica-se que o tratamento realizado na FCA 1 alterou levemente seu valor de $\mathrm{pH}_{\mathrm{PCZ}}$, passando de 4 para 3,25 .

O deslocamento da curva de FCA 1 em relação a FCB indica que essa biomassa possui uma maior carga superficial negativa. Feng et al. (2009) relataram que a biomassa que possui maior quantidade dos grupos de ácidos carboxílicos possuem maior carga superficial negativa, o que comprovou um maior índice de ácidos carboxílicos formados na FCA 1 em relação a FCB, além de corroborar com os resultados de infravermelho (FIG. 27).

\subsection{Biossorção de íons $\mathrm{Sr}^{2+}$ de solução aquosa}

Os resultados obtidos nos experimentos de biossorção dos íons de $\mathrm{Sr}^{2+}$ com a fibra de coco nas formas bruta e ativada estão apresentados a seguir.

\subsubsection{Efeito do $\mathrm{pH}$ na biossorção de $\mathrm{Sr}^{2+}$}

A FIG. 30 apresenta o comportamento das capacidades de biossorção dos íons de $\mathrm{Sr}^{2+}$ pela fibra de coco bruta em soluções de $\mathrm{Sr}$ com concentração de $2 \mathrm{mg} . \mathrm{L}^{-1}$, em pH 3, 6 e 9, utilizando $10 \mathrm{mg}$ de biomassa, nos diferentes tempos de contato de 5, 10, 30, 60 e 90 minutos. 


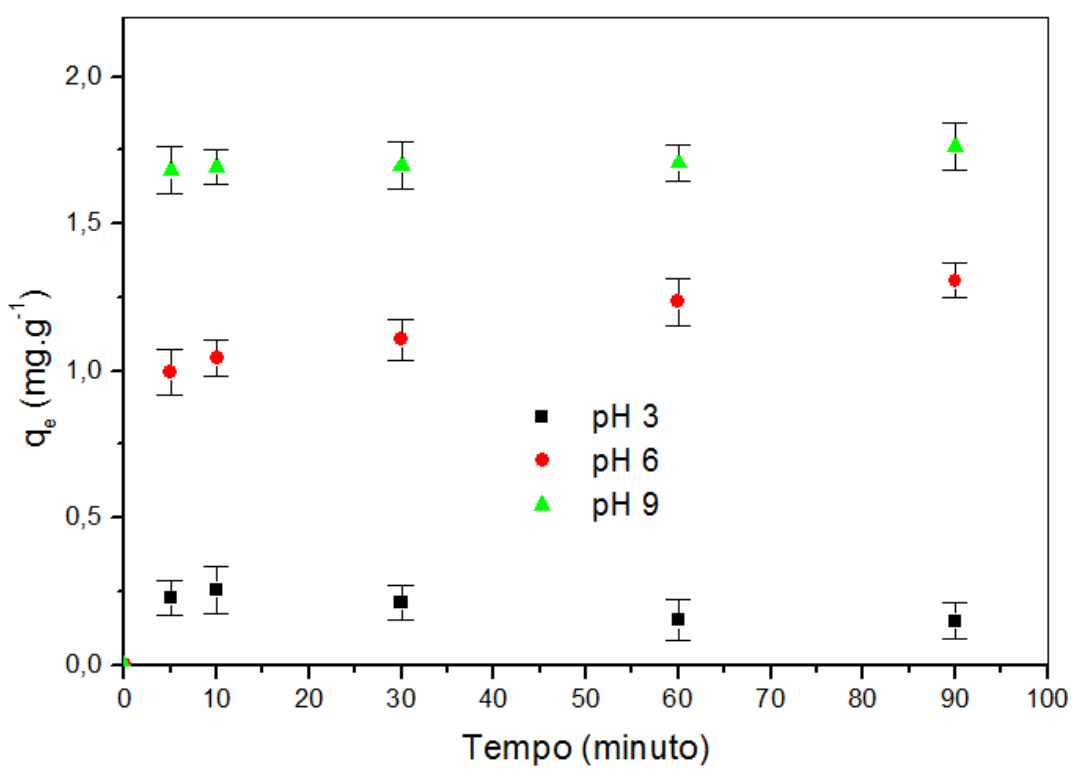

FIGURA 30 - Biossorção de $\mathrm{Sr}^{2+}$ utilizando fibra de coco bruta.

De acordo com os resultados apresentados na FIG. 30, verificou-se que a capacidade de biossorção de $\mathrm{Sr}^{2+}$ foi de $0,3 \mathrm{mg} \cdot \mathrm{g}^{-1} \mathrm{em} \mathrm{pH} \mathrm{3;1,2} \mathrm{mg} \cdot \mathrm{g}_{-}{ }^{1}$ para $\mathrm{pH} 6$ e de $1,8 \mathrm{mg}^{-1}$ para $\mathrm{pH} 9$, em 5 minutos de tempo de contato. A melhor eficiência ocorreu em pH 9 com cerca de 95\% de remoção dos íons de estrôncio presente em solução aquosa.

Em baixos valores de $\mathrm{pH}$ a dissociação dos sítios ativos no material biossorvente $(-\mathrm{COOH}$ e $-\mathrm{OH})$ é dificultada devido a alta concentração de íons $\mathrm{H}^{+}$, consequentemente esses grupos funcionais protonados ocasionam a repulsão eletrostática dos íons metálicos, além de haver uma competição entre os metais com o hidrogênio do meio pelos grupos funcionais (PANDEY E BANERJEE, 2012). Analogamente, em altos valores de pH ocorre um aumento da dissociação de grupos funcionais de ácidos carboxílicos presentes na superfície dos biossorventes favorecendo as interações entre os íons metálicos com os sítios.

Porém, segundo o diagrama de especiação apresentado na FIG. 31 é possível verificar quais os possíveis compostos de estrôncio e sua proporção em diferentes valores de $\mathrm{pH}$. 


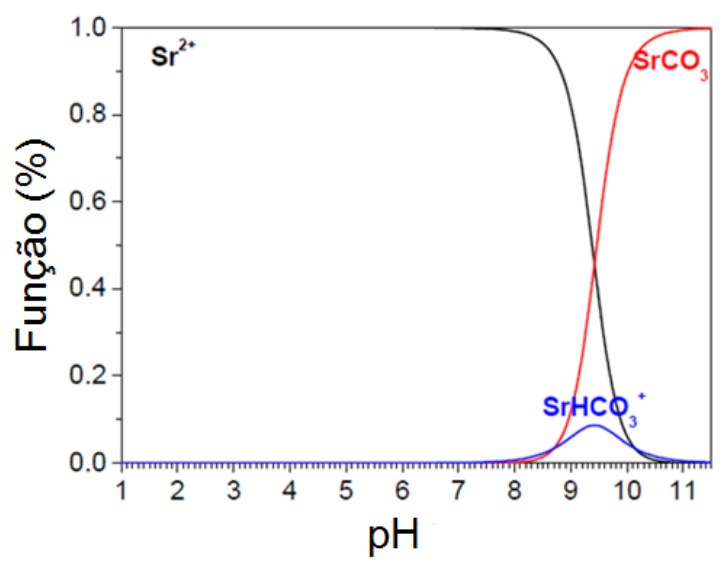

FIGURA 31 - Diagrama de especiação do estrôncio.

FONTE: ROMANCHUK et al., 2013; FUKS et al., 2015.

Acima de pH 8,5 parte dos íons metálicos estão na forma de compostos insolúveis de estrôncio e provavelmente no experimento de biossorção de estrôncio em pH 9 a remoção pode ter ocorrido principalmente como adsorção física.

\subsubsection{Efeito da ativação da biomassa na remoção dos íons de estrôncio}

Nas FIG. 32, 33 e 34 estão apresentadas os comportamentos da capacidade de biossorção dos íons de estrôncio com uma concentração de $2 \mathrm{mg} \cdot \mathrm{L}^{-1}$ em meio aquoso em pH 9, com $5 \mathrm{mg}$ de biomassa, FCB, FCA 1 e FCA 2, respectivamente. Os experimentos foram realizados em tempo de contato de 2, 5, $10,30,90,150$ e 200 minutos.

A diminuição da quantidade de biomassa foi realizada para verificar o efeito da dose de biomassa no processo de biossorção. 


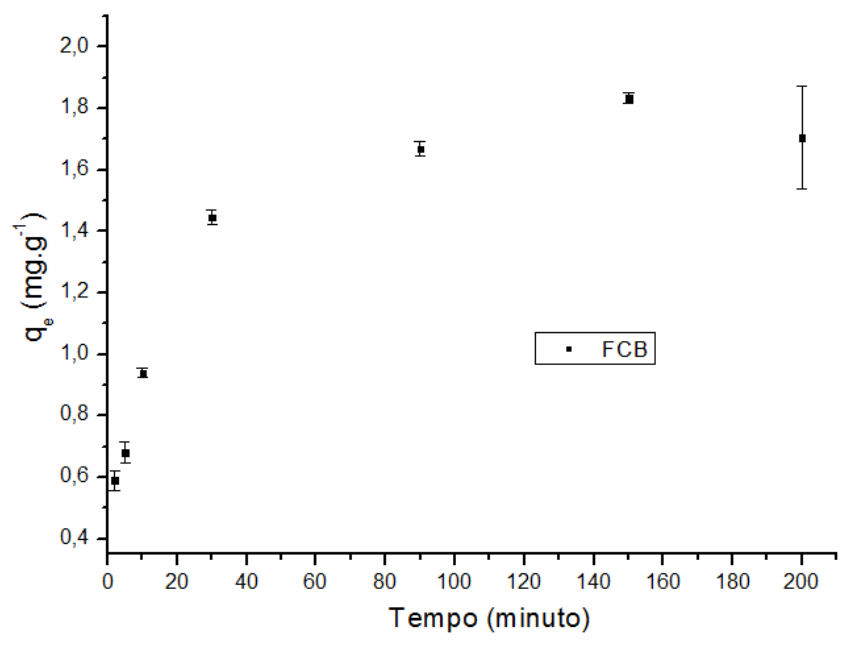

FIGURA 32 - Biossorção de estrôncio utilizando 5 mg de FCB, em pH 9.

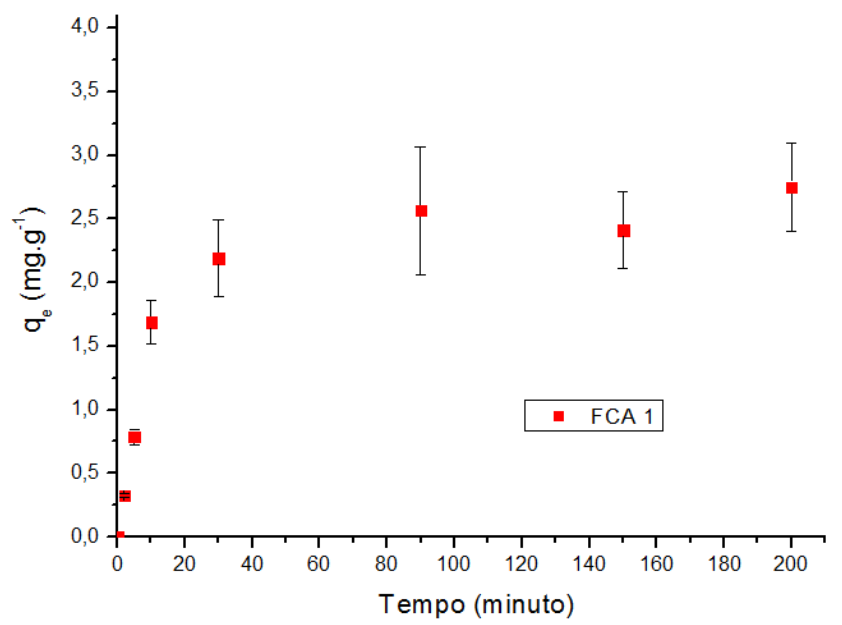

FIGURA 33 - Biossorção de estrôncio utilizando 5 mg de FCA 1, em pH 9.

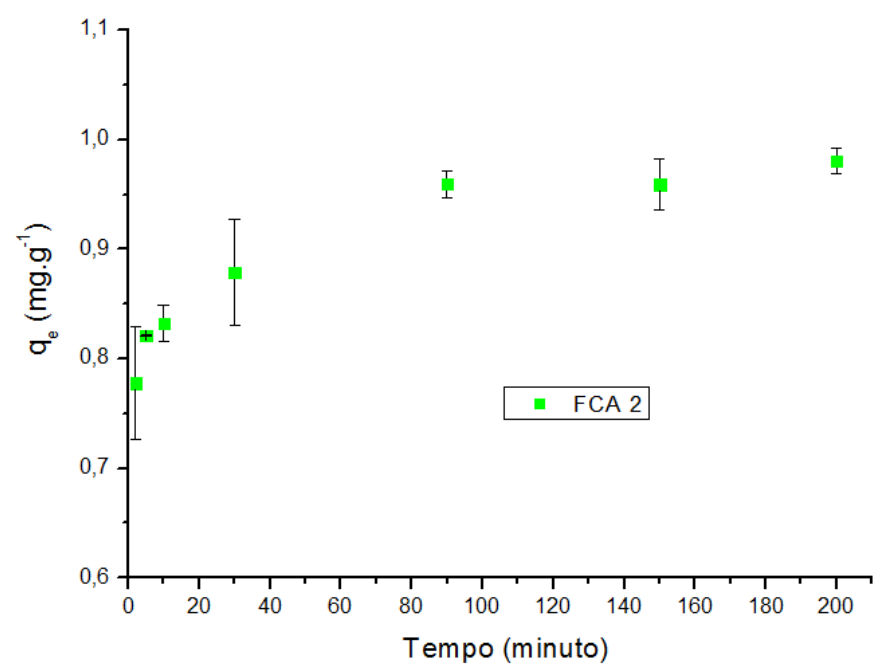

FIGURA 34 - Biossorção de estrôncio utilizando 5 mg de FCA 2, em pH 9. 
As capacidades de adsorção de estrôncio $\left(\mathrm{q}_{\mathrm{e}}\right)$ pela fibra de coco bruta e fibras de coco ativada FCA 1 e FCA 2 são de $1,84 \mathrm{mg} \cdot \mathrm{g}^{-1}, 2,41 \mathrm{mg} \cdot \mathrm{g}^{-1} \mathrm{e}$ $0,96 \mathrm{mg} \cdot \mathrm{g}^{-1}$, respectivamente em tempo de contato de 150 minutos. Portanto, a FCA 1 é a mais eficiente, seguida da FCB e FCA 2. Segundo Shukla et al. (2009), a maior eficiência é em razão da maior quantidade de grupos funcionais de ácidos carboxílicos produzidos após o tratamento básico com peróxido de hidrogênio. Por outro lado, assume se que a baixa eficiência de remoção de íons de estrôncio da FCA 2, em relação a FCB, está associada a alta degradabilidade dos materiais ligno-celulósicos, levando também a uma menor quantidade de grupos de ácidos carboxílicos da FCA 2 comparado com a FCA 1, conforme apresentado no espectro de infravermelho da FIG. 27.

Como houve a adsorção física em $\mathrm{pH} 9$ foram realizados novos experimentos em pH 6 utilizando a fibra de coco bruta e a fibra ativada mais eficiente, neste caso a FCA 1.

Nas FIG. 35 e 36 são apresentadas as curvas de remoção do tempo de contato da FCB e FCA 1 em relação a capacidade de biossorção $\left(q_{\mathrm{e}}\right)$, respectivamente. $O$ experimento de biossorção foi realizado com $5 \mathrm{mg}$ de amostra em solução de $\mathrm{Sr}^{2+}\left(2 \mathrm{mg} \cdot \mathrm{L}^{-1}\right)$, em $\mathrm{pH} 6$ com tempo de contato de 5 a 200 minutos.

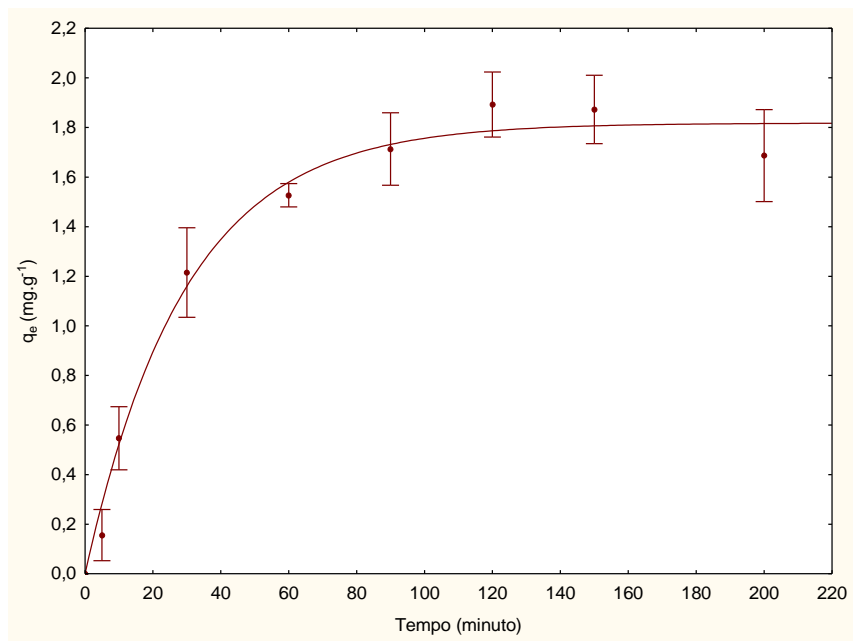

FIGURA 35 - Análise do tempo de contato da fibra de coco bruta $\left(R^{2}=0,9883\right)$. 


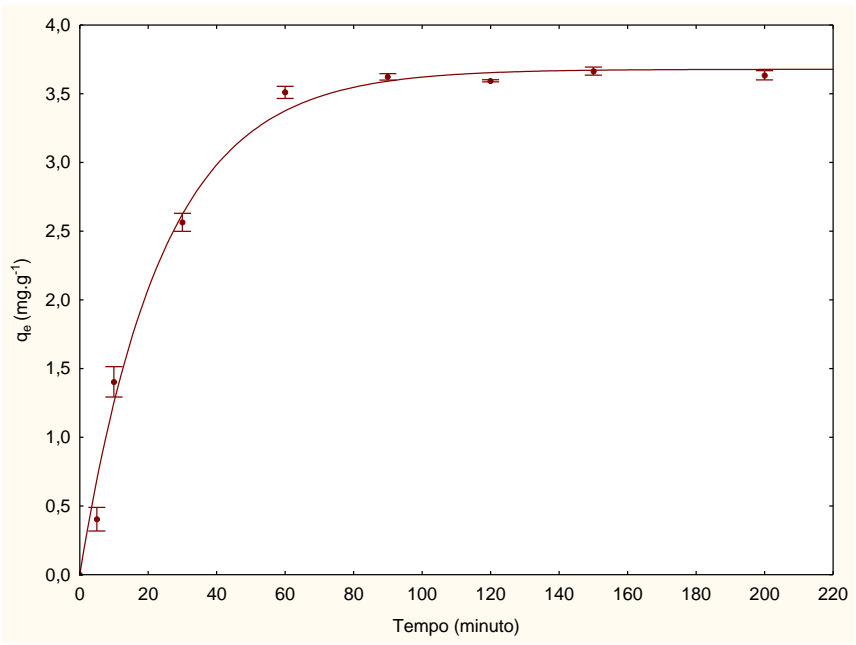

FIGURA 36 - Análise do tempo de contato da fibra de coco ativada $\left(R^{2}=0,9931\right)$.

Nas FIG. 35 e 36 verificou-se que as capacidades de biossorção $\left(q_{e}\right)$ aumentam conforme o aumento do tempo de contato até 90 minutos para ambas as fibras (FCB e FCA 1). De acordo com as curvas obtidas para um tempo de contato maior a 90 minutos a capacidade de biossorção se mantém constante, atingindo o equilíbrio. As capacidades de biossorção de $\mathrm{Sr}^{2+}$ para as FCB e FCA 1 foram de $1,7 \mathrm{mg} \cdot \mathrm{g}^{-1}$ e 3,6 mg. $\mathrm{g}^{-1}$, respectivamente.

Segundo Homaidan et al. (2014), no inicio do experimento de biossorção os sítios ativos da biomassa estão disponíveis e não existe impedimentos para a adsorção do íons, já em etapas posteriores a biossorção torna-se lenta devido ao impedimento dos sítios ativos ocupados pelos íons metalicos.

\subsection{Análise da fibra de coco bruta após a biossorção}

As FIG. 37, 38, 39, 40 e 41 apresentaram a composição das fibras antes e após os experimentos de biossorção.

\subsubsection{Análise Térmica da FCB antes e após a biossorção de $\mathrm{Sr}^{2+}$}

Na FIG. 37 é apresentada as curvas de TGA da fibra de coco bruta antes e após o processo de biossorção de $\mathrm{Sr}^{2+}\left(40 \mathrm{mg} \cdot \mathrm{L}^{-1}\right)$ em $\mathrm{pH} 9$, obtidas em atmosfera dinâmica de ar. 


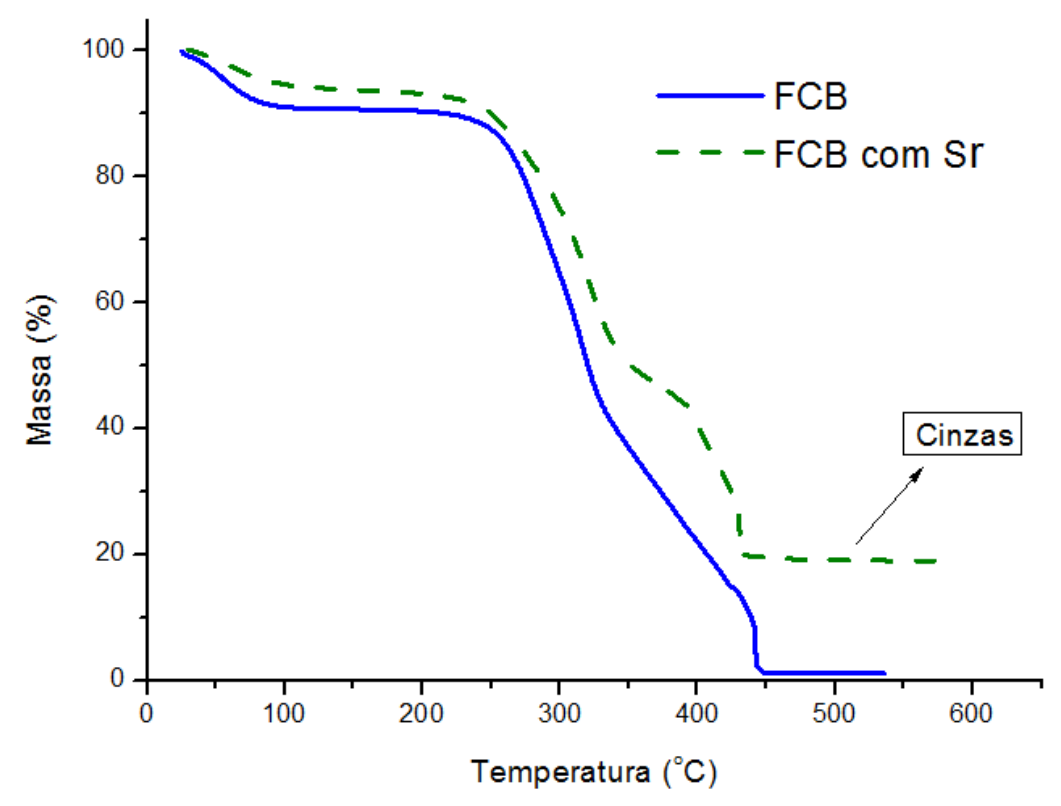

FIGURA 37 - Curvas de TG das Fibras de coco bruta (FCB) e com estrôncio, em atmosfera de ar.

Após o aquecimento na mufla entre $400-500^{\circ} \mathrm{C}$, ambas as fibras foram transformadas em cinzas, denominado como resíduo carbonáceo. Pela análise de TGA observa-se que a quantidade de resíduo da fibra de coco bruta antes e após o experimento de biossorção foi de aproximadamente 1 e $10 \%$, respectivamente. Essa diferença de resíduos deve-se ao acumulo dos metais de estrôncio na biomassa após a biossorção, aumentando o teor de resíduos inorgânicos (Barros et al., 2007).

\subsubsection{Difração de raios $X(D R X)$ das cinzas}

As cinzas obtidas pela oxidação das fibras bruta antes e após a biossorção de $\mathrm{Sr}^{2+}$ foram analisadas por difração de raios X, conforme FIG. 38. A amostra da fibra de coco bruta utilizada nesta análise foi obtida a partir de uma solução de estrôncio (40 mg. $\mathrm{L}^{-1}$ ) em pH 9, com tempo de contato de 90 minutos. 


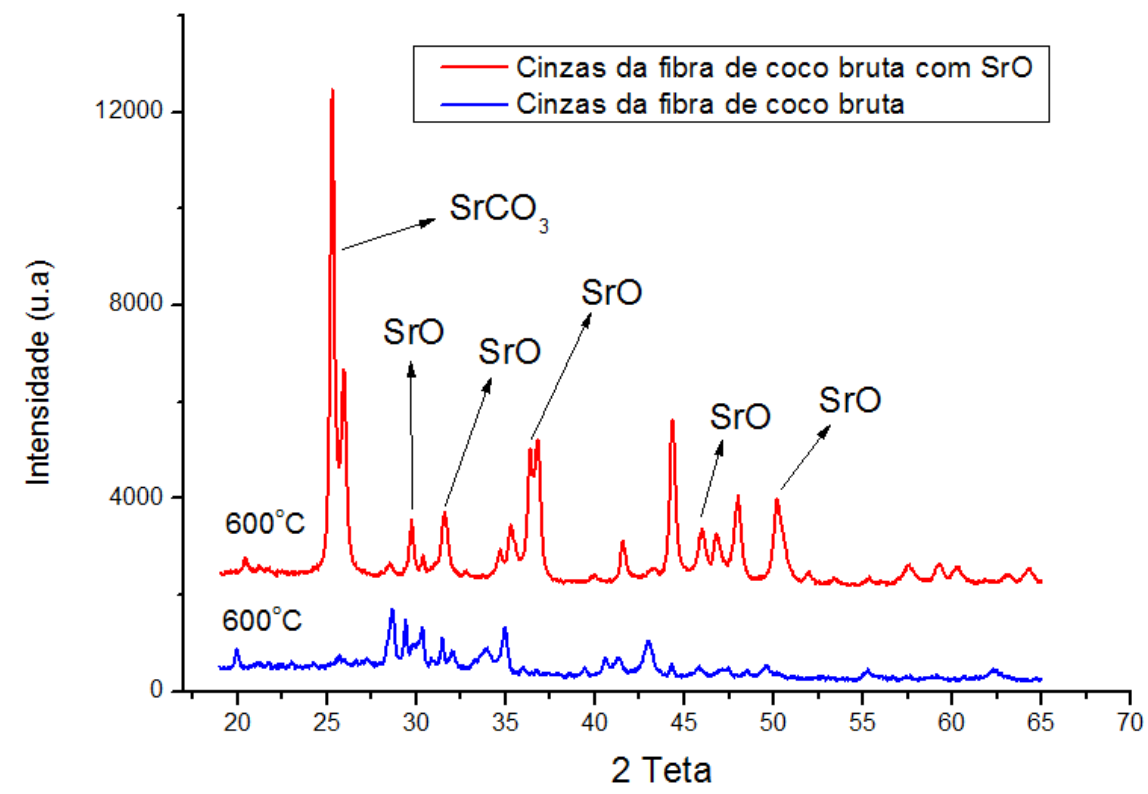

FIGURA 38 - Difratograma de raios $X$ das fibras de coco bruta e com estrôncio, obtidas em atmosfera de ar a uma temperatura de $600^{\circ} \mathrm{C}$.

O cálculo dos comprimentos de onda correspondentes aos picos dos difratogramas e os ângulos $2 \theta$ foram obtidos através da EQ.23 (Lei de Bragg).

$$
\Lambda=2 \mathrm{~d} \cdot \operatorname{sen} \theta
$$

Pelos resultados obtidos verificou-se que os picos no espectro da amostra da fibra de coco bruta após os experimentos de biossorção que não são observados no espectro da fibra de coco bruta antes do experimento. Essas alterações ocorrem uma vez que o material apresenta estrôncio adsorvido em sua estrutura.

Os picos característicos que comprovam a presença de estrôncio no difratograma da fibra de coco bruta com estrôncio foram apresentados em ângulos de Bragg $2 \theta$ de $29,67^{\circ} ; 31,13^{\circ} ; 36,66^{\circ} ; 46,98^{\circ}$ e $50,85^{\circ}$ referentes ao estrôncio na forma de óxido ( $\mathrm{SrO}$ ) e de $25,13^{\circ}$ corresponde ao estrôncio na forma de carbonato $\left(\mathrm{SrCO}_{3}\right)$, de acordo com Swanson e Fuyat, 1998.

Esses resultados corroboram com os observados na análise das curvas de TGA (FIG. 38). A maior quantidade de resíduos após os experimentos de biossorção deve-se à formação de compostos de estrôncio na forma de óxidos e carbonato provenientes da remoção de $\mathrm{Sr}^{2+}$. 
Segundo Barros et. al. (2007), a decomposição da biomassa com metal adsorvido forma um resíduo com menor quantidade de matéria orgânica em relação à biomassa sem metal adsorvido. Admite-se que isto ocorre devido à dissolução de substâncias orgânicas com a consequente formação de radicais hidroxilas e de carboxilatos ( $\mathrm{OH}^{\circ}$ e $\left.\mathrm{CO} 0^{\circ}\right)$ altamente reativos. Por sua vez, esses radicais podem formar compostos com os metais presentes na superfície da biomassa, que precipitam sobre a biomassa posteriormente. A formação de óxido de estrôncio geralmente ocorre devido a oxidação do metal em altas temperaturas em meio de ar, acima de $210^{\circ} \mathrm{C}$ (ROPP, 2012).

Outra possível explicação seria que o carbonato de estrôncio $\left(\mathrm{SrCO}_{3}\right)$ presente nas cinzas pode ter sido formado pela precipitação de $\mathrm{SrCO}_{3}$ na superfície da fibra de coco durante o processo de biossorção, ou seja, o $\mathrm{SrCO}_{3}$ da solução foi adsorvido pela fibra, já que o meio reacional utilizado para a obtenção da fibra de coco com estrôncio foi em $\mathrm{pH} 9$.

\subsubsection{Análise de MEV e EDS das FCB e FCA 1 após o processo de biossorção}

Nas FIG. 39 e 40 são apresentadas as micrografias das fibras de coco bruta e ativada após o experimento de biossorção de estrôncio, seguidos das análises de EDS que forneceram a composição elementar dos materiais.

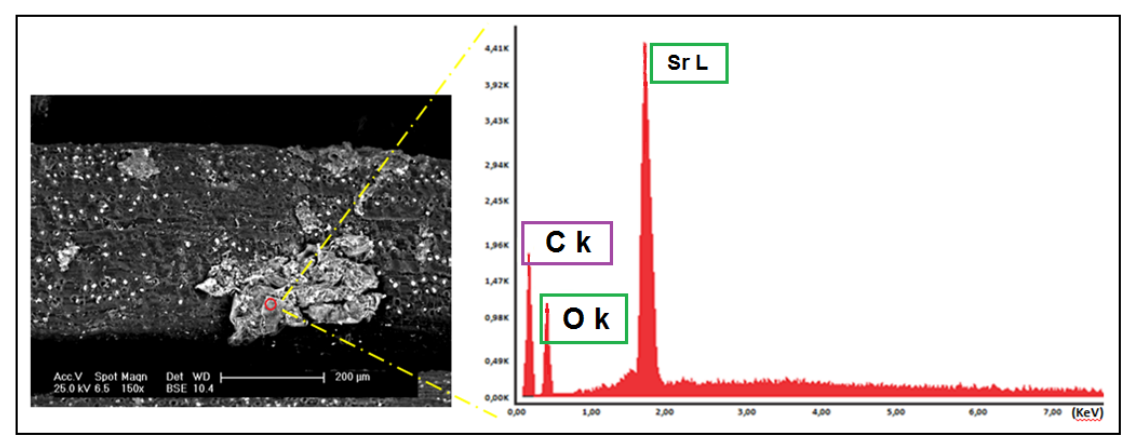

Figura 39 - Micrografia da amostra de FCB após o processo de biossorção de $\mathrm{Sr}^{2+}$ e o espectro correspondente obtido por EDS em certa região da fibra. 


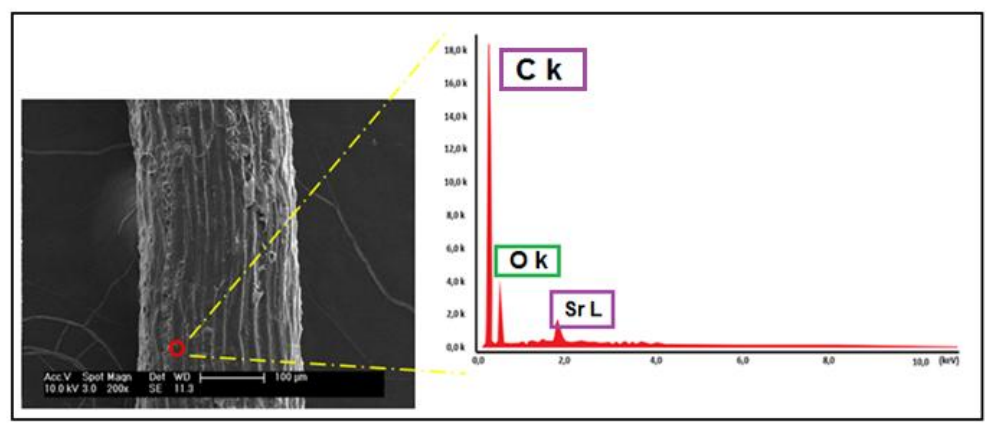

Figura 40 - Micrografia da amostra de FCA 1 após o processo de biossorção de $\mathrm{Sr}^{2+}$ e o espectro correspondente obtido por EDS em cerca região da fibra.

Pelos espectros de EDS foi possível confirmar a presença do metal estrôncio na região superficial, tanto na fibra de coco bruta como na ativada (FCA 1). Por meio dessas análises também foi possível verificar o diâmetro das fibras, que foi de aproximadamente $150 \mu \mathrm{m}$. Munawar et al. (2007) reportaram que o diâmetro da fibra de coco natural varia de 55,6 $\mu \mathrm{m}$ a 197,6 $\mu \mathrm{m}$.

\subsubsection{Análise de infravermelho da FCA 2 antes e após a biossorção}

A FIG. 41 apresenta os espectros de infravermelho da fibra de coco ativada (FCA 2) antes e após os experimentos de biossorção $\mathrm{Sr}^{2+}$, em solução de concentração de $2 \mathrm{mg} \cdot \mathrm{L}^{-1} \mathrm{em} \mathrm{pH} 9$, com $5 \mathrm{mg}$ de amostra, com tempo de contato de 90 minutos.

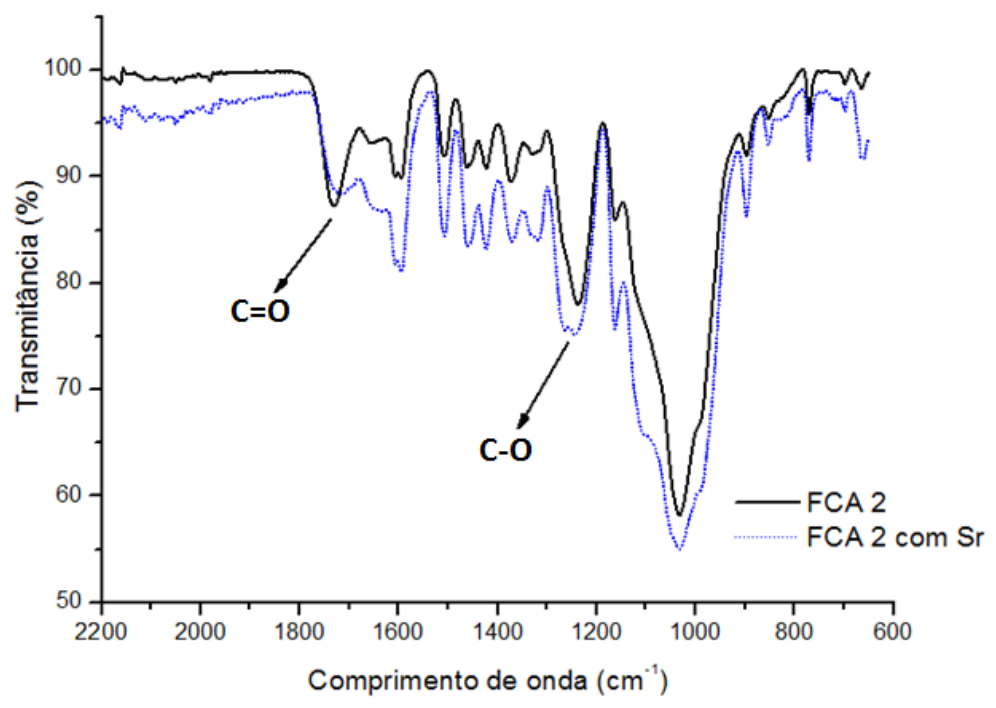

FIGURA 41 - Análise de infravermelho da FCA 2 antes e após a biossorção de íons de estrôncio. 
Observa-se bandas de absorção próximas de $1740 \mathrm{~cm}^{-1}$ e $1240 \mathrm{~cm}^{-1}$ que são atribuídas as vibrações da carbonila $\mathrm{C}=\mathrm{O}$ e da ligação $\mathrm{C}-\mathrm{O}$ de ácidos carboxílicos, respectivamente (NAJA E VOLESKY, 2010). Pelos resultados obtidos observa-se no espectro da FCA 2 com Sr desdobramentos nas bandas de $1740 \mathrm{~cm}^{-1}$ e $1240 \mathrm{~cm}^{-1}$, o que sugere que os carboxilatos estejam envolvidos no processo de biossorção com estrôncio, conforme apresentado na EQ.24 abaixo (GOK et al., 2013).

$$
\mathrm{nCOOH}+\mathrm{Sr}^{2+} \leftrightarrow\left[(-\mathrm{COO})_{n} \mathrm{Sr}\right]^{(2-n)+}+\mathrm{nH}^{+}
$$

\subsection{Isotermas de adsorção}

As isotermas de adsorção representam o equilíbrio existente entre o íon metálico adsorvido na fase sólida (biossorvente) e na líquida (LIU et al., 2012). Os parâmetros dos modelos de Langmuir e Freundlich foram utilizados para o entendimento dos mecanismos de biossorção do $\mathrm{Sr}^{2+}$ pelas fibras estudadas.

A diminuição da quantidade de biomassa de $10 \mathrm{mg}$ utilizadas no estudo da capacidade de adsorção para $5 \mathrm{mg}$ levou a um maior tempo de contato para alcançar o equilíbrio.

Nas FIG. 42 e 43 são apresentadas as isotermas de Langmuir da FCB e FCA 1, respectivamente.

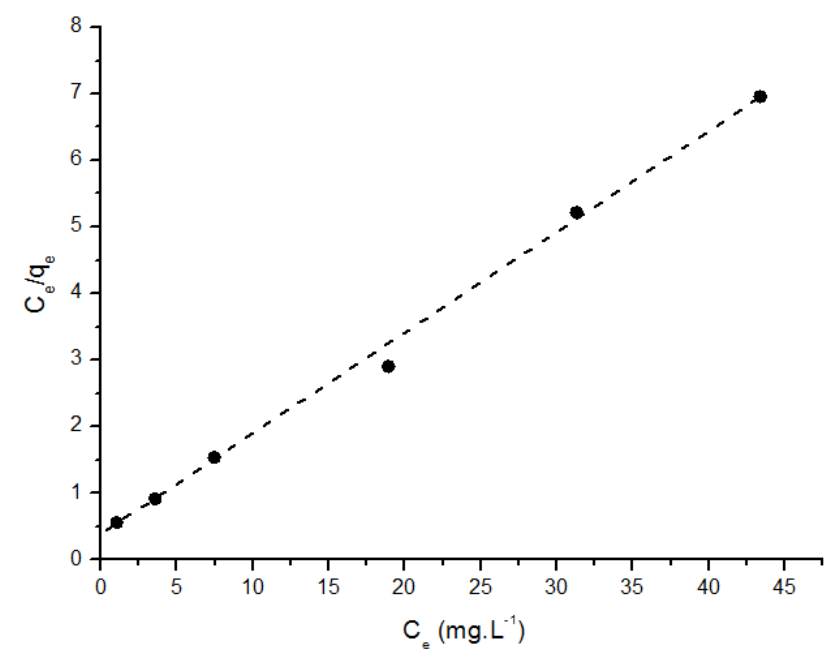

FIGURA 42: Isoterma linearizada de Langmuir para as fibras de coco bruta. 


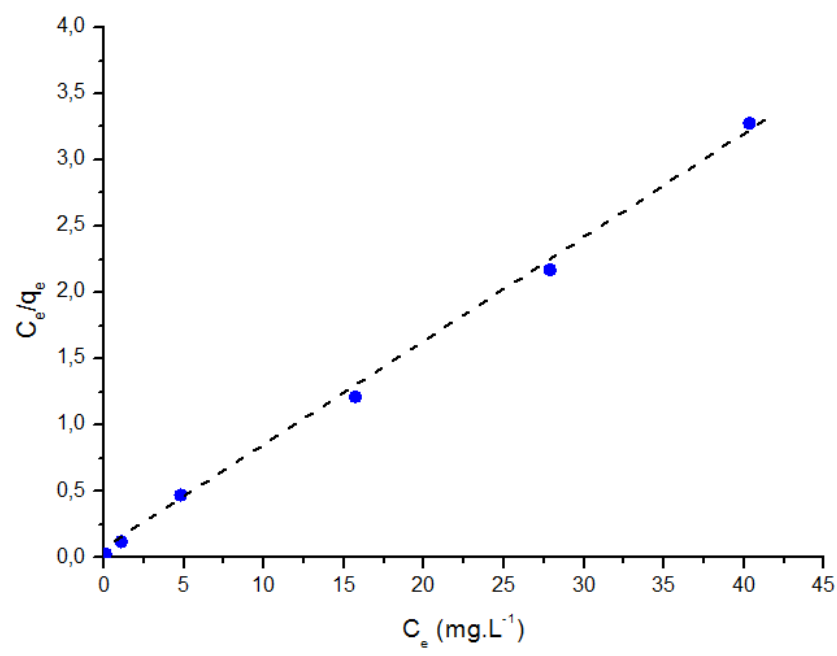

FIGURA 43: Isoterma linearizada de Langmuir para as fibras de coco ativada 1.

Nas FIG. 44 e 45 são apresentadas as isotermas de Freundlich para as FCB e FCA 1 nas formas linearizadas, respectivamentes.

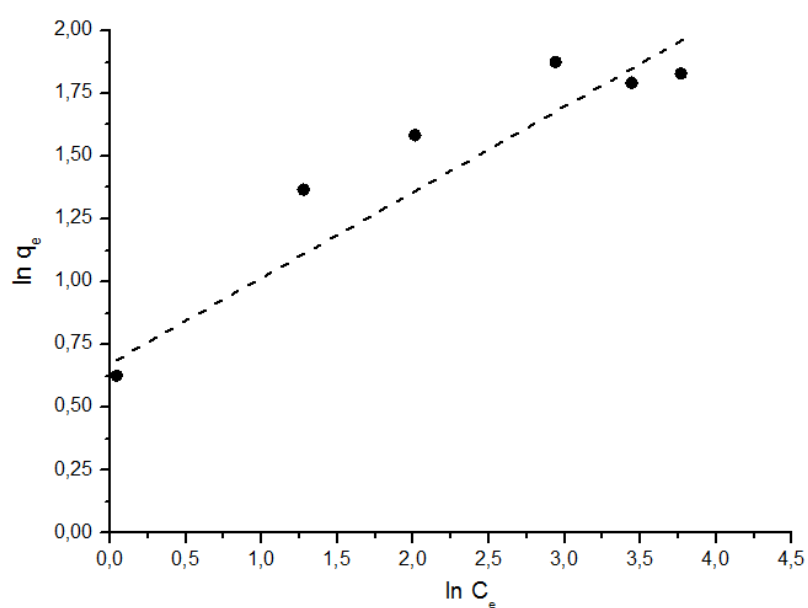

FIGURA 44 - Isoterma linearizada de Freundlich para as fibras de coco bruta. 


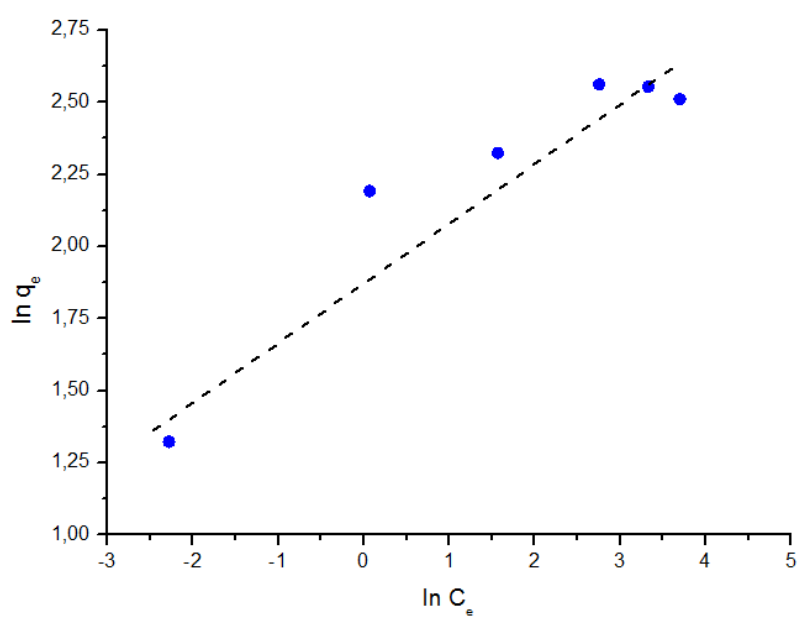

FIGURA 45 - Isoterma linearizada de Freundlich para as fibras de coco ativada 1.

Os parâmetros obtidos através das equações das isotermas de Langmuir e Freundlich das fibras de coco bruta e ativada 1 e o coeficiente de correlação $\left(R^{2}\right)$ estão apresentados nas Tab. 4 e 5, respectivamente.

O coeficiente de correlação indica o ajuste dos dados experimentais aos dados teóricos obtidos pelos modelos matemáticos de Langmuir e Freundlich.

TABELA 4. Parâmetros das isotermas de Langmuir e Freundlich para 0 processo de biossorção dos íons $\mathrm{Sr}^{2+}$ com fibras de coco bruta.

\begin{tabular}{c|c|c|c|c|c|c}
\hline \multicolumn{6}{c}{ Fibra de coco bruta } \\
Parâmetros \\
\hline Íon & \multicolumn{3}{c}{ Langmuir } & \multicolumn{3}{c}{ Freundlich } \\
& $\mathrm{K}_{\mathrm{L}}\left(\mathrm{L} \mathrm{mg}^{-1}\right)$ & $\mathrm{Q}_{0}\left(\mathrm{mg} \mathrm{g}^{-1}\right)$ & $\mathrm{R}^{2}$ & $\mathrm{~K}_{\mathrm{F}}\left(\mathrm{L} \mathrm{g}^{-1}\right)$ & $1 / \mathrm{n}$ & $\mathrm{R}^{2}$ \\
$\mathrm{Sr}^{2+}$ & 0,36 & 7,41 & 0,9724 & 2,02 & 0,42 & 0,908 \\
& 0,36 & & & & \\
\hline
\end{tabular}

TABELA 5. Parâmetros das isotermas de Langmuir e Freundlich para 0 processo de biossorção dos íons $\mathrm{Sr}^{2+}$ com fibras de coco ativada 1 .

\begin{tabular}{c|c|c|c|c|c|c}
\hline \multicolumn{6}{c}{$\begin{array}{c}\text { Fibra de coco ativada 1 } \\
\text { Parâmetros }\end{array}$} \\
\hline ĺon & \multicolumn{3}{c|}{ Langmuir } & \multicolumn{3}{|c}{ Freundlich } \\
& $\mathrm{K}_{\mathrm{L}}\left(\mathrm{L} \mathrm{mg}^{-1}\right)$ & $\mathrm{Q}_{0}\left(\mathrm{mg} \mathrm{g}^{-1}\right)$ & $\mathrm{R}^{2}$ & $\mathrm{~K}_{\mathrm{F}}\left(\mathrm{L} \mathrm{g}^{-1}\right)$ & $1 / \mathrm{n}$ & $\mathrm{R}^{2}$ \\
$\mathrm{Sr}^{2+}$ & 2,91 & 12,64 & 0,9982 & 6,99 & 0,19 & 0,8904 \\
& 2,91 & 12,64 & 6 & \\
\hline
\end{tabular}


Observa-se que os valores de $\mathrm{R}^{2}$ das FCB e FCA 1 são maiores para a equação de Langmuir (Tab. 4 e 5), portanto, admite-se que o modelo de Langmuir descreve melhor os dados experimentais, conforme indicado nos dados experimentais da FCB e FCA 1 nas FIG. 42 e 43, respectivamente.

A capacidade máxima de adsorção $\left(Q_{0}\right)$ das FCB e FCA 1 foram de $7,41 \mathrm{mg} \cdot \mathrm{g}^{-1}$ e $12,64 \mathrm{mg} \cdot \mathrm{g}^{-1}$, portanto, assume se que a FCA 1 possui maior potencial de remoção em relação a FCB e os valores da constante de Langmuir $\left(\mathrm{K}_{\mathrm{L}}\right)$, obtidos a partir do modelo de Langmuir na forma linearizada, foram de 0,36 L. $\mathrm{mg}^{-1}$ e 2,91 L.mg ${ }^{-1}$ para as FCB e FCA 1, indicando uma maior afinidade de remoção pelos íons $\mathrm{Sr}^{2+}$ por parte da FCA 1 em relação a FCB.

O modelo de Langmuir na forma não linear foi aplicado para demonstrar seu ajuste aos dados experimentais. De acordo com o formato convexo das isotermas, admite se que o processo de biossorção é favorável porque alcança o equilíbrio mesmo em baixas concentrações. Os valores do parâmetro de equilíbrio $\left(R_{L}\right)$ para as $F C B$ e FCA 1 foram de 0,29 e 0,03, respectivamente. $O R_{L}$ entre zero e um indica que se trata de uma isoterma classificada como favorável.

As isoterma de adsorção da FCB e FCA 1 na forma não linearizada são apresentadas nas FIG. 46 e 47, respectivamente.

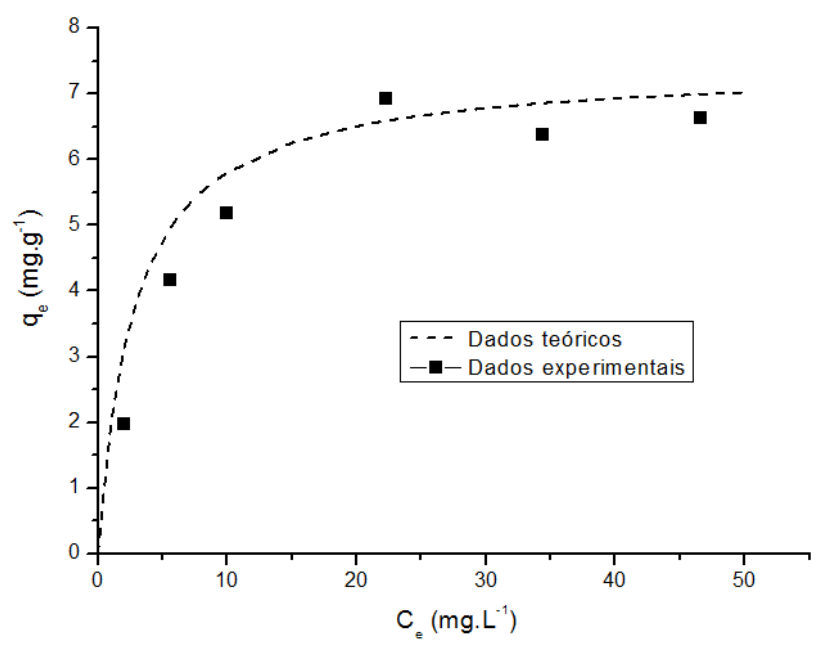

FIGURA 46 - Dados experimentais da isoterma de equilíbrio de adsorção da FCB. para os íons $\mathrm{Sr}^{2+}$ e os dados teóricos obtidos da equação de Langmuir não linearizada 


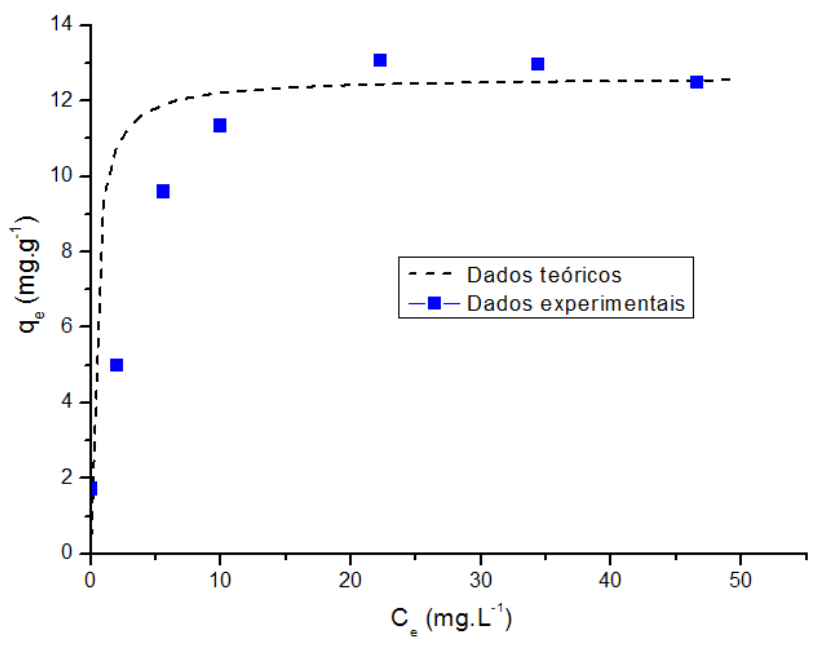

FIGURA 47 - Dados experimentais da isoterma de equilíbrio de adsorção da FCA1 para os íons $\mathrm{Sr}^{2+}$ e os dados teóricos obtidos da equação de Langmuir não linearizada.

\subsection{Cinética de adsorção}

A cinética de adsorção é um importante fator para indicar a taxa de sorção de um dado sistema de biossorção (KUYELCAK E VOLESKY, 1998).

Nas FIG. 48 e 49 são apresentadas as representações da cinética de adsorção de primeira ordem paras as FCB e FCA 1, respectivamente, obtidas através da EQ 14.

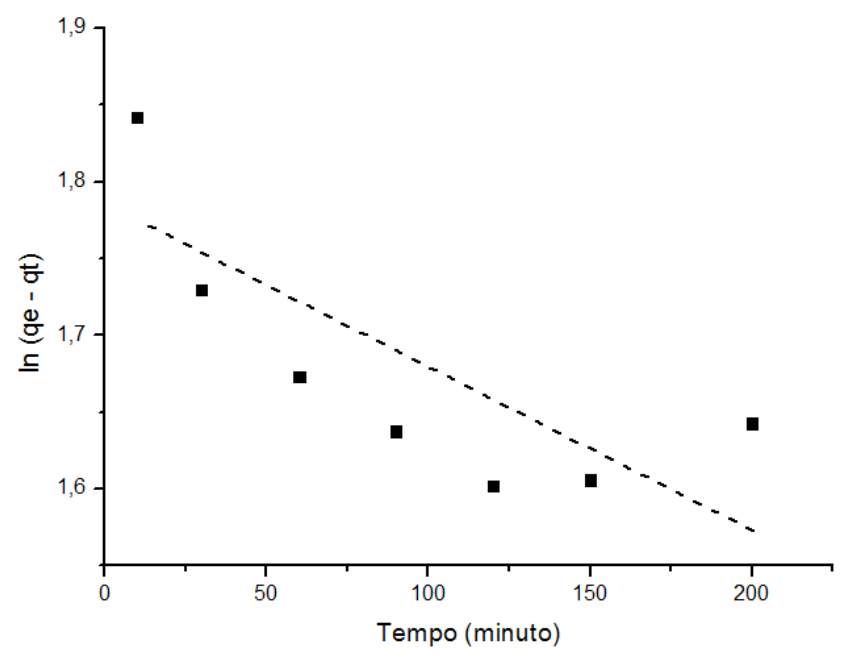

FIGURA 48 - Modelo linear de pseudo-primeira ordem para a adsorção do Sr ${ }^{2+}$ com FCB. 


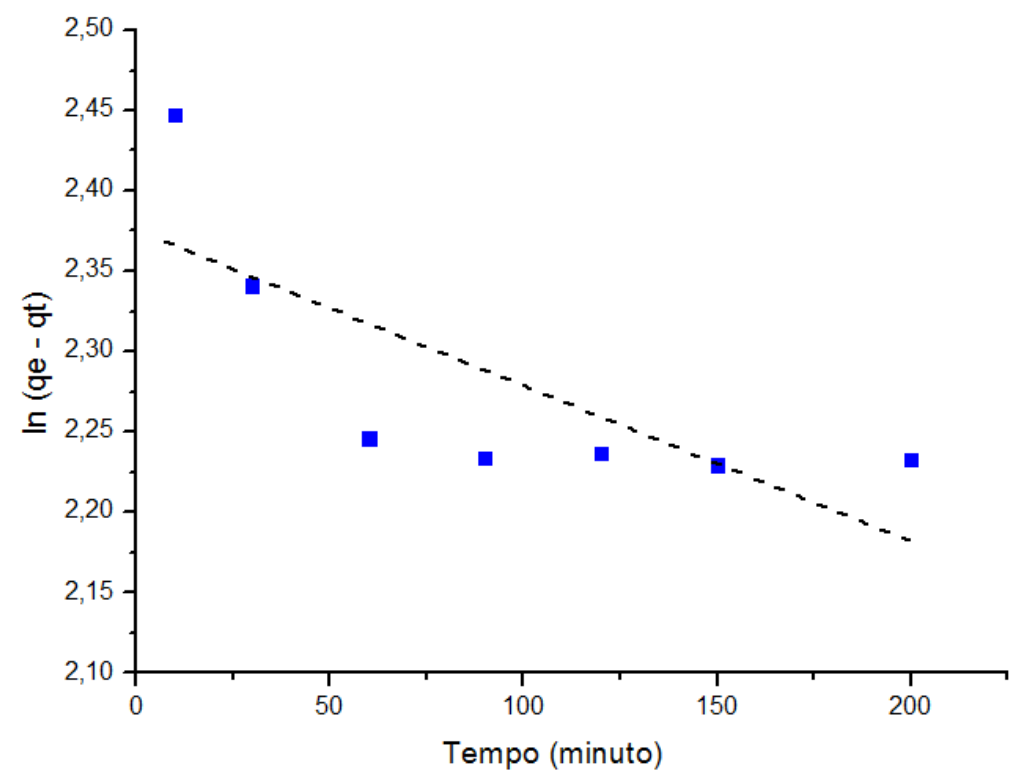

FIGURA 49- Modelo linear de pseudo-primeira ordem para a adsorção do $\mathrm{Sr}^{2+}$ com FCA 1.

Nas FIG. 50 e 51 são apresentadas as representações da cinética de adsorção de segunda ordem para as FCB e FCA 1, respectivamente.

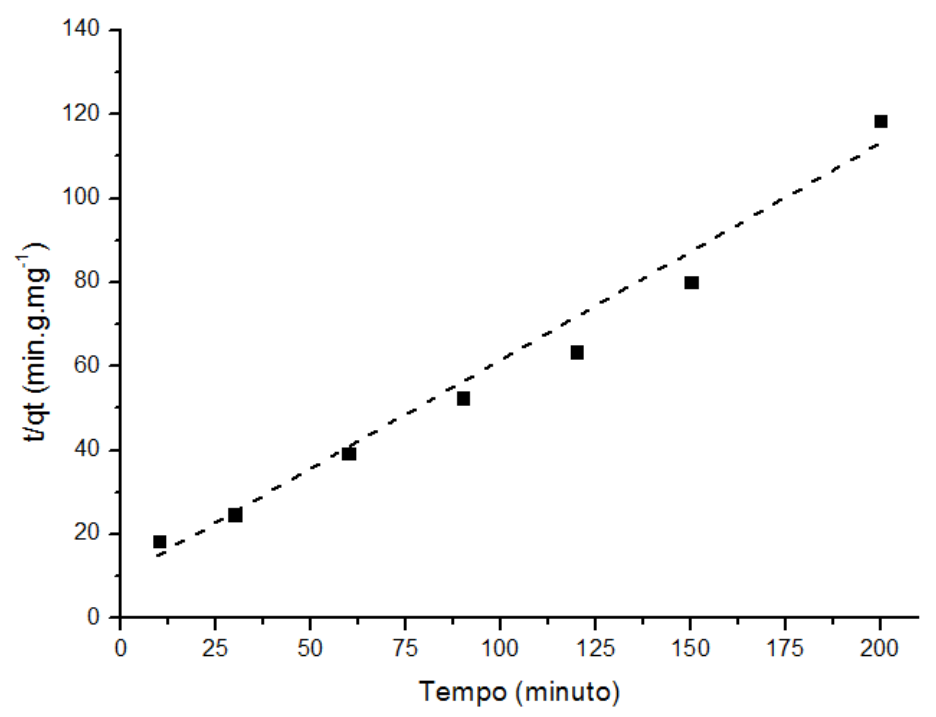

FIGURA 50: Modelo linear de pseudo-segunda ordem para a adsorção do $\mathrm{Sr}^{2+}$ com FCB. 


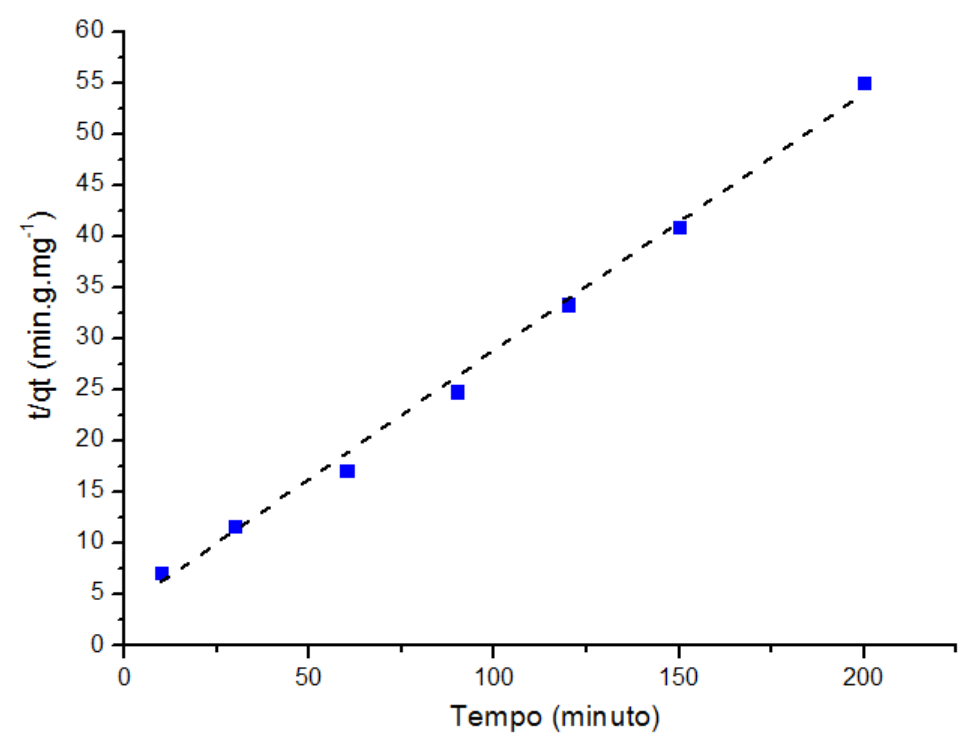

FIGURA 51 - Modelo linear de pseudo-segunda ordem para a adsorção do $\mathrm{Sr}^{2+}$ com FCA 1.

De acordo com os resultados apresentados observa se que os dados experimentais se ajustam melhor ao modelo de pseudo-segunda ordem para ambos os casos, FCB e FCA 1. Esses resultados ressaltam que os íons de $\mathrm{Sr}^{2+}$ são adsorvidos por um ou mais grupos funcionais presentes nas biomassas. Os parâmetros obtidos pelos modelos de primeira e segunda ordem estão apresentados nas Tab. 6 e 7 para as FCB e FCA 1, respectivamente.

TABELA 6. Parâmetros da cinética de adsorção da fibra de coco bruta

\begin{tabular}{c|c|c|c|c|c|c|c}
\hline \multicolumn{1}{c}{ Parâmetros } \\
\hline Íon & \multicolumn{3}{|c|}{ Pseudo-primeira ordem } & \multicolumn{5}{c}{ Pseudo-segunda ordem } \\
& $\mathrm{K}_{1}$ & $\mathrm{q}_{\mathrm{eq}}\left(\mathrm{mg} \cdot \mathrm{g}^{-1}\right)$ & $\mathrm{R}^{2}$ & $\mathrm{~K}_{2}$ & $\mathrm{q}_{\mathrm{t}}$ & $\mathrm{q}_{\mathrm{e}}$ & $\mathrm{R}^{2}$ \\
$\mathrm{Sr}^{2+}$ & 0,01 & 5,853 & 0,5916 & 0,029 & 1,713 & 1,965 & 0,9786 \\
\hline
\end{tabular}

TABELA 7. Parâmetros da cinética de adsorção da fibra de coco bruta 1

\begin{tabular}{c|c|c|c|c|c|c|c}
\hline \multicolumn{8}{c}{ Parâmetros } \\
\hline Íon & \multicolumn{3}{|c|}{ Pseudo-primeira ordem } & \multicolumn{5}{c}{ Pseudo-segunda ordem } \\
& $\mathrm{K}_{1}$ & $\mathrm{q}_{\mathrm{eq}}\left(\mathrm{mg} \cdot \mathrm{g}^{-1}\right)$ & $\mathrm{R}^{2}$ & $\mathrm{~K}_{2}$ & $\mathrm{q}_{\mathrm{t}}$ & $\mathrm{q}_{\mathrm{e}}$ & $\mathrm{R}^{2}$ \\
$\mathrm{Sr}^{2+}$ & 0,001 & 7,036 & 0,5901 & 0,029 & 1,713 & 1,965 & 0,9786 \\
\hline
\end{tabular}


Os valores teóricos de qeq obtidos através do modelo de pseudo-primeira ordem (Tab. 6 e 7) não estavam em conformidade com os dados experimentais. Por meio dos valores de coeficiente de correlação $\left(R^{2}\right)$ também foi possível confirmar que 0 modelo de pseudo-segunda ordem se ajustam melhor para ambas as fibras (FCB e FCA 1) no experimento de biossorção de $\mathrm{Sr}^{2+}$. Os valores de $\mathrm{q}_{\mathrm{e}}$ foram próximos dos dados obtidos teoricamente pelo modelo de pseudosegunda ordem.

\subsection{Parâmetros termodinâmicos}

Os parâmetros termodinâmicos avaliados foram a constante de distribuição $\left(K_{D}\right)$ e a energia livre de Gibbs $(\Delta G)$, considerados importantes parâmetros que indicam o potencial de biossorção e a espontaneidade da reação de adsorção.

\subsubsection{Coeficiente de distribuição $\left(K_{D}\right)$}

Para o cálculo do coeficiente de distribuição foi utilizada a Equação 11. Os valores de $K_{D}$ para a FCB e FCA 1 foram de 265,3 L. $\mathrm{Kg}^{-1}$ e 824,3 L. $\mathrm{Kg}^{-1}$, respectivamente. Pelos resultados obtidos de $K_{D}$, verifica se que a FCA 1 possui maior potencial de biossorção de $\mathrm{Sr}^{2+}$, em relação a $\mathrm{FCB}$. Entretanto, os resultados de $\mathrm{K}_{\mathrm{D}}$ podem variar quanto à taxa de $\mathrm{V} \cdot \mathrm{m}^{-1}$ previamente definidos no processo de biossorção.

\subsubsection{Energia Livre de Gibbs}

A energia livre de Gibbs foi obtida a partir dos valores da constante de Langmuir $\left(\mathrm{K}_{\mathrm{L}}\right)$ em L.mol${ }^{-1}$, utilizando-se a EQ.16 para a obtenção dos resultados.

Pelos resultados obtidos verifica-se que a energia livre de Gibbs para as FCB e FCA 1 foi de $-0,90 \mathrm{~kJ} \mathrm{~mol}^{-1}$ e $-7,2 \mathrm{~kJ} \cdot \mathrm{mol}^{-1}$, respectivamente. De acordo com esses valores negativos $(\Delta G<0)$ admite-se que o processo de biossorção para ambas as fibras ocorrem de forma espontânea. 


\section{CONCLUSÕES}

Com base nos dados apresentados conclui-se que as FCB, FCA 1 e FCA 2 possuem características favoráveis como material biossorvente de íons $\mathrm{Sr}^{2+}$ em baixas concentrações em soluções aquosas.

Verificou-se que o tratamento químico com peróxido de hidrogênio em meio básico confere maior porosidade a fibra de coco ao longo de toda sua superfície devido à degradação de parte de sua matéria orgânica, conforme as análises de MEV.

Mediante as análises de infravermelho foi possível verificar que o tratamento com peróxido de hidrogênio em meio básico aumenta a quantidade dos grupos funcionais de ácidos carboxílicos pela oxidação de alcoóis presentes no material ligno-celulólico da biomassa.

Verificou-se pelas análises de difração de raios $X$ que os valores de taxa de cristalinidade das FCB, FCA 1 e FCA 2 são de 39\%, 46\% e 51\%, respectivamente. Esses resultados demonstraram que a remoção de componentes pouco cristalinos como a lignina e hemicelulose, no processo de oxidação, aumentam a cristalinidade desses materiais.

$\mathrm{O} \mathrm{pH}$ possui bastante influência no processo de biossorção de íons estrôncio pelas fibras de coco. Em pH 9 houve a precipitação do íon estrôncio e a remoção deu-se por adsorção física, em pH 6 os ácidos carboxílicos estão na forma de carboxilatos e a adsorção torna-se química e finalmente em $\mathrm{pH} 3$ verificou-se uma menor remoção do íon estrôncio, em virtude da competição com os íons $\mathrm{H}^{+}$presentes na solução aquosa.

A fibra de coco ativada (FCA 1) apresenta maior eficiência na remoção dos íons de estrôncio $\left(\mathrm{Sr}^{2+}\right)$ em comparação com a fibra de coco bruta. A maior eficiência ocorre em razão da maior quantidade de carboxilatos, os quais possuem afinidade por íons metálicos. A capacidade de remoção da FCA 2 proveniente de um tratamento com maior teor de peróxido de hidrogênio foi menor que a FCA 1. A oxidação levou a degradação dos sítios responsáveis por essa remoção. 
$\mathrm{Em} \mathrm{pH} 6$ todos os íons de estrôncio estão totalmente na forma dissociada $\left(\mathrm{Sr}^{2+}\right)$ e a biomassa nessas condições possui carga superficial negativa, neste caso o ácido carboxílico está na forma do sal carboxilato. A capacidade de adsorção de $\mathrm{Sr}^{2+}$ utilizando $5 \mathrm{mg}$ de FCB e FCA 1 é de $1,7 \mathrm{mg} \cdot \mathrm{g}^{-1}$ e 3,6 $\mathrm{mg} \cdot \mathrm{g}^{-1}$, respectivamente. O equilíbrio dinâmico no processo foi alcançado com 90 minutos de tempo de contato para ambas as fibras.

O processo de biossorção de $\mathrm{Sr}^{2+}$ ajusta-se adequadamente ao modelo de Langmuir e obedece a cinética de pseudo-segunda ordem para a fibra de coco bruta e fibra de coco ativada (FCA 1). O modelo de Langmuir admite que o processo de biossorção ocorre com a formação de uma monocamada e a cinética de pseudo-segunda ordem assume que dois ou mais sítios ativos podem remover um íon metálico. De acordo com os valores obtidos do parâmetro de equilíbrio $\left(R_{L}\right)$ as isotermas são classificadas como favoráveis, apresentando formato convexo. O potencial de biossorção de $\mathrm{Sr}^{2+}$ é maior para a FCA 1, conforme os seus resultados do coeficientes de partição $\left(K_{D}\right)$ e pelos valores de energia livre de Gibbs os processos de biossorção de $\mathrm{Sr}^{2+}$ com as FCB e FCA 1 são favoráveis.

As análises combinadas de MEV/EDS, difração de raios $X$ e espectroscopia de infravermelho demonstraram a presença de estrôncio adsorvido pelas biomassas, FCB e FCA 1.

A fibra de coco, um material abundante e de baixo custo, possui um grande potencial como material biossorvente na remoção de íons ${ }^{90} \mathrm{Sr}$ em baixas concentrações em rejeito radioativo líquido, além de estar de acordo com práticas ambientalmente corretas de reuso de resíduos agrícolas. 


\section{REFERÊNCIAS BIBLIOGRÁFICAS}

ABBAS, S. H.; ISMAIL, I. M.; MOSTAFA, T. M.; SULAYMON, A. H. "Biosorption of heavy metals: A review". J. Chem. Sci. Tech., v. 3, p. 74-102, 2014.

ABDEL, R. R. O.; IBRAHIUM, H. A.; HUNG, Y. T. "Liquid radioactive wastes treatment: a review", Wat., v. 3, p. 551-565, 2011.

ABRAHAM, E.; DEEPA, B.; POTHEN, L. A.; CINTIL, J.; THOMAS, S.; JOHN, M. J.; ANANDJIWALA, R.; NARINE, S. S. "Environmental friendly method for the extraction of coir fibre and isolation of nanofibre", Carbohydr. Polym., v. 92, p. 1477-1483, 2013.

Agency for Toxic Substances and Disease Registry (ATSDR). 2004. Toxicological profile for Strontium. Atlanta, GA: U.S. Department of Health and Human Services. Disponível em: http://www.atsdr.cdc.gov/toxprofiles/tp.asp?id=656\&tid=120. Acesso em: 20 de julho de 2015.

AHALYA, N.; KANAMADI, R. D.; RAMACHANDRA, T. V. "Biosorption of iron (III) from aqueous solutions using the husk of Cicer arientinum". Indian J. Chem. Technol., v. 13, p. 122-127, 2006.

ALI, M. "Coconut fibre - A versatile material and its applications in engineering". Second International Conference on Sustainable Construction Materials and Technologies, p. 1-10, Italia, 2010.

ALVES, R. E. "Caracterização de fibras lignocelulósicas pré-tratadas por meio de técnicas espectroscópicas e microscópicas ópticas de alta resolução". Dissertação (mestrado) - Universidade de São Paulo, São Paulo, 2011.

AMANO, H.; YANASE, N. "Measurement of ${ }^{90} \mathrm{Sr}$ in environmental samples by cation-exchange and liquid scintillation counting". Talanta, v. 37:6, p. 585-590, 1990. 
AMJED, M.; JUNG, H. G.; DONKER, J. D. "Effect of alkaline hydrogen peroxide treatment on cell wall composition and digestion kinetics of sugarcane residues and wheat straw". J. Anim. Sci., v. 70, p. 2877-2884, 1992.

ASIAGWU, A. K. "Sorption kinetics of Pb (II) and Cd (II) íons via biomass surface of plantain peel waste". IJRRAS, v. 13, p. 626-635, 2012.

ATKINS, P.; JONES, L.; "Princípios de Química - Questionando a vida moderna e o meio ambiente: Os elementos - os primeiros quatro grupos principais", p. 636637, 3a ed. Bookman, 2006.

BAROT N. S.; BAGLA, H. K. "Biosorption of radiotoxic $90 \mathrm{Sr}$ by green adsorbent: dry cow dung powder". J. Radioanal. Nucl. Chem., v. 294, p. 81-86, 2012.

BARROS, A. J. M.; SANTOS, J. C. O.; PRASAD, S.; LEITE, V. D.; SOUZA, A. G.; SOLEDADE, L. E. B.; DUARTE, M. S. B.; SANTOS, V. D. "Thermal decomposition study of sewage sludge and of organic waste used in the sorption of metals". J. Therm. Anal. Calorim., v. 83:2, p. 291-295, 2007.

BAYRAMOGLU, G.; GURSEL, I.; TURALI, Y.; ARICA, M. Y. "Biosorption of phenol and 2-chlorophenol by Funalia trogii pellets". Bioresour. Technol., v. 100, p. 2685-2691, 2009.

BONIOLO, M. R. "Biossorção de urânio nas cascas de banana". Dissertação (mestrado) - Instituto de Pesquisas Energéticas e Nucleares (IPEN), São Paulo, 2008.

BULGARIU, D.; BULGARIU, L. "Equilibrium and kinetics studies of heavy metal ions biosorption on green algae waste biomass". Bioresour. Technol., v. 103, p. 489-493, 2012.

BUSCHILE-DILLER, G.; ZERONIAN, S. H. "Enhancing the reactivity and strength of cotton fibers", J. Appl. Polym. Sci., v. 6, p. 967-979, 1992.

BYKOV, I. "Characterization of natural and technical lignins using FTIR spectroscopy'. Dissertação (mestrado) - Lulea University of Technology, 2008. 
CASTRO, H. F. "Processos químicos industriais II: Papel e celulose". Universidade de São Paulo - Escola de Engenharia de Lorena, 2009.

CHEN, J. P.; WANG, L. "Characterization of metal adsorption kinetic properties in batch and fixed-bed reactors". Chemosphere, v. 54, p. 394-404, 2004.

CHOI, J.; LEE, J. Y.; YANG, J. S. "Biosorption of Heavy Metals and Uranium Starfish and Pseudomonas Putida". J. Hazard. Mater., v. 161, p. 157-162, 2009.

COMISSÃO NACIONAL DE ENERGIA NUCLEAR (CNEN); "Gerência de rejeitos radioativos de baixo e médio níveis de radiação (CNEN-NE 6.05)", 2014.

CORRADINI. E.; ROSA, M. F.; MACEDO, B. P; PALADIN, P. D.; MATTOSO, L. H. C.; "Composição química, propriedades mecânicas e térmicas da fibra de frutos de cultivares de coco verde". Rev. Bras. Frutic., v. 31, p. 837-846, 2009

CRESPI, A. M. "Aplicação de isótopos de estrôncio, oxigênio e hidrogênio como traçadores de anomalias hidrogeoquímicas de bário no sistema aquífero bauru no município Gália (SP)" Dissertação (mestrado) - Instituto de Geociências (USP), São Paulo, 2013.

DABBAGH, R.; GHAFOURIAN, H.; BAGHVAND, A.; NABI, G. R.; RIAHI, H.; FAGHIH, M. A. A. "Bioaccumulation and biosorption of stable strontium and ${ }^{90} \mathrm{Sr}$ by Oscillatoria homogenea cyanobacterium". J. Radioanal. Nucl. Chem., v. 272, p. 53-59, 2007.

DADA, A. O.; OlALEKAN, A. P.; OlATUNYA, A. M.; DADA, O. "Langmuir, Freundlich, Temkin and Dubinin-radushevich isotherms studies of equilibrium sorption of $\mathrm{Zn}^{2+}$ unto phosphoric acid modified Rice husk". IOSR Journal of Applied Chemistry, v. 3, p. 38-45, 2012.

DAS, N.; VIMALA, R.; KARTHIKA, P. "Biosorption of heavy metal - An overview". Indian J. Biotechnol., v. 7, p. 159-169, 2008.

DELLAMANO, J. C. "Otimização da etapa de armazenamento de rejeitos radioativos". Tese (doutorado) - Instituto de Pesquisas Energéticas e Nucleares (IPEN), São Paulo, 2005. 
DING, S.; YANG, Y.; HUANG, H.; LIU, H.; HOU, L. "Effects of feed solution chemistry on low pressure reverse osmosis filtration of cesium and strontium". $J$. Hazard. Mater., v. 294, p. 27-34, 2015.

EDRIS, G.; ALHAMED, Y.; ALZAHRANI, A. "Biosorption of cadmium and lead from aqueous solutions by Chlorella vulgaris biomass: Equilibrium and kinetic study". J. Sci. Eng., v. 39, p. 87-93, 2014.

EMPRESA BRASILEIRA DE PESQUISA AGROPECUÁRIA (EMBRAPA). "Beneficiamento da casca de coco verde", 2012. Disponível em: http://www.ceinfo.cnpat.embrapa.br/arquivos/artigo 3830.pdf. Acesso em: 17 de junho de 2015.

EROGLU, H.; YAPICI, S.; NUHOGLU, Ç.; VAROGLU, E. "Na Environmentally Friendly Process; Adsorption of Radionuclide TI-201 on Fibrous Waste Tea". J. Hazard. Mater., v.163, p. 607-617, 2009.

FAURE, G.; MENSING, T. M. "Isotopes: Principles and applications", p. 297, 3"a ed. Wiley, Hoboken, New Jersey, 2005.

FENG, N.; GUO, X.; LIANG, S. "Adsorption study of copper (II) by chemically modified Orange peel", J. Hazar. Mater., v. 164, p. 1286-1292, 2009.

FIGUEIREDO, N. M. "Tratamento de efluentes sintético contendo níquel e zinco por biossorção utilizando Sargassum filipendula". Dissertação (mestrado) - Universidade Federal do Rio de Janeiro, Rio de Janeiro, 2013.

FLORES, W. F.; MACHADO, N. R. C. F. "Traramento de efluentes com cátions metálicos por troca iônica com xeólitas comerciais e material zeolítico netural". VIII Congresso Brasileiro de Engenharia Química em Iniciação Cientifica, Minas Gerais, Uberlândia, 2009.

FOO, K. Y.; HAMEED, B. H. "Insights into the modelling of adsorption isotherm systems". Chem. Eng. J., v. 156, p. 2-10, 2010. 
FREITAS, A. F. "Estudo da adsorção de ácidos carboxílicos em diferentes materiais adsorventes". Dissertação (mestrado) - Universidade Federal Rural do Rio de Janeiro, Rio de Janeiro, 2005.

FUKS, L.; OSZCZAK, A.; GNIAZDOWSKA, E. "Calcium alginate and chitosan as potential sorbents for strontium radionuclide". J. Radioanal. Nucl. Chem., v. 304, p. 15-20, 2015.

GHAEDI, M.; BRAZESH, B.; KARIMI, F.; GHEZELBASH, G. R. "Equilibrium, thermodynamic, and kinetic studies on some metal ions biosorption using black yeast Aureobasidium pullulans biomass". Environ. Prog. Sustain. Energy, v. 33, p. 769-776, 2004.

GHAEDI, M.; HAJATI, S.; KARIMI, F.; BARAZESH, B.; GHEZELBASH, G. "Equilibrium, kinetic and isotherm of some metal ion biosorption". J. Ind. Eng. Chem., v. 19, p. 987-992, 2013.

GOK, C.; AYTAS, S. "Biosorption of Uranium(IV) from Aqueous Solution Using Calcium Alginate Beads". J. Hazard. Mater., v. 168, p. 369-375, 2009.

GOK, C.; GERSTMANN, U.; AYTAS, S. "Biosorption of radiostrontium by alginate beads: application of isotherm models and thermodynamic studies". J. Radioanal. Nucl. Chem., v. 295, p. 777-788, 2013.

HAMEED, B. H.; MAHMOUD, D. K.; AHMAD, A. L. "Equilibrium modelling and kinetic studies on the adsorption of basic dye by a low-cost adsorbent: Coconut (Cocos Nucifera) bunch waste", J. Hazard. Mater., v. 158, p. 65-72, 2008.

HARMSEN, P. F. H.; HUIJGEN, W. J. J.; LÓPEZ, L. M. B.; BAKKER, R. R. C. "Literature review of physical and chemical pretreatment process for lignocellulosic biomass". Energy Research Centre of the Notherlands, p. 1-49, 2010. Disponível em: ftp://ftp.ecn.nl/pub/www/library/report/2010/e10013.pdf. Acesso em: 25 de maio de 2015. 
HE, Y.; PANG, Y.; LIU, Y.; LI, X.; WANG, K. "Physicochemical characterization of rice straw pretreated with sodium hydroxide in the solid state for enhancing biogas production". Energy \& Fuel, v. 22, p. 2775-2781, 2008.

HIROMOTO, G.; DELLAMANO, J.C.; MARUMO, J.T.; ENDO, L.S.; VICENTE, R.; HIRAYAMA, T., "Introdução à gerência de rejeitos radioativos", Instituto de Pesquisas Energéticas e Nucleares, Departamento de Rejeitos Radioativos, São Paulo, 1999.

HO, Y. S. "Second-order kinetic model for the sorption of cadmium onto tree ferm: A comparison of linear and non-linear methods". Water Res., v. 40, p. 119-125, 2006.

HOMAIDAN, A. A. A.; HOURI, H. J. A.; HAZZANI, A. A. A.; ELGAALY, G.; MOUBAYED, N. M. S. "Biosorption of copper ions from aqueous solutions by Spirulina platensis biomass". Arabian J. Chem., v. 7, p. 57-62, 2014.

HUBBE, M. A.; HASAN, S. H.; DUCOSTE, J. J. "Cellulosic substrates for removal of pollutants from aqueous systems: A review. 1. metals". BioRes, v. 6:2, p. 21612287, 2011.

HUBBE, M. A.; LUCIA, L. A. "The Love-hate relationship present in lignocellulosic materials". BioRes, v. 2, p. 534-535, 2007.

INTERNATIONAL ATOMIC ENERGY AGENCY (IAEA). "Disposal of Radioactive Waste - Safety Standards Series No. SSR-5”, Vienna, 2001.

INTERNATIONAL ATOMIC ENERGY AGENCY (IAEA). "Radioactive waste management glossary", Vienna, 2003.

INTERNATIONAL COMMISSION ON RADIOLOGICAL PROTECTION (ICPR). "limits for intakes of radionuclides by workers: Strontium" ICRP publication 30 supplement to part 1 Annals of the ICRP3 (1 - 4), p. $83-85,1978$.

JAIKUMAR, V. "Effect of biosorption parameters kinetics isotherm and thermodynamics for acid green dye biosorption from aqueous solutions by brewery waste". Int. J. Chem., v. 1, p. 1-12, 2009. 
JESUS, N. N. M. "Remoção de césio e amerício utilizando fibras de coco para a aplicação no tratamento de rejeitos radioativos". Dissertação (mestrado) Instituto de Pesquisas Energéticas e Nucleares (IPEN), São Paulo, 2013.

KADIRVELU, K.; GOEL, J. Eco-friendly technologies for removal of hazardous heavy metal from water and industrial wastewater. In: LEWINSKY, A.A. (Ed). Hazardous Materials and Wastewater: Treatment, Removal and Analysis. Nova York: Nova Science Publishers, v. 60:8 p. 126-148, 2007.

KALALAGH, S. S.; BABAZADEH, H.; NAZEMI, A. H.; MANSHOURI, M. "Isotherm and kinetic studies on adsorption of $\mathrm{Pb}, \mathrm{Zn}$ and $\mathrm{Cu}$ by kaolinite". Caspian J. Env. Sci., v. 9, p. 243-255, 2011.

KHALIL, H. P. S. A.; JAWAID, M.; FIROOZIAN, P.; RASHID, U.; ISLAM, A.; AKIL, H. M. "Activated carbon from various agricultural wastes by chemical activation with $\mathrm{KOH}$ : preparation and chatacterization”, J. Biobased Mater. Bio., v. 7, p. 1-7, 2013.

KIM, J. S.; JUNG, C. H.; OH, W. Z.; RYU, S. K. "Electrosorption and separation of $\mathrm{Co}^{2+}$ and $\mathrm{Sr}^{2+}$ ions from decontaminated liquid wastes". Carbon, v. 3, p. 6-12, 2002.

KLEMM, D.; SCHMAUDER, H. P.; HEINZE, T. "Biospolymers online: Cellulose". Wiley-VCH, p. 275-287, 2005.

KODAMA, Y. "Avaliação dos efeitos da radiação ionizante em compósitos de PCL/PLLA com fibra de coco". Tese (doutorado) - Instituto de Pesquisas Energéticas e Nucleares (IPEN), São Paulo, 2011.

KUYELCAK, N.; VOLESKY, B. "Biosorbent for recovery of metals from industrial solutions. Biotechnol. lett., v. 10, p. 137-142, 1998.

LAINE, C. "Structure of hemicelluloses and pectins in wood and pulp". Tese (doutorado) - Helsinki University of Technology, 2005. Disponível em: http://lib.tkk.fi/Diss/2005/isbn9512276909/. Acesso em: 17 de junho de 2015. 
LAVARDA, F. L. "Estudo do potencial de biossorção dos ions Cd (II), Cu(II) e Zn (II) pela macrófita e Eichhornia Crassipes". Dissertação (mestrado) Universidade Estadual do Oeste do Paraná, 2010.

LEE, Y. J. ; CHUNG, C. H.; DAY, D.F.“ Sugarcane bagasse oxidation using a combination of hypochlorite and peroxide” - Bioresour. Technol., v100, p 935942, 2009

LEONARDO, L. "Determinação de trício e estrôncio-90 no controle radiológico do IPEN-CNEN/SP'. Dissertação (mestrado) - Instituto de Pesquisas Energéticas e Nucleares (IPEN), São Paulo, 2004.

LIDE, D. R. "CRC Handbook of Chemistry and Physics". CRC Press, Boca Raton, FL, 2005.

LIU, L.; LIU, J.; LI, H.; ZHANG, H.; LIU, J.; ZHANG, H. "Equilibrium, kinetic, and thermodynamic studies of lead (II) biosorption on sesame leaf", BioRes., v. 7:3, p. 3555-3572, 2012.

MAMMAN, S.; ABDULLAHI, I.; UKWEDE, R. O. "Isotherms and batch kinetics of the biosorption of cadmium onto pre-treated tridax procumbens". Der Pharma Chem., v. 3:4, p. 94-101, 2011.

McCABE, W. L.; SMITH, J. C.; HARRIOT, P. "Units operations of chemical engineering - Adsorption”. McGraw Hill, 5ª ed., p. 810-821, 1993.

McCARTHY, J. L.; ISLAM, A. "Lignin chemistry, technology, and utilization: A brief history". Am. Chem. Soc., v. 79:16, p. 4495-4499, Seattle, 1999.

MIMURA, A. M. S.; VIEIRA, T. V. A.; MARTELLI, P. B.; GORGULHO, H. F. "Aplicação da casca de arroz na adsorção dos íons $\mathrm{Cu}^{2+}, \mathrm{Al}^{3+}, \mathrm{Ni}^{2+}$ e $\mathrm{Zn}^{2+"}$, Quim. Nova., v. 33, p. 1279-1284, 2010.

MIMURA, H.; OHTA, H.; AKIBA, K.; ONODERA, Y. "Uptake bahavior of americium on alginic acid and alginate polymer gels". J. Radioanal. Nucl. Chem., v. 247, p. 33-38, 2001. 
MINAMISAWA, M.; MINAMISAWA, H.; YOSHIDA, S.; TAKAI, N. "Adsorption Behavior Metals on Biomaterials". J. Agric. Food Chem, v. 52, p. 5606-5611, 2004.

MIRETZKY, P.; MUÑOZ, C.; CHAVEZ, A. C. "Cd (II) removal from aqueous solution by Eleocharis acicularis biomass, equilibrium and kinetic studies". Bioresour. Technol., v. 101, p. 2637-2642, 2010.

MOHAN, D.; CHANDER, S. "Single Component and Muiti-Component Adsorption of Metal lons by Activated Carbons". Physicchem. Eng. Asp., v. 177, p. 183-196, 2001.

MONTANHER, S. F. "Utilização da biomassa de bagaço de laranja como material sorvente de íons metálicos presentes em soluções aquosas". Tese (doutorado) - Universidade Estadual de Maringá, 2009.

MONTANHER, S. F.; OLIVEIRA, E. A.; ROLLEMBERG, M. C. "Removal of metal ions from aqueous solutions by sorption onto Rice bran". J. Hazard. Mater., p. 207-211, 2005.

MONTEIRO, R.A., “Avaliação do potencial de adsorção de $U$, Th, Pb, Zn e $\mathbf{N i}$ pelas fibras de coco". Dissertação de Mestrado - Instituto de Pesquisas Energéticas e Nucleares, 2009.

MOREIRA, A. S. "Biossorção utilizando alga marinha (Sargassum sp.) aplicada em meio orgânico". Tese (doutorado) - Universidade Federal do Rio Grande do Norte, Natal, 2007.

MOTHÉ, C. G.; MIRANDA, I. C. "Characterization of sugarcane and coconut fibers by thermal analysis and FTIR". J. Therm. Anal. Calorim., v. 97, p. 661-665, 2009.

MUNAWAR, S. S.; UMEMURA, K.; KAWAI, S. "Characterization of the morphological, physical, and mechanical properties of seven nonwood plant fiber bundles". J. Wood Sci., v. 53, p. 108-113, 2007.

MUSSATO, S. L.; TEIXEIRA, J. A. "Current Research, Technology and Education Topics in Applied Microbiology and Microbial Biotechnology: 
Lignocellulose as raw material in fermentation process", p. 897 - 907, A. MéndezVilas (Ed.), 2010.

NAJA, G.M. \& VOLESKY, B. Treatment of Metal-Bearing Effluents: Removal and Recovery L.K. Wang, J.P. Chen, Y.T. Hung, N.K. Shammas (Eds.), Handbook on Heavy Metals in the Environment, p. 248 - 291, Taylor \& Francis and CRC Press, Boca Raton, FL, USA, 2010.

NICOLL, W. D.; SMITH, F. "Stability of dilute alkaline solutions of hydrogen peroxide". Ind. Eng. Chem., v. 47, p. 2548-2554, 1955.

NUHOGLU, Y.; MALKOC, E. "Thermodynamic and kinetic studies for environmentaly friendly $\mathrm{Ni}(\mathrm{II})$ biosorption using waste pomace of olive oil factory". Bioresour. Technol., v. 100, p. 2375-2380, 2009.

OLADOJA, N. A.; ABOLUWOYE, C. O.; OLADIMEJI, Y. B. "Kinetics and Isotherm studies on methylene blue adsorption onto ground palm kernel coat". J. Eng. Env. Sci., v. 32, p. 303-312, 2008.

OSASONA, I.; ODEBAYO, A. O.; AJAYI, O. O. "Biosorption of $\mathrm{Pb}$ (II) from aqueous solution using cow hooves: Kinetics and thermodynamics". ISRN Phys. Chem., p. 1-8, 2013.

PANDEY, A.; BANERJEE, D. "Biosorption of cadmium (II) using discarded biomass of Aspergillus aculeatus DBF9". Terrestrial and Environmental Toxicology, v. 6:11, p. 8-13, 2012.

PARAGEORGIOU, S. K.; KATSAROS, F. K.; KOUVELOS, E. P.; NOLAN, J. W.; DEIT, H. L.; KANELLOPOULOS, N. K. "Heavy Metal Sorption by Calcium Alginate Beads from Laminaria Digitata”. J. Hazard. Mater. B137, p, 1765-1772, 2006.

PARK, S.; BAKER, J. O.; HIMMEL, M. E.; PARILLA, P. A.; JOHNSON, D. K. "Cellulose crystallinity index: measurement techniques and their impact on interpreting cellulose performance". Biotechnol. Biofuels, v. 3:10, p. 1-10, 2010. 
PAVIA, D.; LOMPMON, G.; KRIZ, G. S; VYVYAN, J. R; "Introdução à espectroscopia”, p. 15 - 98, Tradução da 4⿳⺈ ed. Norte Americana, Cengage Learning, 2010.

PINO, G. H. "Biossorção de metais pesados utilizando pó de casca de coco verde (Cocos Nucifera)". Dissertação (mestrado) - Pontifícia Universidade Católica do Rio de Janeiro, 2005.

RABELO, S. C. "Avaliação e otimização d pré-tratamentos e hidrólise enzimática do bagaço de cana-de-açúcar para a produção de etanol de segunda geração". Tese (doutorado) - Faculdade Estadual de Campinas, São Paulo, 2010.

RADUAN, R. N. "Requisitos ambientais para disposição final de rejeitos radioativos em repositórios de superfície". Dissertação (mestrado) - Instituto de Pesquisas Energéticas e Nucleares (IPEN), São Paulo, 1994.

RAHMAN, R. O. A.; IBRAHIUM, H. A.; HUNG, Y. T. "Liquid radioactive wastes treatment: A review". Water, v. 3, p. 551-565, 2011.

RAMIREZ, M. G. L. "Desenvolvimento de biocompósitos de amido termoplástico reforçados por fibra de coco verde". Tese (doutorado) Universidade Federal do Paraná, Curitiba, 2011.

ROMANCHUK, A. Y.; SLESAREV, A. S.; KALMYKOV, S. N.; KOSYNKIN, D. V.; TOUR, J. M. "Graphene oxide for effective radionuclide removal”, Phys. Chem. Chem. Phys., v. 15, p. 2321-2327, 2013.

ROPP, R. C. "Encyclopedia of the alkaline earth compounds: Alkaline earth compounds". Elsevier, p. 110-113, 2012.

ROSA, M. F.; MEDEIROS, E. S.; MALMONGE, J. A.; GREGORSKI, K. S.; WOOD, D. F.; MATTOSO, L. H. C.; GLENN, G.; ORTS, W. J.; IMAM, S. H. "Cellulose nanowhiskers from coconut husk fibers: Effect of preparation conditions on their thermal and morphological behavior". Carbohydr. Polym., v. 81, p. 83-92, 2010. 
SALEEM, N.; BHATTI, H. N. "Adsorptive removal and recovery of $\mathrm{U}(\mathrm{VI})$ by citrus waste biomass". BioResources, v. 6:2, p. 2522-2538, 2011.

SALEHI, P.; ASGHARI, B.; MOHAMMADI, F. "Biosorption of Ni(II), Cu(II) and $\mathrm{Pb}$ (II) by Punica geranatum from aqueous solutions". J. Water Resource Protect., v. 2, p. 701-705, 2010.

SANGIAN, H. F.; KRISTIAN, J.; RAHMA, S.; DEWI, H. K.; PUSPASARI, D. A.; AGNESTY, S. Y.; GUNAWAN, S.; WIDJAJA, A. "Preparation of reducing sugar hydrolyzed from high-lignin coconut coir dust pretreated by the recycled ionic liquid [mmim][dmp] and combination with alkaline". Bull. Chem. React. Eng. Catal., v. 10:1, p. 8 - 22, 2015. Disponível em: http://ejournal.undip.ac.id/index.php/bcrec/. Acesso em: 03 de janeiro de 2015.

SANTOS, D. O. "Mesocarpo do coco verde: caracterização e potencialidade de adsorção frente a corantes da indústria têxtil'. Universidade Federal do Maranhão, São Luiz, 2009.

SÁtIRO, J. R.; BARROS, P. H. S.; BRANDÃO, M. C. R.; FIGUEIROA, J. A. "Estudo do potencial da casca do coco verde para obtenção de etanol lignocelulósico". Congresso Norte Nordeste de Pesquisas e Inovação, p. 1-5, Tocantins, $2002 . \quad$ Disponível em: http://propi.ifto.edu.br/ocs/index.php/connepi/vii/paper/viewFile/4639/1360. Acesso em: 13 de abril de 2015.

SEKER, A.; SHAHWAN, T.; EROGLU, A. E.; YILMAZ, S.; DEMIREL, Z.; DALAY, M. C. "Equilibrium, thermodynamic and kinetic studies for the biosorption of aqueous lead (II), cadmium (II) and nickel (II) ions on Spirulina platensis". J. Hazard. Mater., v. 154, p. 973-980, 2008.

SENHORAS, E. M. “Estratégias de uma agenda para a cadeia agroindustrial do coco: Transformando a ameaça dos resíduos em oportunidades ecoeficientes". Tese (mestrado) - Universidade Estadual de Campinas, São Paulo, 2003. 
SHINZATO, M. C. "Remoção de metais pesados em solução por ziólitas naturais: Revisão crítica". Rev. Inst. Geol., v. 27, p. 65-78, 2007.

SHRIVER, D.; ATIKINS, P. W. "Química inorgânica". Bookman, 4ª ed, p. 295308, 2008.

SHUKLA, R. S.; GAIKAR, V. G.; PAI, R. S.; SURYAVANSHI, U. M. "Batch and Column Adsorption of $\mathrm{Cu}(\mathrm{II})$ on Unmodified and Oxidized Coir". Separ. Sci. Technol., v. 44:1, p. 40-62, 2009.

SLOVAK, N. M.; PAYTAN, A. "Handbook of Environmental Isotope Geochemistry: Applications of Sr isotopes in Archaeology". Springer, p. 734-768, 2011.

SOLVAY CHEMICALS. "Determination of hydrogen peroxide concentration (30\% to 70\%)", Technical Data Sheet, TDS HH-121, 2004. Disponível em: www.solvay.us/en/binaries/H2O2 determ 20-70-236748pdf. Acesso em: 26 de março de 2015.

SOUZA, F. W. "Adsorção de metais tóxicos em efluente aquoso usando pó da casca de coco verde tratado". Dissertação (mestre) - Universidade Federal do Ceará, Fortaleza, 2007.

SOUZA, J. L. "Mesocarpo do coco verde (Cocos Nucifera) como adsorvente para os corantes: turquesa remazol e azul remazol'. Dissertação (mestrado) Universidade Federal do Maranhão, São Luiz, 2009.

STELLA, R.; VALENTINI, M. T. G.; MAGGI, L. "Determination of $90 \mathrm{Sr}$ in Milk by using two inorganic exchangers". Appl. Radiat. Isot., v. 44:8, p. 1093-1096, 1993.

STERNBERG, S. P. K.; DORN, R. W. "Cadmium removal using cladophora in batch, semi-batch and flow reactors". Bioresour. Technol., v. 81:3, p. 249-255, 2002.

SWANSON, H. S.; FUYAT, R. K. International Centre for Diffraction Data (JCPDSICDD), Number 71-2393. Natl. Bur. Stand. (U.S.), 1998. 
TARLEY, C. R. T.; ANDRADE, F. N.; SANTANA, H.; ZAIA, D. A. M.; BEIJO, L. A.; SEGATELLI, M. G. "Ion-imprinted polyvinylimidazole-silica hybrid copolymer for selective extraction of $\mathrm{Pb}(\mathrm{II})$ : Characterization and metal adsorption kinetic and thermodynamic studies". React. Funct. Polym., v. 72, p. 83-91, 2012.

TAUHATA, L.; SALATI, I. P. A.; PRINZIO, R. Di.; PRINZIO, A. R. Di. "Radioproteção e Dosimetria: Fundamentos", Rio de Janeiro - IRD, CNEN, 2003, 5 revisão.

TOMCZAK, F.; SYDENSTRICKER, T. H. D.; SATYANARAYANA, K. G. "Studies on lignocellulosic fibers of Brazil. Part II: Morphology and properties of Brazilian coconut fibers", Composites: Part A - APPLS, v. 38, p. 1710-1721, 2007.

U.S. EPA, 2000. Wastewater technology fact sheet: Chemical precipitation. U.S. EPA 832-F-00-018 Washingtion, D.C.

VENETSKII, S. I. “Metallurgist - Strontium”. Springer., v. 15:7, p. 47-49, 1972.

VIEIRA, R. H. S. F.; VOLESKY, B. "Biosorption: a solution to pollution?". Springer - Internatl. Microbiol, v. 3, p. 17-24, 2000.

VOGEL, A. I. "Química orgânica - Análise orgânica qualitativa"; Editora da Universidade de São Paulo. Trad. 3ª ed, p. , Rio de Janeiro, 1971,.

VOLESKY, B. Biosoption of heavy metals. Boston: CRC Press, Inc., p. 396, 1990.

VOLESKY, B.; "Sorption and Biosorption", BV Sorbex edition, Montreal, Canada, 2004.

WAHLBERG, J. S.; DEWAR, R. S. "Comparison of distribution coefficients for strontium exchange from solutions containing one and two compering cations". Geological Survey Bulletin 1140 - D, Washington (USA), 1965.

WANG, J.; CHEN, C. "Biosorbents for Heavy Metals Removal and Their Future". Biotechnol. Adv., v. 24, p. 195-226, 2009. 
YAMAMURA, A. P. G.; YAMAURA, M. "Estudo da cinética e das isotermas de adsorção de U pelo bagaço de cana-de-açúcar". International Nuclear Conference - INAC, Santos, 2005.

YANG, J.; VOLESKY, B. "Biosorption of Uranium on Sargassum Biomass". Wat. Res, v. 33, p. 3357-3363, 1999.

YANTASEE, W.; WARNER, C. L.; SANGVANICH, T.; ADDLEMAN, R. S.; CARTER, T. G.; WIACEK, R. J.; FRYXELL, G. E.; TIMCHALK, C.; WARNER, M. G.; "Removal of heavy metals from aqueous system with Thioi functionalizes superparamagnetic nanoparticles", Environ. Sci. Technol. v. 41, p. 5114-5119, 2007.

ZHANG, H. "Biosorption of heavy metals from aqueous solutions using keratin biomaterials". Doctoral Thesis. Universitat Autônoma de Barcelona, 2014.

ZHENG, W.; LI, X. M.; WANG, F.; YANG, Q.; DENG, P.; ZENG, G. M. "Adsorption Removal of Cadmium and Copper from Aqueous Solution by Areca-A Food Waste". J. Hazard. Mater., v. 157, p. 490-495, 2008. 